Spring 4-2021

\title{
Occupational Therapy in Youth Violence: An Occupation-Based Program for At-Risk Youth
}

Jasmine Shahin

University of St. Augustine for Health Sciences

DOI: https://doi.org/10.46409/sr.HEXM4199

Follow this and additional works at: https://soar.usa.edu/capstones

Part of the Occupational Therapy Commons, Other Mental and Social Health Commons, and the Psychiatric and Mental Health Commons

\section{Recommended Citation}

Shahin, J. (2021). Occupational Therapy in Youth Violence: An Occupation-Based Program for At-Risk Youth. [Doctoral project, University of St Augustine for Health Sciences]. SOAR @ USA: Student Capstone Projects Collection. https://doi.org/10.46409/sr.HEXM4199

This Capstone is brought to you for free and open access by the Student Research at SOAR @ USA. It has been accepted for inclusion in Student Capstone Projects by an authorized administrator of SOAR @ USA. For more information, please contact soar@usa.edu, erobinson@usa.edu. 
Spring 4-2021

\section{Occupational Therapy in Youth Violence: An Occupation-Based Program for At-Risk Youth}

Jasmine Shahin

Follow this and additional works at: https://soar.usa.edu/capstones

Part of the Occupational Therapy Commons, Other Mental and Social Health Commons, and the Psychiatric and Mental Health Commons 


\title{
Occupational Therapy in Youth Violence: \\ An Occupation-Based Program for At-Risk Youth
}

\author{
Jasmine I. Shahin \\ Department of Occupational Therapy, University of St. Augustine for Health Sciences
}

A Capstone Presented in Partial Fulfillment of the Requirement for the Degree of DOCTOR OF OCCUPATIONAL THERAPY

University of St. Augustine for Health Sciences

April 2021 


\title{
Occupational Therapy in Youth Violence:
}

An occupation-based program for at-risk youth

\author{
Jasmine I. Shahin \\ Department of Occupational Therapy, University of St. Augustine for Health Sciences \\ has been approved \\ April 2021 \\ Pamela Kasyan-Howe, OTD, OTR/L, Doctoral Coordinator \\ Kristen Domville, DrOT, OTR/L, Doctoral Coordinator \\ Jose Rafols, OTD, MHSA, OTR/, Program Director
}

APPROVED:

ACCEPTED AND SIGNED: 
Table of Contents

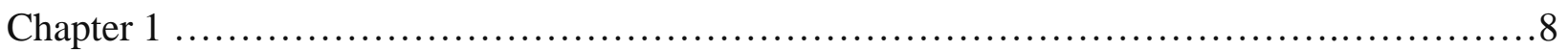

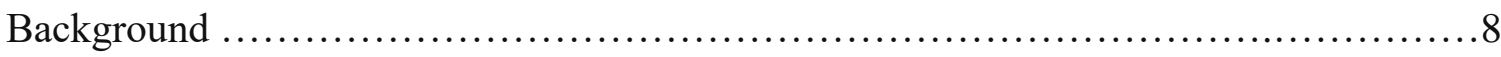

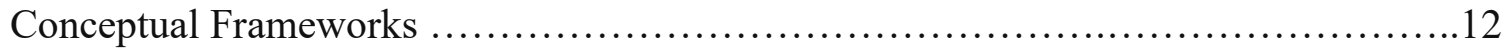

Problem Statement ..........................................................

Purpose Statement.......................................................16

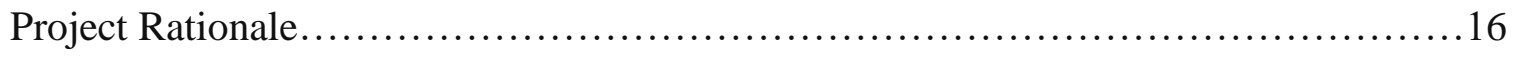

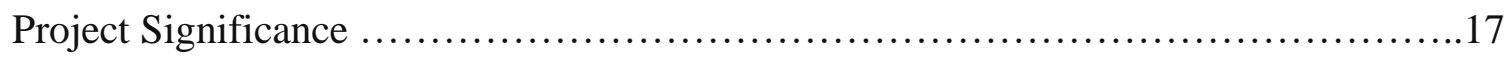

Project Objectives .......................................................19

Learning Objectives............................................... 19

Project-based Objectives............................................... 19

Definition of Terms...................................................... 20

Assumptions..............................................................21

Limitations............................................................ 21

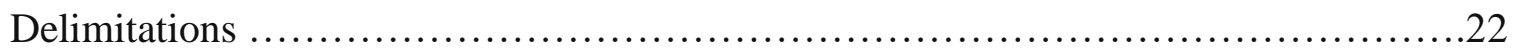

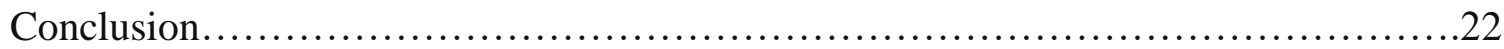

Chapter 2 Literature Review.....................................................24

At-Risk Youth................................................................ 25

Social Support from Family and Peers................................27

Socioeconomic Status...........................................29

Mental Health ............................................................29

Social Participation and Self-Regulation .....................................29

Professionals Working with At-Risk Youth..................................... 34 


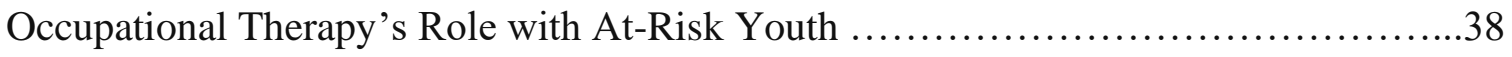

Social Emotional Learning Process and OT ..................................40

Self-awareness.......................................................... 41

Self-management...................................................42

Social awareness................................................... 42

Relationship skills.................................................43

Responsible decision-making ......................................44

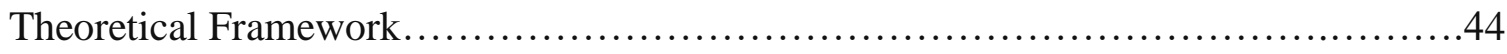

Model of Human Occupation.........................................45

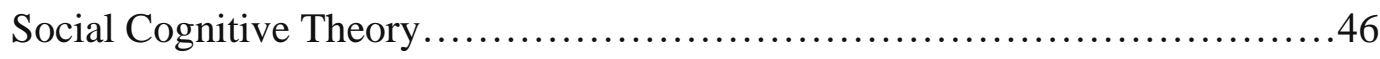

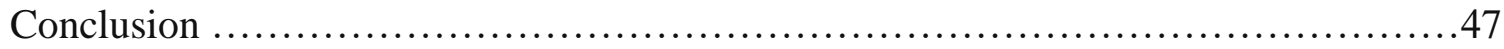

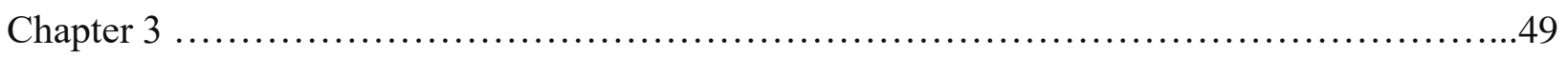

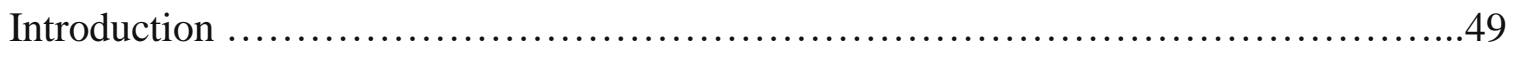

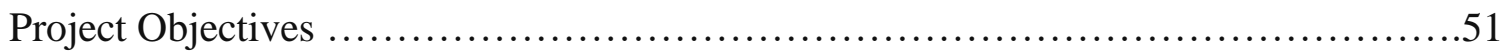

Participants ............................................................. 51

Setting and Measures...................................................... 52

Development and Implementation.........................................53

Theoretical Frameworks..................................................... 54

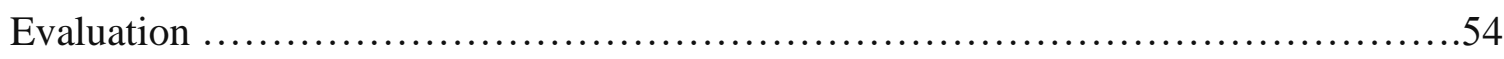

Timeline................................................................ 55

Data Analysis............................................................ 55

Presentation of Findings ............................................ 59

Conclusion.............................................................59 


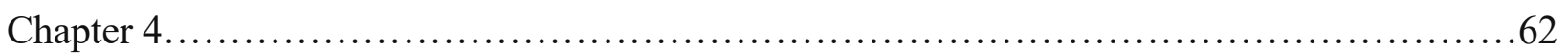

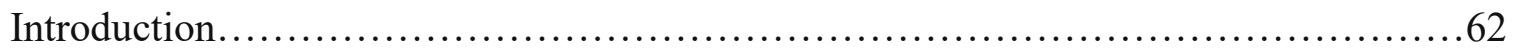

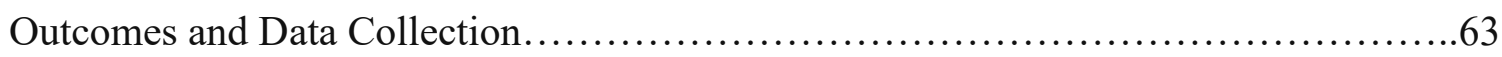

Timeframe and Data Collection....................................63

Participants and Recruitment.....................................63

Discrepancies Between Planned and Final Project..........................64

Project Sample...................................................65

Organization or Personal Conditions ..................................65

Project Objectives.......................................................66

Learning Objectives..............................................66

Project-based Objectives..........................................67

Project Outcomes.........................................................68

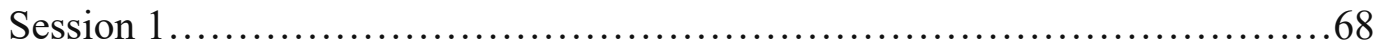

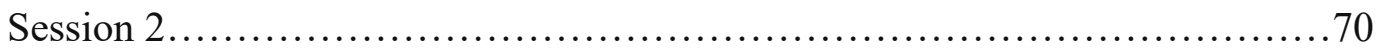

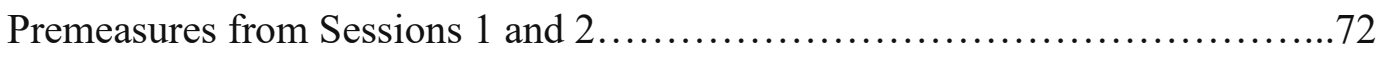

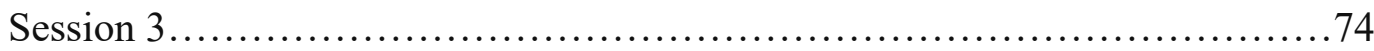

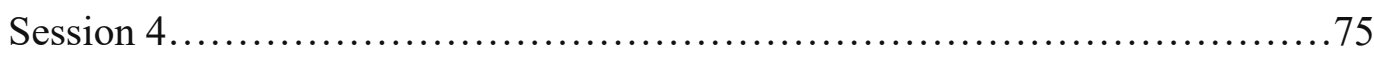

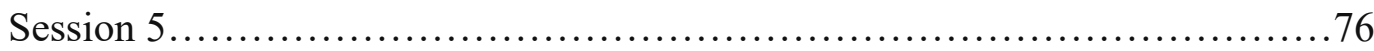

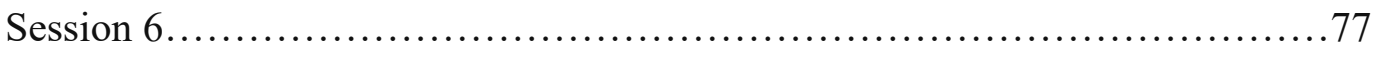

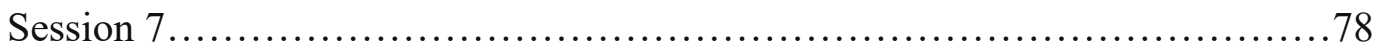

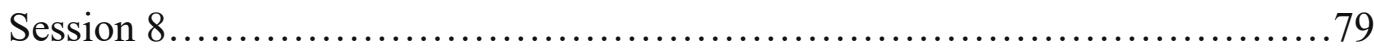

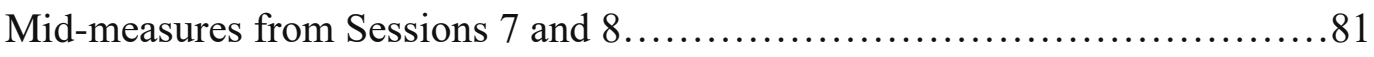

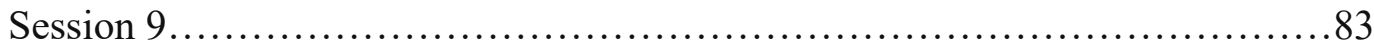




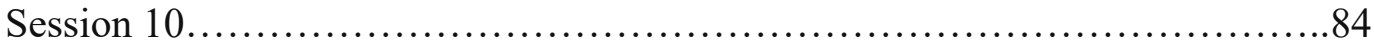

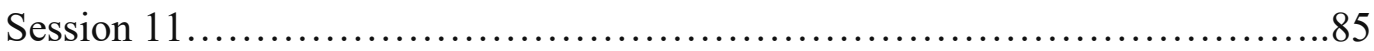

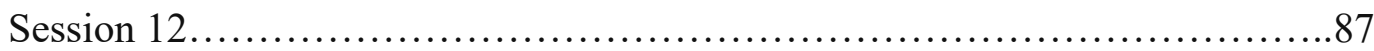

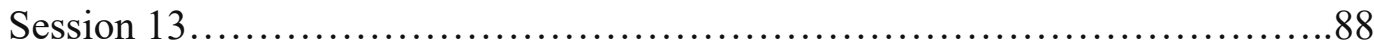

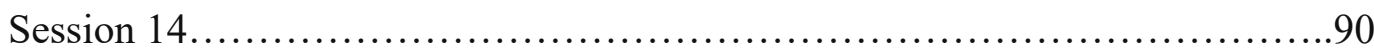

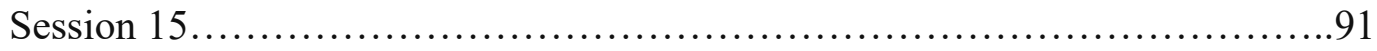

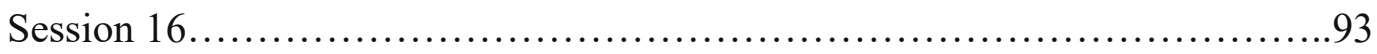

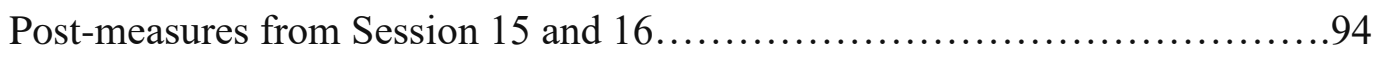

Data Analysis and Findings................................................ 96

Conclusion...........................................................97

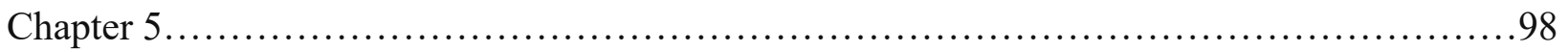

Introduction............................................................ 98

Interpretations of Findings............................................... 99

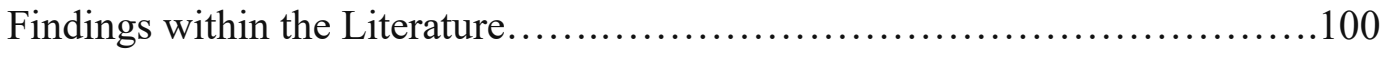

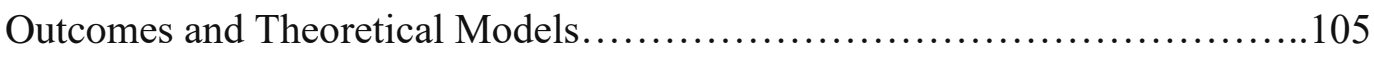

Consistencies and Inconsistencies................................... 106

Strengths and Limitations.............................................. 107

Strengths...................................................... 107

Delimitations..................................................... 108

Assumptions...................................................... 108

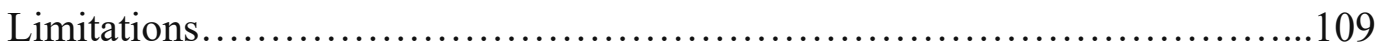

Future Recommendations............................................... 111

Conclusion................................................................. 113 


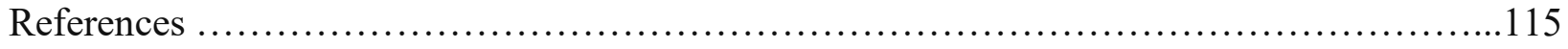

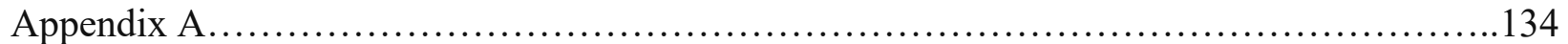

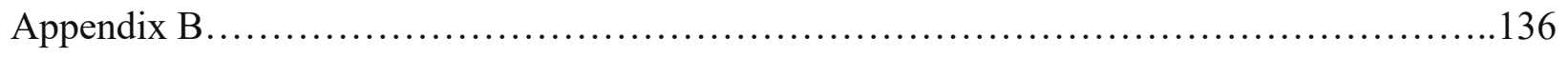

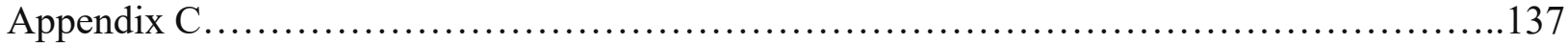

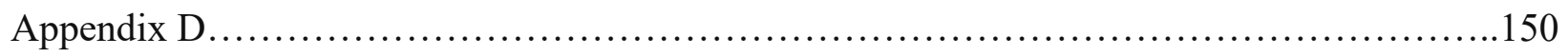

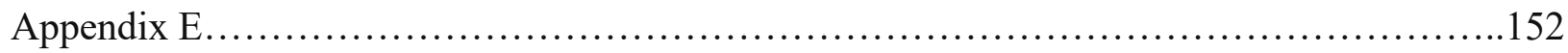

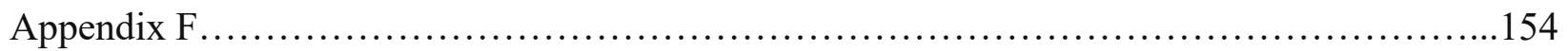

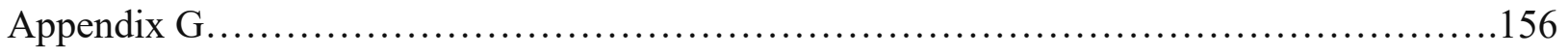

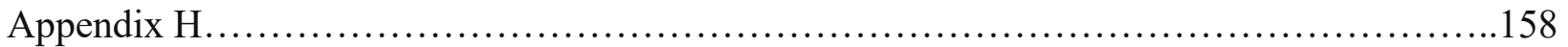




\section{Occupational Therapy in Youth Violence: An occupation-based program for at-risk youth Chapter 1: Introduction}

\section{Background}

Mass school shootings caused by youth, such as Columbine High School, Sandy Hook Elementary, and Stoneman Douglas High School, have increased awareness of youth violence. Mass school shootings have also called for increased efforts in keeping students and school environments safe (Modzeleski, 2018; Jonson, 2017). Along with school shootings, other forms of violence youth participate in are bullying, fighting, threatening with a weapon, sexual assault, or rape (Crawford \& Burns, 2016). Over recent years, there has been an increase in media outlets displaying tragedies occurring in schools due to youth violence. Without appropriate prevention, society's concerns and worries will increase if youth violence continues to rise (Modzeleski, 2018). Current prevention methods implemented across the United States (US) schools include threat assessments, emergency training, prevention programs, and hiring of school resource officers (Crawford \& Burns, 2016, Modzeleski, 2018; Jonson, 2017).

The mental health of children and adolescents has also become an increasing concern. Studies have found a correlation between youth participating in violence due to poor mental health (Ioannou et al., 2015; Oscós-Sánchez, 2017). Poor mental health is the difficulty in coping with life challenges to function in everyday roles and is related to poor achievement and low productivity (Yasuhiro et al., 2021). This, in turn, has led researchers to believe youth with mental health issues that have behaviors such as aggression, low impulse control, and depression are at-risk to perform violence (Ioannou, et al., 2015; Oscós-Sánchez, 2017). Youth with poor mental health are also more likely to experience homelessness, substance abuse, social isolation, and educational failure (Yung, 2016). 
The at-risk youth population is a specific population disadvantaged in engaging in safe and health-promoting activities due to limited resources or opportunities (Farajzadegan et al., 2018; Gallagher et al., 2015a). As a result, at-risk youth make decisions based on their disadvantaged environment (Farajzadegan et al., 2018; Gallagher et al., 2015a). The ability to make autonomous decisions by oneself to participate in various everyday activities that may be influenced by varied factors is known as occupational choices (Gallagher et al., 2015a; Gallagher et al., 2015b). Social factors including socioeconomic status (SES), sociocultural, family, and friends are primary factors that have an impact on an individual's opinions, attitudes, and interests that also influence occupational choices and mental health (Gallagher et al., 2015b).

Social deprivation, socially problematic, and/or self-destructive behaviors are contributing factors in social participation deficits that lead an at-risk youth to be at a greater risk of involvement with violence (Mcdaniel et al.,2016). Challenging behaviors such as aggression, defiance, anxiety, or depression can cause impairments in social relationships with others and lead to appalling outcomes within and out of school (Mcdaniel et al., 2016). A lack of social participation skills in youth has also been linked with having a higher risk for both causing a criminal offense or relapsing as a criminal offender (Demarco, et al., 2016; van der Stouwe et al., 2016). Improving the social participation skills in at-risk youth will aid in decreasing or eliminating the challenges they may face and to help achieve a happy and healthy lifestyle by demonstrating prosocial behaviors.

Along with social participation, self-regulation is also a contributing influence throughout youth development (de Matos \& Simões, 2016; Sibinga et al., 2016). The ability to manage and control emotions, behaviors, and feelings is known as self-regulation (Artuch-Garde, et al., 2017). Self-regulation is viewed as a key factor that can determine failure or success because 
individuals may or may not give in to negative moods or temptations (Artuch-Garde et al., 2017). At-risk youth experience stressors that may steer them to maladaptive coping mechanisms and overall inability to control their feelings or behaviors (de Matos \& Simões, 2016; Sibinga et al., 2016). Consequently, the ability to self-regulate will assist an individual during a stressful or challenging event by playing a protective role in how the person will act, such as in an adverse situation (Artuch-Garde et al., 2017; de Matos \& Simões, 2016; Sibinga et al., 2016).

The consistent stressors experienced throughout at-risk youth's life will influence their level of self-efficacy (Burger \& Samuel, 2017). Self-efficacy is the person's belief in their capacity to organize and execute behaviors and actions to manage situations and attain desired goals (Nols et al.,). Self-efficacy in at-risk youth will enable them to seek and utilize the appropriate resources within their environment to persevere despite facing life challenges (Shankar et al., 2017). When constantly faced with traumatic or significant life challenges, atrisk youth are more likely to have lower self-efficacy or beliefs in their capabilities. Poor selfefficacy will result in inappropriate decisions leading to poor life satisfaction (Burger \& Samuel, 2017).

Mental health professionals, such as social workers, psychologists, and mental health counselors, will help at-risk youth improve academic functioning, build interpersonal relationships with family and peers, improve coping skills, and manage challenging behaviors (Preyde et al., 2017). Mental health professionals will assume responsibilities from at-risk youth and parent-like roles to imitate real-life scenarios and interactions within their services (Ungar \& Ikeda, 2017). Current services provided to at-risk youth include individual therapy, group, and/or family therapy, support groups, case management, cognitive behavioral therapy, and medication monitoring (Murdoch \& Larsen, 2018; Preyde et al., 2017). For example, during individual or 
group therapy, the clients may touch on sensitive topics to them and address personal feelings (Ungar \& Ikeda, 2017). Collaborations with other professionals for the at-risk youth population may include educators, administrators, and nurses (Benson et al., 2016; Mahaffey, 2016).

Occupational therapy began as a service provided within mental health since practitioners promoted full participation in daily and meaningful activities in life (AOTA, 2017). However, over time, OT's role has been diminished and at-risk youth are sent to see social workers, counselors, psychologists, or psychiatrists (Baltag et al., 2015). The number of occupational therapists (OTs) working in mental health and their role within the mental health field has lessened Cahill \& Egan, 2017b). This is due to a lack of funding in facilities to employ OTs, time constraints existing to coordinate interventions focused on mental health, and other mental health professionals and environments not understanding the role of occupational therapy (Baltag, et al., 2015; Cahill \& Egan, 2017b; Parsons \& Saffer, 2018). Additionally, some OTs do not understand their role in addressing social participation needs which is a common concern addressed in mental health (Leigers Myers \& Schneck, 2016).

An important intervention provided by OTs who work with the mental health population is to provide interventions enhancing performance skills for improved social participation. Social participation is an occupation valued within occupational therapy because it intertwines with other occupations and activities and promotes healthy functioning and engagement with others. (Leigers et al., 2016; Shea \& Jackson, 2014, American Occupational Therapy Association [AOTA], 2020). OT's foundation is based on the understanding that engaging in occupations supports and promotes both physical and mental health and improves the quality of life (AOTA, 2017). OTs have the knowledge and training to improve at-risk youth's mental health by facilitating interventions with age-appropriate activities that are meaningful and purposeful 
(Parsons \& Saffer, 2017; Shea \& Jackson, 2014). While incorporating activities into the interventions, OTs can improve at-risk youths' mental health by targeting necessary skills, such as social participation and self-regulation.

\section{Theoretical Framework}

The social-emotional learning (SEL) process has been used by other researchers to guide projects focused on social-emotional development (Buzgar \& Giurgiuman, 2019; O’Conner et al., 2017). The SEL is a framework that will be utilized in the program to assist at-risk youth to improve social and emotional development (Anderson \& Grinder, 2017). SEL is a process that helps youth to acquire the skills and attitudes needed to recognize and manage their emotions and maintain supportive relationships (Anderson \& Grinder, 2017). Five competencies are established within the SEL framework to promote a proper learning environment to enhance development: self-awareness, self-management, social awareness, relationship skills, and responsible decision making. Occupational therapy practitioners can employ the SEL competencies within their interventions for at-risk youth to promote positive social participation and self-regulation skills (Anderson \& Grinder, 2017).

The occupational therapy theories that guide my project are the Model of Human Occupation (MOHO) and the Social Cognitive Theory (Bowyer et al., 2019; Graham et al., 2016). MOHO is relevant to use with at-risk youth because it describes how and why human behavior and the environment influence occupational performance (Bowyer et al., 2019; Graham et al., 2016). At-risk youth face barriers within their environmental context that disable the abilities to participate in healthy roles, occupations, and goals. MOHO further considers human beings to be dynamic systems comprising of motivation, patterns, and performance capacity and explains how these components intertwine with each other and the environment (Bowyer et al., 
2019; Graham et al., 2016). The implementation of MOHO is utilized for individuals of varying needs and can be used throughout any stage in life, making it appropriate to use with the youth population (Bowyer et al., 2019).

In contrast, the Social Cognitive Theory (SCT) posits that an individual's behavior is shaped by both their environments and self-regulation skills. The theory explains how social factors influence cognitive development and self-efficacy (Espelage et al., 2018; Knol et al., 2016). The SCT proposes environmental challenges, behaviors, personal factors, and cognition all influencing each other as individuals make choices on how they will participate in life roles and occupations (Knol et al., 2016). SCT has been used for projects serving at-risk youth, as psychological factors, such as anger and aggressive behaviors, can influence social cognition to pursue violent acts (Espelage et al., 2018; Knol et al., 2016). Together, MOHO and SCT develop the framework to create an optimal environment for at-risk youth to engage and participate in safe and age-appropriate activities within their environment. Both theories emphasize the promotion of favorable and prosocial behaviors while developing suitable habits and interests to continue making optimal lifestyle choices in the future.

The goal of utilizing an occupation-based program is to promote positive social participation skills and self-regulation skills in at-risk youth to improve lifestyle choices (Arbesman et al., 2013; Farajzadegan et al., 2018; Mcdaniel et al., 2016; Shea \& Jackson, 2014). At-risk youth who participate in this occupation-based program has the potential to reduce negative behaviors and violent acts (Arbesman et al., 2013; Farajzadegan, et al., 2018; Mcdaniel et al., 2016; Shea \& Jackson, 2014). OTs are educated on human development throughout the lifespan and how mental illness can influence engagement in meaningful activities and occupations (AOTA, 2017). Providing occupational therapy interventions addressing social 
participation skills and emotional self-regulation skills will benefit at-risk youth because they can develop the skills to create positive relationships with peers, family, future co-workers as well as practice prosocial behaviors within their environment.

\section{Problem Statement}

The problem is children and adolescents who participate in youth violence do so because of poorly developed social participation and self-regulation skills (Cid, 2016; Forrest-Bank et al., 2016; Shea \& Jackson, 2014). A second problem defined is that OTs used to fill in the role of mental health professionals but now they do not (Baltag et al., 2015; Cahill \& Egan, 2017b). OTs are able to provide interventions that assist at-risk youth to improve occupational choices through improving the client factor of self-regulation to develop age-appropriate skills for social participation (Leigers et al., 2016; Parsons \& Saffer, 2018). However, OTs are underutilized on intervention teams for the at-risk youth population (Leigers et al., 2016; Parsons \& Saffer, 2018).

Lack of social participation and self-regulation skills leads to at-risk behaviors in youth prone to violence (Demarco et al., 2016; Whitten et al., 2017). Deficits in social participation and self-regulation skills impair initiating and maintaining positive relationships and the ability to cope and adapt to the social environment (Leigers et al., 2016; Mcdaniel et al., 2016). Difficulty in sustaining relationships and coping with life challenges will gradually worsen the mental health of at-risk youth. OTs are trained and qualified to assist at-risk youth struggling with adverse life situations, yet minimal OTs are working with this population (Baltag et al., 2015; Leigers et al., 2016). In the field of OT, social participation is seen as an area of occupation integral to health (AOTA, 2020). Therefore, social participation is addressed by OTs when working with youth to develop supportive relationships and appropriately interact with others. 
Social situations are encountered daily especially in schools when participating in the occupation of education among peers and adults (Leigers et al., 2016; AOTA, 2020).

Along with a lack of social participation and self-regulation skills, socioeconomic status (SES), or the social standing of an individual or group based on income, occupation, and education, is known as a contributing factor associated with violence (American Psychological Association, n.d.; Farajzadegan et al., 2018; Pincham et al., 2018). Individuals from low or middle-income classes are more associated with violence due to poverty, inequality, lack of resources, and/or lack of quality education (Atienzo et al., 2016; Farajzadegan, et al., 2018; Patel et al., 2018). Limitations due to SES lead to limited opportunities in meaningful occupations and may impact health and well-being.

AOTA (2008) states "Positive change can occur by providing youth with opportunities to replace poor occupational choices with healthy, safe, productive, and socially acceptable activities" (p. 709). Currently, there are minimal effective intervention-based programs that are supportive of refining children's and adolescent's social participation and self-regulation to eliminate at-risk behaviors (Bonell et al., 2016; Farajzadegan et al., 2018; Whitten et al., 2017). The increased concern for youth violence has called for efforts in safety and promoting positive mental health (Modzeleski, 2018; Jonson, 2017). However, the at-risk youth population is specifically disadvantaged due to risk factors that prevent success, but OT's ability to facilitate a supportive environment and participation in valuable occupations will enable these youth to improve their daily roles, behaviors, and patterns to be successful as they continue to grow (Moses \& Villodas, 2017). Filling the gap in services, this project will develop and implement an occupation-based program for at-risk youth to improve social participation and self-regulation skills to decrease youth violence in at-risk youth. 


\section{Purpose Statement}

The purpose of this program development type project is to create and implement an occupation-based program to improve social participation and self-regulation skills for at-risk youth in Covenant House Florida. This project will additionally increase awareness of OT's role in mental health to work with the at-risk youth population. The occupation-based program will consist of group activities, such as arts and crafts, sports, team-building exercises, role-playing, etc. to promote social participation and self-regulation skills. The outcome of the project is reasonable for the 14-week experience as the duration is not too short or too long and may provide significant outcomes.

\section{Project Rationale}

This capstone project will enable at-risk youth to engage in a program to develop positive social relationships and self-regulation skills. The long-term goal of this program type is to increase safe and positive lifestyle choices in the future. Targeting the at-risk youth population is essential to strengthening their abilities in making responsible decisions and maintaining healthy relationships at home, school, and their environment (Whitten et al., 2017). Furthermore, providing group sessions throughout the program will be beneficial to observe the influence of peers within the participants (Bo et al., 2017).

Social participation is essential in youth as it contributes to their quality of life and sense of belonging, which makes the profession of occupational therapy suitable for this project because of this specific occupation (Griswold, 2016). OTs can evaluate the various components in social participation and self-regulation to determine whether an individual's cognitive skills or environmental influences are affecting the ability to meet everyday demands (Jones et al., 2015; Mahaffey, 2016). Interventions provided by OTs are client-centered and based on the 
individual's primary occupation or role to make the treatment process valuable to the client (Mahaffey, 2016). Moreover, OTs can work with various age groups and can facilitate participation in individuals by promoting engagement in their roles and occupations to lead a successful and independent life (Benson et al., 2016).

Many others could also find this occupation-based program valuable in improving social participation and self-regulation skills. Parents could become supportive and encouraging of their children in participating in extracurricular activities so their children can avoid engaging in deviant behaviors (Viau et al., 2015; De Wet et al., 2018). Collaboration with other professionals in an interdisciplinary team would be more effective. Teachers can learn to collaborate with OTs to promote the child's success inside and outside of the classroom as well as share available resources (Benson et al., 2016). Social workers and counselors could also learn to differentiate their roles and collaborate with OTs when finding alternative ideas to promote social participation and self-regulation skills (Lee \& Jonson-Reid, 2015).

\section{Project Significance}

The significance of this capstone is to fill the gap between at-risk youth with poor selfregulation and social participation skills, and the lack of occupational therapy services provided. The program will lead to positive change in three ways: development of social participation and self-regulation in at-risk youth, build support of OTs, and create a positive environment for the community. The program will provide at-risk youth an opportunity to participate in an occupation-based program to develop social participation and self-regulation skills. Developing these necessary skills will have positive effects to build confidence, maintain relationships, and respond effectively in diverse situations (Bonell et al., 2018). 
At-risk youth are often sent to see counselors, psychiatrists, and social workers for mental health services (Baltag et al., 2015). Despite OT's background within mental health, they are often not seen as mental health professionals because of the lack of funding in facilities to employ OTs and other professionals not understanding their role (Baltag et al., 2015; Leigers et al., 2016; Parsons \& Saffer; 2018). The program will be created to support OT’s ability to work with at-risk youth to focus on self-regulation and social participation to help prevent or decrease youth violence. This capstone could empower occupational therapy practitioners in continuing research and providing effective interventions to address social participation and self-regulation skills in at-risk youth. This will also provide OTs, as well as other professionals in an interdisciplinary team and society members, the ability to understand the profession of OT's role in social participation and self-regulation. Improving these skills in at-risk youth amongst their peers and adults may even encourage more OTs to advocate to create programs in schools or communities to prevent youth violence. When the program is completed and outcomes have been evaluated, disciplines within the community center will be provided education and training on OT's ability to work with the at-risk youth population to appropriately develop social participation and self-regulation skills.

If violence occurs in an educational setting such as schools, negative effects may ensue in children and adolescents such as anxiety, insecurity, and fear in which these issues may deteriorate a positive social environment (Farajzadegan et al., 2018). Families sending their children to school will also become fearful without knowing if their child is safe if violence is occurring. Poor social participation and self-regulation skills are influenced by a lack of resources, minimal social support, and environmental factors which ultimately lead at-risk youth to engage in violence (Gestsdottir et al., 2014). Thus, improving these skills in at-risk youth will 
help to maintain relationships, manage emotions, and resolve conflicts in their future (Bonell et al., 2018). The at-risk youth will further continue to promote healthy behaviors within the community and society to support a positive atmosphere.

\section{Project Objectives and Outcomes.}

\section{Learning objectives}

- Compare and contrast problems and issues at-risk youth experience that led them to participate in youth violence and/or experience maladaptive behaviors at Covenant House as compared to the literature - evidenced by a 1-2-pager summary paper

- Compare and contrast the problems experienced by at-risk youth, who participate in youth violence and/or demonstrate maladaptive behaviors, with poorly developed social participation and self-regulation skills - evidenced by a 1-2-page summary paper

- Identify and describe professionals who serve at-risk youth with poor social participation and self-regulation skills who participate in youth violence and/or demonstrate maladaptive behaviors in the literature and at Covenant House - evidenced by a 1-2-page summary paper

- Describe how OTs would fit within the organization of Covenant House to address at-risk youth with poorly developed social participation and self-regulation skills, including reimbursement and job description - evidenced by a 1-2-page summary paper

\section{Project-based objectives}

- Conduct a needs assessment at Covenant House Florida to learn the types of services provided, social participation skills currently taught, and by which disciplines by 1 month of my program development project - evidenced by a 1-2-page summary paper 
- Develop an occupation-based program to improve social participation skills and selfregulation skills for at-risk youth (Appendix C)

- Implement an occupation-based program to improve social participation skills and selfregulation skills for at-risk youth by 2 months of my program development project (Appendix C)

- Develop and collect assessment of the program at the end of the 8-week program evidenced by results and analysis in chapter 4

- Train staff on an occupation-based program to improve social participation and selfregulation skills for at-risk youth by 4 months of the program - evidenced by a PowerPoint presentation presented to staff at Covenant House Florida.

- Write chapters 4 and 5 of the capstone paper.

- Create poster for dissemination using USAHS (University of Saint Augustine for Health Sciences) template.

\section{Definition of Terms}

- Youth violence: intentional use of physical force or power to harm or threaten others by young people of the ages between 10-24 (Center for Disease Control and Prevention [CDC], n.d.).

- Social participation: the engagement and interaction between the community, family, friends, and/or peers AOTA, 2014).

- Self-regulation: ability to manage and monitor behaviors by one-self (Artuch-Garde et al., 2017).

- At-risk youth: young individuals who may experience risk factors that may prevent them from transitioning successfully into adulthood (Moses \& Villodas, 2017). 
- Occupation-based interventions: activities that promote improvement in areas of occupations which include activities of daily living (ADLs), instrumental activities of daily living (IADLs), education, play, leisure, rest and sleep, social participation, and work (Pfeiffer et al., 2017).

- Self-efficacy: an individual's judgment on their ability to organize and execute actions or tasks to attain desired goals (Nols et al., 2017).

- Social and emotional learning (SEL): a process through which individuals appropriately apply critical skills and attitudes to behave ethically, achieve positive goals, develop, and maintain positive relationships, and respect others (Anderson \& Grinder, 2017).

\section{Assumptions}

A few assumptions were made for this project. Assumptions include that the youth will be honest in the assessments given and the facility will allow full access to the youth for this project. Moreover, the participants will fully participate throughout the entire program. It is also an assumption that some of the participants may need interventions to improve or increase social participation and self-regulation skills.

\section{Limitations}

Limitations may include the sample size of participants due to the limited number of children or adolescents that I will have access to at the facility. The length of time to conduct this study will be limited as well as the project is a duration of 14 weeks. The daily attendance of the participants may be a limitation, especially if other programs within Covenant House are occurring during the same time as the occupation-based program. The cost of materials and activities needs to be considered; therefore, the variability of activities offered may be limited. Furthermore, no follow-ups with faculty or the program will be conducted post-study to know if 
social participation and self-regulation skills have been maintained or declined within the participants.

\section{Delimitations}

The program in this study will take place in Fort Lauderdale, Florida, and will only include at-risk youth since social participation and self-regulation skills are key factors in shaping positive behavior and occupational choices in youth. However, findings may not transfer over to other populations of at-risk youth engaging in youth violence. Occupation-based interventions will be used throughout the program to support the participant's engagement in occupations such as in play, education, leisure, and social participation. Activities may include team-building exercises, arts and crafts, sports, games, role-playing, etc. MOHO will guide atrisk youth to develop positive habits and routines and engage in purposeful occupations within their environment (Bowyer et al., 2019; Graham et al., 2016). SCT will guide at-risk youth to think critically about their interactions and behaviors within their environment to make rational choices (Espelage et al., 2018; Knol et al., 2016). The SEL process will help at-risk youth to build necessary attitudes and skills such as making positive choices, managing emotions, recognizing their own goals as well as the goals from others, and maintaining supportive relationships (Anderson \& Grinder, 2017).

\section{Conclusion}

An occupation-based program focused on social participation and self-regulation skills will help at-risk youth to develop their social participation and self-regulation skills and prevent the likelihood of negative engagement in activities. Poor social participation and self-regulation skills leads to difficulties in maintaining healthy relationships with family and peers and making poor occupational choices, such as participating in youth violence or associating with delinquent 
peers (Cid, 2016; Farajzadegan et al., 2018). Self-regulation allows individuals to adapt to the context of their environment and the people with whom they engage. Therefore, self-regulation is thought to improve social participation and interactions because people can control their behaviors and feelings (Barnes, et al., 2017; Gestsdottir et al., 2014).

Both social participation and self-regulation skills in at-risk youth may be influenced by surrounding factors such as environment, family, peers, and resources (Gestsdottir et al., 2014). If one of these factors is lacking or negatively influencing a youth, this may cause poor personality and intellectual development. Limitations in social-emotional development can affect youth to become independent and active individuals in their communities (Gestsdottir et al., 2014). Improving social participation and self-regulation skills in at-risk youth will help them to make responsible decisions, make safe occupational choices, and manage their emotions appropriately in various situations within their environment (Bonell et al., 2018). 


\section{Chapter 2: Literature Review}

\section{Introduction}

The purpose of this chapter is to provide a summary of existing literature on the risk factors faced by at-risk youth and how these factors impact social participation and selfregulation skills leading to maladaptive behaviors and engagement in negative choices. The chapter will additionally provide evidence from the literature on professionals who work with atrisk youth, OT's ability to work the population, and theoretical frameworks that will help guide the capstone project.

The problem is that at-risk youth participate in youth violence because of poorly developed social participation and self-regulation skills (Cid, 2016; Forrest-Bank et al., 2016; Shea \& Jackson, 2014). A second problem is that occupational therapy used to fill in the role of mental health professionals, but now they do not (Baltag et al., 2015; Cahill \& Egan, 2017b). Therefore, the purpose of this capstone project is to implement an occupation-based program for at-risk youth to improve social participation and self-regulation skills to prevent youth violence. OTs are educated and trained to address social participation and self-regulation skill deficits. However, at-risk youth are primarily sent to see other mental health professionals, such as social workers, psychologists, and psychiatrists leading OTs to be underutilized on intervention teams for at-risk youth (Leiger et al., 2016; Parsons \& Saffer, 2018). Improving social participation and self-regulation skills in at-risk youth will enable them to make healthy decisions, sustain positive relationships, and build their self-esteem to handle life challenges. The at-risk youth population is disadvantaged in engaging in safe and health-promoting activities because of the limited opportunities or resources within their environment (Farajzadegan et al., 2018; Gallagher, et al., 2015a). The limited resources or opportunities can lead at-risk youth to make negative decisions 
or experience negative behaviors based on their disadvantaged environment, such as engaging in youth violence (Farajzadegan et al., 2018; Gallagher, et al., 2015a).

At-risk youth may face three of the primary risk factors that can influence their occupational choices, interests, and attitudes: lack of social support from family or peers, low SES, and/or poor mental health (Gestsdottir et al., 2014; Risk and Protective Factors, n.d). These primary risk factors lead to smaller and additional risk factors which gradually hinder an at-risk youth's social participation and self-regulation skills. To help at-risk youth, many professionals work together to provide improve the abilities of at-risk youth. At school, these professionals include teachers, school guidance counselors, psychologists, and social workers. However, despite OTs working in schools and their ability to support a healthy lifestyle, they are not considered in these multidisciplinary teams (Capuzzi \& Gross, 2019). The literature review will further support the profession of occupational therapy in mental health and its ability to fulfill healthy and safe occupational engagement.

\section{At-Risk Youth}

The at-risk youth population experiences a variety of challenges and risk factors that lead to stress and marginalization. Risk factors are psychological, cultural, biological, or social characteristics that can precede as determinants to problem outcomes (Farajzadegan et al., 2018; Risk and Protective Factors, n.d.). When faced with challenging conditions and determinants, atrisk youth will unsuccessfully transition into adulthood and make poor occupational choices (de Matos \& Simões, 2016; Hopper \& Iwasaki, 2017). Primary risk factors at-risk youth experience are a lack of social support from family and peers, poor mental health, and low SES (Risk and Protective Factors, n.d.). Within these primary risk factors, this population may encounter sub- 
factors that include poverty, poor conduct, inequality, social exclusion, broken families, and community violence (Farajzadegan et al., 2018; Wesely et al., 2017).

At-risk youth affected by multiple risk factors are more likely to experience negative outcomes such as failure in school, maladaptive behavior, and poor relationships (de Matos \& Simões, 2016; McDaniel et al., 2016; Sibinga et al., 2016). At-risk youth have scarce opportunities to explore their interests in various occupations that will promote growth and wellbeing because of the restricted resources in their environment (Gallagher et al., 2015a, 2015b; McDaniel et al., 2016; Shea \& Jackson, 2014). As a result of restricted resources, youth make choices that are in opposition to a democratic society such as negative judgment and decision making. Examples of negative decision-making include associating with delinquent peers, accessing weapons, drug use, disregarding school, shoplifting, and isolation from family and peers (Farajzadegan et al., 2018; Gallagher et al., 2015b; Shea, \& Jackson, 2014). Consequently, poor occupational choices and risk factors will impact and negatively alter a youth's development which affects their health and well-being.

Statistics of at-risk youth may vary due to the number of risk factors youth can experience. It is estimated that $20 \%$ of adolescents have a mental health condition and over 3,000 adolescents will run away from their homes due to abuse or a dysfunctional household (At-Risk Youth Programs Editorial Team, 2021). According to the CDC (2020), the 2019 Youth Risk Behavior Survey (YRBS) indicated that $7 \%$ of high school students in the U.S reported current prescription opioid abuse and $14 \%$ reported misuse of opioid prescriptions at least once in their lifetime. The at-risk youth indicating current opioid abuse also reported current use of alcohol and marijuana (CDC, 2020). Furthermore, in 2019, 13.2\% of high school students carried a weapon, of which $2.8 \%$ of those students reported they would carry it to school (CDC, 2020). 
These few statistics display the challenges faced by at-risk youth and the possibilities of what may occur in the future if not addressed appropriately. The lack of social support, low SES, and poor mental health are primary risk factors that may provide consistent stress experienced at-risk youth (Risk and Protective Factors, n.d.). When faced with these primary risk factors, at-risk youth will experience unhealthy social and emotional behaviors that will decrease their selfefficacy and self-esteem.

\section{Social Support from Family and Peers}

Social support from family and friends is associated with positive outcomes in youth. Social support serves as a protective factor to handle stressors, decrease levels of behavioral and emotional problems, and enhances self-esteem (Hardaway et al., 2016; Ridings et al., 2017). However, barriers to providing the necessary support for at-risk youth do occur. Instances in which the family is unable to attend to their child or attend necessary parent-child programs due to low SES, the mental health of the family, parental beliefs, transportation, or scheduling conflicts can contribute to greater difficulty in coping with stressors and associating with negative influences (January et al., 2016). According to Serrano-villar et al. (2017) youth have a higher likelihood of depression, hyperactivity, and social isolation when limited social support is provided by parents. Moreover, youth raised in an abusive or stressful home environment will experience and feel victimization, social withdrawal, and emotional detachment in relationships (Ridings et al., 2017).

Social isolation and the uncertainty of maintaining a relationship may become greater as the child attends the school environment. When students lack the appropriate social skills and capacity to participate with their peers, they choose to disregard group activities or feel insecure about how to initiate peer relationships in school, especially if they have experienced bullying 
(Holland et al., 2017). Socialization in school becomes a primary focus during adolescent years (Schwartz et al., 2016). If adolescents associate with disengaged peers in school, they will not succeed academically and will demonstrate poor classroom performance, such as creating distractions during lectures, commenting negatively towards teachers, and skipping classes (Schwartz et al., 2016). Adolescents affiliating with disengaged peers could also lead to being easily influenced to try drugs, commit violence, and not committing to pursuing future endeavors (Schwartz et al., 2016).

Adolescence is a developmental stage where social relations and social skills are crucial to occur to help youth become independent and self-assertive (Lodder et al., 2016). Building relationships and engaging with peers is important during adolescence as social participation and self-regulation skills further develop (Lodder et al., 2016). Adolescents are learning about the complexity of relationships during this time. However, youth who feel disconnected from others may experience loneliness which hinders their social skills and limits their opportunities to maintain quality relationships with peers. Moreover, youth with minimal social support and poor social skills may face difficulty in coping with life stressors leading to negative behaviors and affect (Lodder et al.,2016). Similarly, the lack of social support from family can increase the risk of poor mental health, insecurity, and coping abilities in youth (Santamaria-Garcia et al., 2020). Additional limitations such as low-SES can also influence at-risk youths' ability to appropriately engage with others and self-regulate as SES can have an impact on familial support provided to the youth (Lohndorf et al., 2018).

\section{Socioeconomic Status}

Low SES can influence at-risk youth's development in several ways. The likelihood of developing poor mental and physical health and socio-emotional and psychological problems is 
much higher in at-risk youth from a low SES background than those from a higher economic class (Devenish et al., 2017; Hosokawa \& Katsura, 2018). The result of overall poor health and development holds to be especially true for at-risk youth living in poverty (Hosokawa \& Katsura, 2018). Furthermore, studies have shown that low familial income and parental education can influence developmental difficulties in children (Hosokawa \& Katsura, 2018). Low-income families and lack of parental support can limit a child's language skills leading the child to deal with social problems that can interfere with learning (Lohhndorf et al., 2018). Within the home environment, less stimulation may be provided because limited resources are made available due to economic hardship (Lohndorf et al., 2018). Moreover, parents in the household may be experiencing stress because of economic struggle and will devote less time to play, converse, or read with their children (Lohndorf et al., 2018).

In low SES communities, schools are also often poorly funded and are to only provide minimal resources to the students (American Psychological Association [APA], 2017). Therefore, school readiness and achievement can become negatively affected and can even contribute to dropping out of school (APA, 2017; Devenish \& et al., 2017). For example, in 2014, low-income families had the highest dropout rate in high school, where the students were between the ages of 16-24 (APA, 2017). Identifying and incorporating safe and healthy activities that are available within the environment is helpful to positively shape the child's development.

\section{Mental Health}

The cause of mental disorders among at-risk youth may occur due to mental functioning, cognitive and physical health, social context, and stressful events (Shahraki-Sanavi et al., 2020). In the U.S alone, 4.5 million children and adolescents had a diagnosed behavior problem in 2018 (CDC, 2020; Children's Defense Fund, 2019). When experiencing poor mental health, at-risk 
youth are more prone to negative behaviors such as hopelessness, low self-esteem, anxiety, poor conduct, and aggression (Ioannou et al., 2015; Oscós-Sánchez, 2017). If mental health problems are prolonged, at-risk youth experience consequences that include unemployment, homelessness, substance abuse, educational failure, and social deprivation (Yung, 2016).

However, according to Malla et al. (2016), less than $30 \%$ of youth seek the necessary help for their mental health disorders. Many young people avoid looking for professional help because of embarrassment, discrimination, or shame that they may feel about their problems (Malla et al., 2016; Yung, 2016). At-risk youth may delay seeking treatment if they are experiencing early onset of anxiety, substance abuse, or mood disorders (Yung, 2016). Moreover, at-risk youth who have sought treatment are still at-risk of disengaging from services if they feel like they are being treated like an adult and not their current age (Yung, 2016). When expected to behave like an adult, this can lead at-risk youth to believe that they are faced with societal or personal challenges (Yung, 2016). Services that respond to at-risk youth with poor mental health by providing age-appropriate activities and services will help to improve their mental health and promote positive and prosocial behavior (Yung, 2016). Mental health services will promote healthy living and make the behavioral changes needed in at-risk youth to prevent youth violence (Samson \& Sankar, 2018; Yung, 2016).

A common outcome and concern from the confluence of risk factors is participation in youth violence (Cid, 2016; DeMarco et al., 2016; Farajzadegan et al., 2018). The limited positive opportunities to promote social participation and self-regulation skills within the environment can lead to unfavorable decisions. To illustrate, an at-risk youth may turn to delinquent peers, such as in a gang, to feel connected with others and not isolated. If violence is not resolved at a young age, it can lead to a reoccurrence in offending and more serious actions of violence 
(DeMarco et al., 2016; van der Stouwe et al., 2016). For instance, at-risk youth engaging in bullying behavior could result in physical fighting which could even include the use of weaponry for a fight or to carry for self-defense to inflict pain to those who provoked their anger (Samson \& Sankar, 2018).

Youth violence is seen as a contributor to biological and psychological factors as well as emotional distress (Farajzadegan, et al., 2018). However, social, and emotional issues can influence violent behaviors and actions in at-risk youth (Cid, 2016; DeMarco et al., 2016; Farajzadegan et al., 2018). Adolescent students who felt depressed were three times more likely to carry a gun to school in comparison to students who were not depressed (Juan \& Hemenway, 2017). Along with emotional problems or mental illness, this study also identified social issues being a key element as the predictor of gun-carrying (Juan \& Hemenway, 2017). Therefore, social participation and self-regulation skills are two crucial factors needed to decrease or eliminate violence in at-risk youth.

\section{Social Participation and Self-Regulation}

Social participation and self-regulation are important components to learn and develop, especially at an early age, because they can either support or hinder desired goals (Leigers, 2016; Whitten et al., 2017). Unlike many young individuals, at-risk youth have a disadvantage in engaging in health-promoting activities because of the few opportunities accessible to them (Farajzadegan et al., 2018; Gallagher et al., 2015a, 2015b). The inability to explore occupational such as aggression and anxiety, which could lead to youth violence (Shea \& Jackson, 2014; Sibinga et al., 2016). According to Sibinga et al. (2016), if young individuals consistently experience stressors, it can eventually deplete coping mechanisms as this can affect temper and psychological issues in the future. Poor development of social participation and self-regulation 
skills in at-risk youth could also impact the ability to feel accepted, maintain positive

relationships with family and peers, and behave appropriately in various social contexts (Leigers et al., 2016; Whitten et al., 2017).

At-risk youth experience strain due to the introduction of or inability to avoid negative stimuli in the environment as well as the inability to achieve positive goals (Wesley et al., 2017). Both the negative stimuli and inability to achieve positive or desired goals can lead to a lack of personal control within the lives of at-risk youth which lowers their self-efficacy (Selsnick \& Brakenhoff, 2017). When strain is experienced over an extended period, the likelihood of negative and delinquent behaviors, such as violence and anger, can occur (Wesley et al., 2017). As a result, these negative behaviors and feelings lead to poor social participation and selfregulation skills (Patel et al., 2018; Wesley et al., 2017). Social participation and self-regulation skills strengthen the sense of self-efficacy because it demonstrates proficiency in the ability and confidence to make appropriate, quality decisions and communicate effectively with others (AlMehsin, 2017). Difficulty with controlling thoughts and feelings, and socially interacting improperly at an early age could cause present and future problems, such as youth violence, as the population transitions to adulthood (Gallagher et al., 2015b; McDaniel et al., 2016; Shea \& Jackson, 2014).

Social participation, specifically for at-risk youth, involves positive social interaction, peer acceptance, and building social relationships and friendships with classmates and peers (Mcdaniel et al., 2016; Piškur et al., 2014). Studies have shown that positive social relationships improve the sense of belonging as well as academic achievement in school (Leigers et al., 2016; McDaniel et al., 2016). According to DeMarco et al. (2016) targeting the at-risk youth should be a priority to decrease youth violence and negative social behaviors. A lack of social participation 
skills has been correlated with behavioral issues, including hopelessness, anxiety, and delinquency (van der Stouwe et al., 2016). These issues are primarily due to not feeling accepted by others leading to social isolation (Leigers et al., 2016). The inability to develop and maintain relationships and feeling unaccepted can steer at-risk youth towards psychological problems (Leigers et al., 2016). At-risk youth with poor social participation skills are at a much greater risk of participating in violence and even increasing their risk of offending in the future (DeMarco et al., 2016; van der Stouwe et al., 2016).

Poorly developed self-regulation skills are an additional concern for at-risk youth (de Matos \& Simões, 2016; Sibinga et al., 2016). Despite the ability to control behaviors, feelings, and emotions, self-regulation is comprised of three elements: sustaining attention, recalling instructions, and inhibiting negative behaviors (Cadima et al., 2016; Pears et al., 2015). These elements combined will allow at-risk youth to act rationally within their environment including in a classroom setting. Promoting self-regulation during childhood years predicts academic achievement, transition during school years, and social adjustment (Cadima et al., 2016; Pears et al., 2015).

Continuous exposure to external and internal stressors impacts an at-risk youth's selfregulatory system, which will eventually decrease the at-risk youth's ability to cope or manage negative responses and stress (Sibinga et al., 2016). This is concerning for at-risk youth because they experience stressors such as limited resources, inequality, community violence, and illegal encounters (Sibing et al., 2016). Enhancing self-regulation skills within this population will allow them to develop effective coping strategies to protect themselves from psychological and behavioral issues (de Matos Simões, 2016; Sibinga et al., 2016). 
The development of social participation and self-regulation skills in at-risk youth will promote positive outcomes in developing relationships, thinking rationally in situations, and communicating effectively with others (Mcdaniel et al., 2016; Piškur et al., 2014). Appropriate social participation and self-regulation skills can help decrease negative thoughts or behaviors and can improve an at-risk youth's confidence and self-efficacy (Al-Mehsin, 2017). At-risk youth who are facing challenges in their mental health and social participation and selfregulation skills will benefit from seeking help from professionals to address their problems and provide the necessary support they need.

\section{Professionals Working with At-risk Youth}

Current literature provides evidence supporting the understanding that many professions are working together to improve the experience of at-risk youth, such as teachers, counselors, and social workers. Each profession has strengths and limitations in approaching different problems. The role can support includes developing a healthy lifestyle through habit formation, social participation, self-regulation skills, and self-efficacy of at-risk youth. Identifying the roles of other disciplinaries and utilizing a multidisciplinary approach provides a wide range of expertise to be applied to prevent youth violence in at-risk youth (Capuzzi \& Gross, 2019).

Teachers are often seen as the front line when working with the youth population due to being educators and seeing students every day within their classrooms (Kundu \& Debdulal, 2016). The role of teachers includes providing knowledge on various topics in a positive learning environment (Haggis, 2017; Kundu \& Debdulal, 2016). Particularly for at-risk youth, teachers should structure opportunities in the classroom that focus on team building, encouragement, social participation, and emotional challenges to continue promoting a healthy atmosphere 
(Haggis, 2017). Teachers can also motivate students to believe they can be successful in and out of the classroom (Haggis, 2017).

According to Shewark et al. (2018), teachers who are socially and emotionally competent will take advantage of providing teaching opportunities to build resiliency and positive behavior (p.790). In contrast, the quality of teaching is usually negatively impacted by teachers who are less socially and emotionally competent as classroom experiences are less arousing to students. In cases where the teachers don't stimulate social and emotional experiences for at-risk youth, the students will continue to disengage and show disinterest within the classroom (Shewark et al., 2018). This will lead teachers to have difficulty in handling at-risk youth and punishing them. The student-teacher ratio also presents a challenge for teachers to effectively produce quality education in a classroom (Koc \& Celik, 2015). Studies have shown smaller student-teacher ratios allow teachers to spend more one-on-one time with each student and provide more individualized learning (Koc \& Celik 2015). However, when given a larger classroom size, teachers can find it demanding to provide sufficient time to help teach or speak to each student individually. If an at-risk youth is displaying behavior and social disorder, teachers may also find it difficult to help control the student while simultaneously controlling the behaviors of other students in the class (Koc \& Celik 2015). When such factors are encountered, the quality of teaching and the effectiveness of teachers are negatively impacted to help increase success and performance in at-risk youth.

Counselors, such as school guidance counselors and mental health counselors, respond to the emotional, social, and psychological needs of youth that have identified risk factors (Hines et al., 2017). To improve social participation and self-regulation in at-risk youth, counselors could provide assessments, individual and group counseling, and work on communication and 
decision-making skills (Hines et al., 2017; Merali, 2017). These professionals can provide advice and teach skills to handle stressors in an at-risk youth's life and advocate creating a positive environment (Hines et al., 2017; Merali, 2017).

School guidance counselors are to provide support in academics, career, and social and emotional development of students (Robertson et al., 2016). Despite the ability to provide appropriate mental health services, counselors seldom have the opportunity in schools to perform their role in addressing mental health concerns (Slaten et al., 2015). The school guidance counselor's focus goes towards making sure students are planning and meeting their academic courses (Slaten et al., 2015). School guidance counselors will become too busy to be sources of support and to attend to everyone appropriately. According to Martinez \& Deil-Amen (2015), because school guidance counselors are pressed with time and the minimal availability of school guidance counselors, at-risk youth are given low academic expectations, such as finishing high school as an end goal or attending a local college rather than a university. The lack of quantity and quality of counseling services to at least encourage at-risk youth to excel in school can diminish self-perceptions and jeopardize the at-risk youth to reach or believe in their full potential (Martinez \& Deil-Amen, 2015).

Social workers can also assist with behavioral concerns and mental health issues to see what may be affecting the individual's performance (Lee \& Jonson-Reid, 2016). The social worker will guide and advise an at-risk youth to consider different strategies that will steer away from delinquent activity (Frost, 2017). However, the duties of social workers may vary depending on the setting they are in. For example, school social workers aim to promote school success, especially for students at-risk, such as advocating for resources for students and families, managing case records, and providing teacher training (Frost, 2017). A social worker 
who works with at-risk youth outside of the school setting will also manage case records as well as arrange for needed services by other professionals and peer support programs (Frost, 2017). In addition, the social worker will monitor the progress of the at-risk youth to see if the services are working well (Frost, 2017).

There are several challenges faced by social workers to help the at-risk youth population. When a caregiver and/or teacher doesn't understand the role of the social worker, it can make it confusing or difficult for them to carry out skills and tasks provided by the social worker to help at-risk youth succeed (Balli, 2016). Instances where the caregiver does not realize school is the at-risk youth's solution to a better life and does not provide the support required, contribute to the lack of collaboration with the social worker (Trancă, 2020). Time management becomes difficult as social workers need to keep up to date with cases, activities, and documents to be completed for beneficiaries (Trancă, 2020). The lack of funding in schools may additionally cause ethical dilemmas for social workers. Some social workers are unable to recommend outside services to parents because the school districts will have to pay for them (Trancă, 2020). Although social works can connect at-risk youth and their families to community resources and provide their professional knowledge to at-risk youth, they face barriers that prevent their services from being often effective (Trancă, 2020).

An occupational therapist aims to promote health and well-being by discovering the strengths and occupational interests of at-risk youth. They also identify factors and deficits that are creating a barrier to success in activities and occupations (Samson \& Sankar, 2018; Shea \& Jackson, 2014). For at-risk youth, OTs want to promote healthy transitioning into adulthood, and engagement in meaningful and age-related occupations, such as socializing with peers, participating in extracurricular activities, performing well in school, and building positive 
relationships (Arbesman et al., 2013; Benson \& et al., 2016; Shea \& Jackson, 2014). For example, if a child is experiencing aggressive behavior, an occupational therapist can provide interventions that utilize and adapt activities the child enjoys while targeting the aggressive behavior to promote a more positive behavior (Arbesman et al., 2013; Samson \& Sankar, 2018).

Teachers, school counselors, and social workers can collaborate with an occupational therapist to ensure at-risk youths' needs are being met, maximize overall treatment, and prevent or decrease the participation in youth violence. In a school setting, an occupational therapist identifies strengths and factors of the at-risk youth student that are impacting learning and participation (Benson et al., 2016). The teacher and the occupational therapist can collaborate to discuss strategies and create a plan for the student to implement in the classroom to support educational participation (Benson et al., 2016). When a counselor and occupational therapist work together, they can discuss assessment outcomes and intervention ideas they would like to utilize to implement in their treatment plans. A counselor may facilitate emotional and cognitive processing by providing coping skills and guidance to handle stressors, which then an occupational therapist will reinforce those skills learned in activities and occupations during sessions (Torchalla et al., 2019). In collaboration with an occupational therapist, the social worker will help at-risk youth adjust to changes within their environment, coordinate services for the at-risk youth to attend, and provide coping mechanisms (Children's Social Work Matters, n.d.). Meanwhile, an occupational therapist could assist the at-risk youth in building healthy habits by educating and training them on how to engage and make safe and responsible decisions within their environment. Teachers, counselors, social workers, and OTs will treat at various times or settings, so close collaboration is necessary to understand each professional's role and optimize treatment outcomes for the at-risk youth. 


\section{Occupational Therapists Role with At-Risk Youth}

Literature shows evidence that occupational therapist practitioners promote mental health by supporting individuals, such as at-risk youth, to participate in meaningful activities to successfully engage in occupations (Bazyk et al., 2015). However, they are underutilized on intervention teams to help this population (Jaegers et al., 2020; Leigers et al., 2016; Parsons \& Saffer, 2018). It is more common in present days to refer an at-risk youth to see a counselor, social worker, or psychiatrist when mental health is the area of concern, which may include the poor development of self-regulation and social participation skills (Baltag et al., 2015). The problem of OTs being underutilized could be due to several factors. Some OTs do not understand or are unaware of their role in mental health prevention and promotion, or social participation (Bazyk et al., 2015; Leigers et al., 2016). In a study done by Leigers et al., (2016) more than half of the participants, which included 102 OTs and 10 occupational therapy assistants, did not understand their role in improving the social participation needs of children. Another factor for OTs being underutilized is the lack of funding and time constraints to coordinate interventions, such as in community-based programs and schools (Jaegers et al., 2020; Leigers et al., 2016; Parsons \& Saffer, 2018). As a result of these issues, OTs advocate for their field to bring awareness needed to support the profession and to increase opportunities for at-risk youth to improve their health and well-being (American Occupational Therapy Association, 2017; Bazyk et al., 2015.

To deliver effective and client-centered treatment, OTs are creative with the services they provide. When working with at-risk youth, OTs are trained to apply occupation-based interventions that focus on socialization, play, and leisure, which are supportive in building social participation and self-regulation skills, and overall mental health (Cahill et al., 2020a; 
Shea \& Jackson, 2014). According to Simpson et al., (2018), to prevent youth violence, viewing how at-risk youth spend their free time is helpful. This population has a higher likelihood of participating in negative activities. Therefore, providing leisure and play participation in occupational therapy interventions offers opportunities to use time productively and promote the development of interests and social participation skills (Simpson et al., 2018). To deliver these occupation-based interventions, OTs can lead a group of at-risk youth throughout a program as part of the treatment process (Tanner et al., 2015). Providing therapy in groups will allow them to build social connections, increase positive interactions, and share similar interests (Simpson et al., 2018; Tanner et al., 2015). Group sessions provide opportunities to use the support of peers through problem-solving and decision-making with one another (Simpson et al., 2018).

OTs are well educated and trained in the importance of mental health for all individuals and use it as a focus when supporting engagement in activities and occupations (Bazyk et al., 2015). OT's offer a unique service to help at-risk youth by focusing on the use of occupation to improve mental health. Occupational therapy can enable at-risk youth to participate in meaningful and purposeful activities to further develop necessary skills, such as social participation and self-regulation skills (Parsons \& Saffer, 2017; Shea \& Jackson, 2014). At-risk youth can learn to behave ethically or think responsibly when participating and engaging in activities during interventions with an OT. To build critical skills for life effectiveness for at-risk youth, such as developing relationships and managing emotions, OTs can focus on the social and emotional learning process during interventions.

\section{Social and Emotional Learning Process}

Social-emotional learning (SEL) is a process that provides at-risk youth with the necessary skills to reduce mental health risks and promote social and emotional wellbeing 
(Dowling et al., 2019, Whatman et al., 2019). Programs that have utilized the SEL process have been found to decrease challenging behaviors while improving communication skills, selfcontrol, and academic performance (Minney et al., 2019). The process will support at-risk youth to demonstrate prosocial behaviors, set desired goals, and cope with everyday challenges (Whatman et al., 2019). Five competencies are integrated within SEL: self-awareness, selfmanagement, social awareness, relationship skills, and responsible decision-making (Minney et al., 2019, Whatman et al., 2019). These five competencies will provide at-risk youth a foundation for healthy development and to promote achievement within their lives. Occupational therapy practitioners can employ the SEL competencies within their interventions for at-risk youth to promote positive social participation and self-regulation skills (Anderson \& Grinder, 2017).

\section{Self-Awareness}

Self-awareness is the ability to recognize personal emotions and values (Minney et al., 2019). Self-awareness will allow at-risk youth to identify their feelings and how those feelings can influence their behaviors (Schonert-Reichl, 2017). Recognizing strengths, weaknesses, and other characteristics is also part of the self-awareness competency which will enable at-risk youth to have a better understanding of themselves (Schonert-Reichl, 2017). With greater understanding, at-risk youth will feel empowered to improve themselves and build on areas of their strengths and weaknesses.

Occupational therapy considers the importance of personal beliefs, empathy, and dignity when working with individuals as it is linked to one of the core values of the profession (AOTA, 2015). However, depending on the interrelationships between the environment, occupations and the individual can lead to a self-awareness deficit (Anderson \& Grinder, 2017). According to Chong et al., (2015), at-risk youth with delinquent behavior demonstrate a strong correlation 
with poor self-awareness. At-risk youth pay minimal attention to their feelings, therefore, do not connect their feelings with their thoughts (Chong et al., 2015). OTs allow at-risk youth to participate in appropriate activities and occupations while providing compensatory strategies and performance-based feedback to focus on the at-risk youth's belief in their ability to function while performing a task (Bazyk et al., 2015). By building a collaborative relationship with at-risk youth, OTs improve or restore the at-risk youth's ability to accept criticism, be confident, and be aware of their goals and values (Bazyk et al., 2015; Chong et al., 2015).

\section{Self-Management}

Self-management is the ability to self-regulate emotions, thoughts, and behaviors in different contexts (Minney, 2019). Self-management also involves setting and achieving personal and life goals using self-motivation and self-discipline (O'Conner et al., 2017). At-risk youth will learn to motivate themselves to overcome obstacles and monitor their progress to achieve desired goals (O'Conner et al., 2017). They will be able to express their emotions in an appropriate manner depending on their environment as well.

OTs focus on behavioral change when aiming for improved self-management (Kos et al., 2016). Interventions will include strategies to support at-risk youth to monitor their behavior and understand how their performance or actions can affect others within their environment (Chung \& McBride, 2015; Kos et al., 2016). Intervention strategies or techniques that will support behavioral change include self-monitoring, setting goals, and providing feedback (Kos et al., 2016).

\section{Social Awareness}

Social awareness is the ability to empathize with the perspective of others (Minney et al., 2019). The social awareness competency will allow at-risk youth to understand the feelings, 
behaviors, and thoughts of individuals and groups (O'Conner et al., 2017). At-risk youth will develop the ability to appreciate diversity and respect others from various cultures and backgrounds.

OTs can utilize interventions that will provide opportunities for at-risk youth to think critically and use empathy to help develop their social awareness (Chung \& McBride, 2015). During group sessions especially, OTs provide prompts or lead open discussions to individuals to think about the feelings and the perspectives of others. For example, OTs may use activities for the occupations of play or leisure that will target perspective-taking and interaction with others, such as charades or the game Hedbanz (Nabors et al., 2019). When OTs provide these activities, they can focus on other life areas as well such as interacting appropriately and respecting others (Simpson et al., 2018).

\section{Relationship Skills}

Relationship skills involve the ability to establish and maintain healthy relationships with various individuals and groups (Minney et al., 2019). Developing appropriate relationship skills will benefit at-risk youth by preventing and resolving interpersonal conflicts (O'Conner et al., 2017). They will demonstrate the ability to communicate, listen, and cooperate with others (Esen-Aygun \& Sahin-Taskin, 2017). At-risk youth will learn to resist inappropriate social pressure and seek help when needed (O’Conner et al., 2017).

At-risk youth have experienced trauma or unstable relationships that may have hindered their social participation and self-regulation skills (Shea \& Jackson, 2014; Sibinga et al., 2016). OTs provide methods and strategies, such as group discussion, role play, and brainstorming, to support the development of relationship skills (Abaoğlu et al., 2017). For example, OTs may use team-building exercises during interventions to provide at-risk youth opportunities to 
communicate and demonstrate teamwork. During individual or group sessions, utilizing purposeful activities that focus on communication and conflict resolution, will allow OTs to educate the benefits of working cooperatively and seeking or giving help when needed to build effective relationship skills (Simpson et al., 2018).

\section{Decision-Making}

Decision-making is the ability to analyze situations including safety, social norms, and ethical standards (Minney et al., 2019; O’Conner et al., 2017). Responsible decision-making will enable at-risk youth to consider the needs of themselves and others within various contexts, such as in school, home, and in their communities (O’Conner et al., 2017). When at-risk youth consider themselves and others, they are also considering the consequences and actions of the current situation (O’Conner et al., 2017). Responsible decision-making provides opportunities for at-risk youth to reflect on their actions and decisions for future circumstances as well.

OTs are trained to evaluate and treat on cognitive skills, such as problem-solving, critical thinking, and decision-making (Abaoğlu et al., 2017). For at-risk youth, their decision-making process may be influenced based on their perception of their social or cultural context (Gallagher et al., 2015). As a result, the choices and decisions made over time can influence the way at-risk youth engage in occupations. OTs will not only simply provide opportunities for at-risk youth to change their patterns or habits but will teach at-risk youth to recognize how occupational choices can affect an individual (Gallagher et al., 2015). During sessions, OTs can facilitate activities that require trial and error, setting goals, analyzing situations, and problem-solving (Chung \& McBride, 2015). These activities will increase the ability of at-risk youth to make responsible decisions, think rationally within their environment, and consider their well-being as well as others. 


\section{Theoretical Framework}

The theories used to frame this project are The Model of Human Occupation (MOHO) and the Social Cognitive Theory (SCT). OTs follow various theoretical constructs to help conceptualize an OT's way of thinking when providing treatment for a client,

\section{Model of Human Occupation}

MOHO is an occupation-based model created by Gary Kielhofner in 1980 and is one of the most used theories by OTs worldwide (Park et al., 2019). MOHO focuses on promoting engagement in meaningful activities and behaviors that maintain and organize healthy lifestyles and motives (Bowyer et al., 2019; Graham et al., 2016). The participation in meaningful activities and occupations help individuals transition themselves to become more adaptive and healthy beings within their environment (Bowyer, 2019).

When experiencing limitations in occupations, at-risk youth experience disorder within their volition, habituation, performance capacity and environmental contexts, affecting their overall occupational performance (Ivzori et al., 2020). Volition refers to an individual's motivation to participate in occupations (Scott et al., 2017). Habituation refers to everyday patterns and routines that an individual has developed (Scott et al., 2017). Performance capacity is the capability to perform activities and occupations based on physical and mental components of the individual (Ivzori et al., 2020; Scott et al., 2017). Environmental context refers to social, physical, or cultural features within the environment that influence an individual's behavior or occupational participation (Ivzori et al., 2020; Scott et al., 2017). In addition to these four components, $\mathrm{MOHO}$ describes how occupational adaptation, or adapting to one's identity and achieving occupational competence, can occur throughout the life span and influences the quality of life (Ivzori et al., 2020; Scott et al., 2017). At-risk youth may experience challenges in 
maintaining quality of life or life changes because of the stressors or barriers they have endured (de Matos \& Simões, 2016; Sibinga et al., 2016; Scott et al., 2017). As a result of these challenges, at-risk youth may continue to have trouble in adapting to life changes and struggle with transitioning into adulthood (Ivzori et al., 2020).

At-risk youth may be negatively influenced by their peers, participate in leisure activities that are not considered safe or healthy, be exposed to negative behaviors and actions in the environment, and/or take on roles they may not find value in (Farajzadegan, et al., 2018). MOHO has been used to support studies of at-risk youth because it focuses on motivation, habituation, and physical and social aspects of the environments that are all interconnected in influencing performance of occupations (Ivzori et al., 2020; Popova, \& Wescott, 2019). Poor occupational performance within at-risk youth leads to deficits in communication, processing, and/or motor responses that may affect both social participation and self-regulation skills (de Matos \& Simões, 2016; Park et al., 2019). The way MOHO will be used for this project will be to apply the interventions to acquire new habits and interests in an appropriate environment, as well as for atrisk youth to learn about themselves as occupational beings.

\section{Social Cognitive Theory}

The SCT, derived from the Social Learning Theory by Albert Bandura, suggests that an individual's behavior is shaped by their ability to regulate and shape their environment (Annesi James et al., 2016; Knol et al., 2016). The SCT focuses on the triadic interaction between an individual's environment, personal factors, and behavior, also known as reciprocal determinism, which influences and determines human behavior (Knol et al., 2016). Along with reciprocal determinism, several other constructs are involved in this theory which includes self-control, observational learning, reinforcements, and self-efficacy (Knol et al., 2016). At-risk youth who 
have observed or experienced maladaptive and/or violent behaviors have a higher likelihood of participating in violence than other youth who have not had such exposure (Salimi et al., 2019). According to the SCT, when at-risk youth learn by observing negative actions within their environment, it contributes to supporting the development of aggressive conduct, relational aggression, and poor social participation skills (Espelage et al., 2018; Salimi et al., 2019).

SCT posits that at-risk youth experiencing psychological factors, such as depression and anger, influence social cognition, affecting the ability to process, think, and self-regulate (Espelage et al., 2019; Salimi et al., 2019). Poor social cognition contributes to decreased motivation and self-efficacy in at-risk youth due to the inability to appropriately learn and choose strategies to overcome obstacles and difficulties that arise (Al-mehsin, 2017; Espelage et al., 2018; Salimi et al., 2019). Increased self-efficacy in at-risk youth will help maintain healthpromoting behaviors and appropriate decision-making (Al-mehsin 2017; Salimi et al., 2019). SCT is applied to the project since strategies within the project will aim to adapt at-risk youths' behaviors, their environment, and personal factors by allowing them to observe and experience positive role-modeling, engagement, and social participation and self-regulation skills (Knol et al., 2016).

\section{Conclusion}

The literature provided evidenced that at-risk youth experience barriers that include poor mental health, low SES, and lack of social support from family and peers. At-risk youth facing any of these barriers are highly associated with violence because of the lack of resources within their environment, challenging behaviors, broken families, and exposure to community violence (Farajzadegan et al., 2018; Wesely et al., 2017). They do not have the advantage of engaging in health-promoting activities because of the lack of opportunities accessible to them (Farajzadegan 
et al., 2018; Gallagher et al., 2015b). The inability to explore occupational interests hinders social participation and self-regulation skills as at-risk youth fall into social isolation, problematic behaviors, and negative affective experiences (Shea \& Jackson, 2014; Sibinga et al., 2016).

Various studies determined the effectiveness of different programs and interventions to reduce youth violence and to promote social and self-regulation skills in at-risk youth. Similarly, studies determined the effectiveness of occupational therapy in addressing social participation and psychosocial barriers in youth (Leigers \& et al., 2016; Shea \& Jackson, 2014). However, the literature examining the role of occupational therapy in social participation and self-regulation is directed towards children and adolescents with autism (Leigers \& et al., 2016). OTs are underutilized to work on prevention teams to work with at-risk youth and even more so to help prevent youth violence. The literature makes recommendations to determine appropriate occupational therapy interventions in the at-risk youth population to enhance these skills and fulfill healthy and safe occupational engagement (Bonell \& et al., 2018; Farajzadegan \& et al., 2018; Shea \& Jackson, 2014). Thus, this capstone project will create and implement an occupation-based program in a community center to improve social participation and selfregulation skills in at-risk youth to decrease youth violence. 


\section{Introduction}

\section{Chapter 3: Project Description}

The purpose of this chapter is to describe the project developed based on the review of literature. A program to further develop social participation and self-regulation skills in at-risk youth will strengthen their abilities to make safe and positive lifestyle choices manage emotions, and maintain healthy relationships, especially within the context of their environment (Whitten et al., 2017). The purpose of the project is to create and implement an occupation-based program to improve social participation and self-regulation skills for at-risk youth to decrease and prevent youth violence and maladaptive behaviors. The program will be completed at Covenant House Florida, a youth homeless shelter located in Fort Lauderdale, Florida. The project will additionally increase awareness of OT's role in mental health to work with the at-risk youth population alongside other mental health professionals. The occupation-based program will consist of group activities, such as arts and crafts, and team-building exercises, to appropriately facilitate engagement and interaction among the youth.

The capstone project will provide the opportunity to fill the gap between at-risk youth with poor self-regulation and social participation skills, and the lack of occupational therapy services provided. The program will allow at-risk youth to engage in various activities to develop their social participation and self-regulation skills and to carry on these developed skills as they continue to grow to create a positive environment for the community. The program will further build support of OTs to work with the at-risk youth population as well as inform mental health professionals of the role of occupational therapy. Although OTs have a background in mental health, at-risk youth are often sent to see other mental health professionals, such as counselors, psychologists, and social workers (Baltag et al., 2015). Currently, there is a lack of funding to employ occupational therapy practitioners and many other professionals are now aware of OT's 
role and how they may work with at-risk youth (Baltag et al., 2015; Leigers et al., 2016; Parsons \& Saffer; 2018).

The project could build evidence to support occupational therapy practitioners' effective interventions and programs to improve social participation and self-regulation skills in at-risk youth in a way similar to other populations. These interventions or programs within the communities can contribute to prevent youth violence. Factors such as lack of social support from family and friends, poor mental health, and low socioeconomic status negatively influence at-risk youths' social participation and self-regulation skills, which may lead to risky behaviors and a higher likelihood of participating in youth violence (Gestsdottir et al., 2014). Therefore, this program will create, implement, and evaluate a program for at-risk youth to face life challenges, and promote healthy, prosocial behaviors to support a positive atmosphere within their environment.

\section{Project Objectives}

\section{Learning objectives}

- Compare and contrast problems and issues at-risk youth experience that led them to participate in youth violence and/or experience maladaptive behaviors at Covenant House as compared to the literature.

- Compare and contrast the problems experienced by at-risk youth, who participate in youth violence and/or demonstrate maladaptive behaviors, with poorly developed social participation and self-regulation skills.

- Identify and describe professionals who serve at-risk youth with poor social participation and self-regulation skills who participate in youth violence and/or demonstrate maladaptive behaviors in the literature and at Covenant House. 
- Describe how OTs would fit within the organization of Covenant House to address at-risk youth with poorly developed social participation and self-regulation skills, including reimbursement and job description.

\section{Project-based objectives}

- Conduct a needs assessment at Covenant House Florida to learn the types of services provided, social participation skills currently taught, and by which disciplines by 1 month of my program development project.

- Develop an occupation-based program to improve social participation skills and selfregulation skills for at-risk youth (Appendix C)

- Implement an occupation-based program to improve social participation skills and selfregulation skills for at-risk youth by 2 months of my program development project.

- Develop and collect assessment of the program at the end of the 8-week program

- Train staff on an occupation-based program to improve social participation and selfregulation skills for at-risk youth by 4 months of the program.

- Write chapters 4 and 5 of the capstone paper.

- Create poster for dissemination using USAHS template.

\section{Participants}

Participants for this study will be recruited from Covenant House Florida in Fort Lauderdale, FL. Covenant House shelters up to 76 youth from the ages of 11 to 21 years old (Covenant House Florida, n.d.). The participants recruited for the program will be from the ages of 16 to 21 years old because most of the youth that stay at Covenant House falls within that age range. Therefore, youth from the ages of 11 to 15 years old will be excluded. The program will consist of a heterogeneous group to allow for both males and females to be included. 
Participation in the program will be voluntary as youth at Covenant House are given free choice to participate in courses and programs of their choosing.

\section{Setting and Measures}

Three forms of measures will be provided throughout the program. The General SelfEfficacy Scale (GSES) and a social skills assessment will be given to each participant as pre- and post-measures (Appendix D). The GSES is a self-report measure consisting of 10 items and takes less than 10 minutes to complete. The scale will provide the participants perspective on their ability to cope and respond to meet a variety of life challenges (Zhou, 2016). The measure is based on a 4-point scale: (1) not at all true, (2) hardly true, (3) moderately true, and (4) exactly true. The GSES will help to identify if the participant's level of self-efficacy has increased from the beginning to the end of the program. The social skills assessment, created by the author, is also a self-report measure consisting of 6 items and takes less than 5 minutes to complete. The measure will allow the participants to provide their perspective on their communication skills. The measure is based on a Likert scale from strongly disagree to strongly agree. The social skill assessment will help determine if the participants' social participation skills have improved from the beginning to the end of the program. Both the GSES and social skills assessment may help determine the effectiveness of the occupation-based program.

The third form of measure will be a 6-survey questionnaire given to the participants at the end of each session (Appendix D). The questionnaires will allow participants to provide their perspective and reflection on the session, such as identifying the benefits of the session for future challenges and whether it assisted in strengthening social and self-regulation skills. The questionnaires will also provide opinions as to how the sessions could have been better. Names 
will not be written on the questionnaires to maintain personal information about the program anonymously.

\section{Development and Implementation Process}

The development of the program will occur prior to beginning the experiential hours at Covenant House as well as well during the first two weeks at Covenant House. Research on various interventions and activities utilized to promote social participation and self-regulation skills will be done to develop the program. Collaboration with the project mentor will be helpful when creating the program as she will provide suggestions and ideas based on her knowledge of expertise in the field of OT. One or more SEL competencies will be addressed in each session to ensure that the participants are applying the appropriate knowledge and skills that correspond with activity. Age-appropriate activities will also be provided for the participants to promote developmental maturity.

During the first two weeks at Covenant House, the site supervisor will be given the program plan to examine over and provide any suggestions, if needed. Interests of the at-risk youth at Covenant House will be considered as well to integrate within the program.

Incorporating the interests of the at-risk youth would also allow the sessions to be more meaningful and engaging to the participants. Final edits will be made to the program after discussing it with the site supervisor and project mentor within the first month to finalize the program before implementing it.

Implementation of the program will occur within the first month at Covenant House. The frequency and duration of the program will be for 8 weeks, 2 times a week for 1-hour sessions. Depending on the sessions provided on certain days, it will determine the area or room utilized at Covenant house to provide adequate space to complete the activities. 


\section{Theoretical Frameworks}

The development of the program will be guided by MOHO, SCT, and SEL theories. MOHO focuses on providing interventions that will develop skills that are lacking, in which case social participation and self-regulation skills are the areas of concern for at-risk youth (Bowyer et al., 2019; Graham et al., 2016). Utilizing MOHO within sessions will encourage at-risk youth to change maladaptive behaviors, negative occupational performance, and promote healthy habits and routines. Sessions will occur in an appropriate environment for the participants to increase occupational performance and to facilitate engagement and feedback as a group.

SCT focuses on the triadic interaction between behaviors, environment, and personal factors (Espelage \& et al., 2018). SCT will guide the sessions to provide opportunities to interact with others within an appropriate environment while acknowledging the role of social cognition. Participants will be provided with education and skill-training during sessions to improve social participation and self-regulation skills. Incorporating SCT will facilitate positive interactions, rationalize behaviors and emotions, and build self-efficacy (Espelage \& et al., 2018).

The SEL process will provide the participants with opportunities to develop prosocial behaviors, cope with life challenges, and set desired goals to achieve in the future (Whatman et al., 2019). The five competencies will be integrated within the sessions of the program to promote healthy social and emotional development: self-awareness, self-management, social awareness, relationship skills, and responsible decision-making (Minney et al., 2019). Depending on the session provided on the given day, one or more SEL competencies will correspond to that specific session to enhance certain skills. For example, creating a vision board and discussing it with others in the group during a session will correspond to self-awareness and social awareness.

\section{Evaluation}


The project will be evaluated through deliverables and the measures used for the program. Deliverables are the output of the scope of the project. The deliverables for this project will be provided in the form of charts or reflection papers after meeting the learning objectives. For example, the first learning objective for this project is "Compare and contrast problems and issues at-risk youth experience that led them to participate in youth violence at Covenant House as compared to the literature". The deliverable will be provided as a chart or a 1-2-page paper identifying the similarities and differences that Covenant House sees with the at-risk youth population compared to what has been read in the literature.

The GSES, social skill assessment and the survey questionnaires will determine selfperceived improvement of social participation, self-regulation skills, and self-efficacy of the participants (Appendix D). The GSES will measure if the self-efficacy of the participants and the ability to handle life challenges have improved from the beginning to the end of the program. The social skill assessment will determine if communication skills have additionally improved from the beginning to the end of the program. The survey questionnaire will be provided at the end of every session as a reflection and to determine if the participants found the session to be beneficial towards life situations in the future. These three measures will provide sufficient information to determine the effectiveness and outcomes of the program.

\section{Timeline}

\section{Figure 1 Weekly Schedule at Covenant House Florida.}




\section{Covenant House Florida \\ January 4, 2021 - April 8, 2021}

$\begin{array}{rlll}1 & \text { Learning Objectives }\end{array}$

L1: Compare and contrast problems and issues at-risk youth experience that lead them to experienceldemonstrate maladaptive behaviors at Covenant House as compared to the literature.

L2: Compare and contrast the problems expereinced by at-risk youth, who experienceedemonstrate maladpative behaviors, with poorly develop social participation and self-regulation skills.

L3: Identify and describe the professionals who serve at-risk youth with poor social participation and self-regulation skills who experience maladaptive behaviors in the literature and at Covenant House.

L4: Describe how OTs would fit within the organization of Corenant House to address at-risk youth with poorly developed social participation and self-regulation skills, including rembursement and job description.

Project-Based Objectives

PB1: Conduct a needs assessment at a Covenant House to learn the types of services provided, social participation skills currently taught, and by which disciplines by 1 month of my program development project.

PB2: Develop an occupation-based program to improve social participation skills and self-regulation skills for at-risk youth.

PB3: Implement an occupation-based program to improve social participation skills and self-regulation skills for at-risk youth by 2 months of my program development project

PB4: Traim staff on an occupation-based proeram to improve social participation skills and self-regulation skills for at-risk youth - Develop and review with mentor and site mentor week 1 and 2 proeran

PB5: Develop and collect assessment of the prooram at the end of the 8-meek prooran

PB6: Create a poster for dissemination using USA template.

PB7: Write chapters 4 \& 5 of the capstone paper.

PB 8: Submit completed and aproved project (Chapter 1-5 plus appendices into SOAR)

\begin{tabular}{|c|c|c|c|c|c|}
\hline Weekly Schedule/Plan: Minimum 14 weeks & 2021 & $\begin{array}{l}\text { DIRECT (staff, } \\
\text { participants): } \\
448 \mathrm{hrs}\end{array}$ & $\begin{array}{c}\text { INDIRECT: } 112 \\
\text { hrs - max indirect } \\
\text { hours for all project } \\
\text { types }\end{array}$ & OBJECTIVES & ACTIVITIES (With specificity) \\
\hline \multirow[t]{8}{*}{ Week 1} & $\operatorname{Jan} 4-8$ & 25 & & 3 & $\begin{array}{l}\text { Learn about the programs and activities offerred for at-risk youth, how professionals work with the youth, and build } \\
\text { rapport with staff and youth. }\end{array}$ \\
\hline & & 1 & & & Learn some of the reasons why youth come to Covenant House \\
\hline & & 2 & & 4 & $\begin{array}{l}\text { Discuss with staff on an occupation-based program to improve social participation skills and self-regulation skills for } \\
\text { at-risk youth }\end{array}$ \\
\hline & & 4 & & $1 \& 2$ & Develop an occupation-based program to improve social participation skills and self-regulation skills for at-risk youth \\
\hline & & & 4 & & Complete orientation trainings online for Covenant House \\
\hline & & & 5 & & Continue looking for activities to implement at Covenant House and into the program \\
\hline & & & 1 & & Discuss with mentor on activities and development of program \\
\hline & & & 1 & 1 & Complete delivarable chart for learning objective 1 \\
\hline \multirow[t]{9}{*}{ Week 2} & $\operatorname{Jan} 11-15$ & 20 & & 3 & $\begin{array}{l}\text { Continue building rapport with youth, learning about their interests in activities, and programs offered at Covenant } \\
\text { House }\end{array}$ \\
\hline & & 2 & & 4 & $\begin{array}{l}\text { Discuss with staff on an occupation-based program to improve social participation skills and self-regulation skills for } \\
\text { at-risk youth }\end{array}$ \\
\hline & & 2 & & & Implement small activities within Covenant House (e.g. trivia, Wii). \\
\hline & & 6 & & $1 \& 2$ & $\begin{array}{l}\text { Continue developing and finalize an occupation-based program to improve social participation skills and self- } \\
\text { regulation skills for at-risk youth. }\end{array}$ \\
\hline & & 1 & & & Discuss with site supervisor and staff about days/times to implement 8-week program and how to gather participants \\
\hline & & 1 & & 2 & Develop and print measures, survey questionnaires, and sign-in sheets for program. \\
\hline & & & 5 & 2 & Continue looking for activities to implement at Covenant House and into the program \\
\hline & & & 1 & 2 & Discuss with mentor on finalized program to implement at Covenant House \\
\hline & & & 1 & & Complete delivarable chart for learning objective 2 \\
\hline \multirow{8}{*}{ Week3 } & $\operatorname{Jan} 18-22$ & 3 & & 2 & 3-hour staff training on child sexual eploitation provided by Covenant House \\
\hline & & 2 & & & Commence week 1 of 8 -week program, 2 days a week \\
\hline & & 2 & 2 & & Reflect on week 1 sessions with site supervisor and project mentor \\
\hline & & 20 & & & Implement small activities within Covenant House (e.g. table top games, movies) and continue engaging with youth \\
\hline & & & 3 & & Editing program activities to increase engagement for youth participation \\
\hline & & 5 & 3 & & Continue searching for activities to implement at Covenant House on non-program days \\
\hline & & & 2 & & Continue edits for chapter 3 \\
\hline & & & 1 & & Complete delivarable for learning objective 3 \\
\hline \multirow[t]{9}{*}{ Week 4} & $\operatorname{Jan} 25-29$ & 2 & & 4 & Commence week 2 of 8-week program, 2 days a week \\
\hline & & 2 & 1 & & Reflect on week 2 sessions with site supervisor and project mentor \\
\hline & & 1 & & & Attend "Independent Living" course for youth \\
\hline & & 5 & 1 & & Continue lookng for activities to implement at Covenant House \\
\hline & & 3 & & & Assist staff in organizing life skills area \\
\hline & & 19 & & & Implement activities within Covenant House (e.g. table top games) and continue engaging with youth \\
\hline & & & 4 & & Document and reflect on session outcomes \\
\hline & & & 1 & 4 & Complete deliverable for learning objective 4 \\
\hline & & & 1 & & Begin writing chapter 4 \\
\hline \multirow[t]{7}{*}{ Week 5} & Feb 1.5 & 2 & & 4 & Commence week 3 of 8-week program, 2 days a week \\
\hline & & 4 & & & Assist staff in organizing life skills area \\
\hline & & 2 & 1 & & \multirow{5}{*}{$\begin{array}{l}\text { Reflect on week } 3 \text { sessions with site supervisor and project mentor } \\
\text { Implement activities within Covenant House (e.g. table top games) and continue engaging with youth } \\
\text { Document and reflect on session outcomes } \\
\text { Complete week } 5 \text { deliverable } \\
\text { Edit chapters } 1,2 \text {, and } 4 \\
\end{array}$} \\
\hline & & 24 & & & \\
\hline & & & 2 & & \\
\hline & & & 1 & & \\
\hline & & & 3 & & \\
\hline
\end{tabular}




\begin{tabular}{|c|c|c|c|c|c|}
\hline \multirow[t]{8}{*}{ Week 6} & Feb 8-12 & 2 & & 4 & Commence week 4 of 8 -week program, 2 days a week \\
\hline & & 24 & & & Implement activites at Covenant House (e.g table top games, movies, etc.) and continune engaging with youth \\
\hline & & 2 & 1 & & Refiect on week 4 sessions with site superisor and project mentor \\
\hline & & 1 & & & Attend "Independent Living" course for youth \\
\hline & & 3 & & & Attend Covenant House meetings to improve youths' experience at he site \\
\hline & & & 2 & & Document and refect on session outcomes \\
\hline & & & 1 & & Complete deliverable 6 \\
\hline & & & 3 & & Editchapters 2 and 4 \\
\hline \multirow[t]{9}{*}{ Week7 } & Feb 15.19 & 3 & & 4 & Commence week 5 of 8 -week program, 2 days a week \\
\hline & & 2 & & & Attend "Independent Living" courses for youth \\
\hline & & 1 & & & Observe Canine Therapy at Coveranat House \\
\hline & & 2 & & & Attend staff meetings \\
\hline & & 22 & & & Implement activites at Covenanit House (e.g. table top games, movies, etc.). and continune engaging with youth \\
\hline & & 2 & 1 & & Reflect on week 5 sessions with site supervior and project mentior \\
\hline & & & 1 & & Documentiand refection session outcomes \\
\hline & & & 1 & & Complete deliverable 7 \\
\hline & & & 3 & & Editchapters $4 \& 5$ \\
\hline \multirow[t]{8}{*}{ Week 8} & Feb 222.26 & 3 & & 4 & Conmence week 6 o \& 8 -week program, 2 days a week \\
\hline & & 22 & & & Implement activites at Covenant House (e.g. table top games, movies, etc.) and continune engaging with youth \\
\hline & & 4 & & & Attend staff meetings \\
\hline & & 2 & 1 & & Reflect on week 6 session outcomes with site superisor and project mentior \\
\hline & & 1 & & & Attend "Independent Living" course for the youth \\
\hline & & & 1 & & Complete deliverable 8 \\
\hline & & & 3 & & Editchapters 2,485 \\
\hline & & 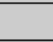 & 1 & & Meet with doctioral coordinatiors for midterm meeting on capsitone project \\
\hline \multirow{11}{*}{ Week 9} & {$[\operatorname{lar} 1.5$} & & 1 & 4 & Documentitand reflect on session outcomes \\
\hline & Mart 1.0 & 2 & & 4 & 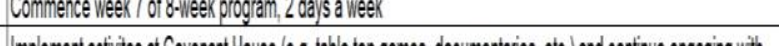 \\
\hline & & 21 & & & 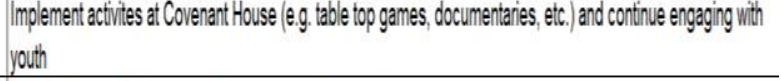 \\
\hline & & 2 & 1 & & Reflection week 7 session outcomes with site supervisor and project mentior \\
\hline & & & 1 & & Create a "Heath \& Wellness" powerponit to presennt to some youth at Coverant House \\
\hline & & 1 & & & Attend "IIndependent Living" course for the youth \\
\hline & & 1 & & & Presenta "Heath \& Wellness" powerpoint to the youth \\
\hline & & 5 & & & Attend siaff metings \\
\hline & & & 1 & & Complete deliverable 9 \\
\hline & & & 2 & & Editchapter 485 \\
\hline & & & 2 & & Document and reflection session outcomes \\
\hline \multirow[t]{10}{*}{ Week 10} & Mar 8.12 & 2 & & 4 & Commence week 8 of \& - meek program, 2 days a week \\
\hline & & 20 & & & Imolement actitites at Covenanit House (e.g, table top games, movies, etc.) and continune engaging with youth \\
\hline & & 2 & 1 & & Reflection week 8 session outcomes with site superisor and project mentior \\
\hline & & 1 & & & Observe Canine Therapy a Coveranrit House \\
\hline & & 1 & & & Attend "Independent Living" course for the youth \\
\hline & & 2 & & & "Signs and Sympotoms of litoxication" tanining course \\
\hline & & 4 & & & Attend stafif metings \\
\hline & & & 2 & & Edic chapters 485 \\
\hline & & & 1 & & Compete deliverable 10 \\
\hline & & & 2 & & Document and reflection session outcomes \\
\hline
\end{tabular}




\begin{tabular}{|c|c|c|c|c|c|}
\hline \multirow[t]{11}{*}{ Week 11} & Mar $15-19$ & 23 & & & Implement activites at Covenant House (e.g. table top games, movies, etc.) and continune engaging with youth \\
\hline & & 2 & & & Attend "Independent Living" cousses for the youth \\
\hline & & 1 & & & Meet with superisor for weekly meeting \\
\hline & & 2 & & & Provide youth with voluniteer opportunities at Covenant House for community service hours \\
\hline & & 4 & & & Attend staff meetings \\
\hline & & & 2 & & Edit chapters 485 \\
\hline & & & 1 & & Speak with project mentor for weekly meeting \\
\hline & & & 1 & & Speak to OT at Covenant House Toronito via phone \\
\hline & & & 1 & & Meet with doctoral coordinatoros to discuss capstone project \\
\hline & & & 2 & 4 & Create powerpoint presentation for staff at Covenant House on OT and occupation-based program \\
\hline & & & 1 & & Complete deliverable 11 \\
\hline \multirow[t]{10}{*}{ Week 12} & Mar 22.26 & 22 & & & Implement activites at Covenant House (e.g. table top games, movies, etc.) and continune engaging with youth \\
\hline & & 1 & & & Meet with suprisor for weekly meeting \\
\hline & & 3 & & & Attend "Independent Living" courses for youth \\
\hline & & & 1 & & Meet with project mentor for weekly meeting \\
\hline & & 2 & & & Provide youth with volunteer opportunities at Covenant House for community service hours \\
\hline & & 4 & & & Attend staff meetings \\
\hline & & & 1 & & Research jounnals to publish capstone project \\
\hline & & & 1 & & Complete deliverable 12 \\
\hline & & & 2 & & Meet with writing center to fix APA references on capstone paper \\
\hline & & & 2 & & Wite chapters 4 and 5 of capstone project \\
\hline \multirow[t]{12}{*}{ Week 13} & Mar 29-Apr 2 & 21 & & & Imolement activities at Covenant House (e.g. table top games, movies, etc.) and continune engaging with youth \\
\hline & & 1 & & & Meet with supervisor for weekly meeting \\
\hline & & 2 & & & Attend "Independent Living" courses for youth \\
\hline & & 5 & & & Attend staff meetings \\
\hline & & 3 & & & Provide youth with volunteer opportunities at Covenant House for community service hours \\
\hline & & & 1 & & Edit chapter 5 \\
\hline & & & 1 & & Meet with project mentor for weekly meeting \\
\hline & & & 1 & & Complete Powerpoint presentation for staff at Covenant House \\
\hline & & & 1 & & Meet with doctoral coordinators for edits on capstone \\
\hline & & & 2 & & Meet with writing center twice to edit capstone paper \\
\hline & & & 3 & & $\begin{array}{l}\text { Watched webinar recordings on "Bullying Prevention and Suicide Prevention for Schools" \& "Champions for } \\
\text { Change" }\end{array}$ \\
\hline & & & 1 & & Complete deliverable 13 \\
\hline \multirow[t]{14}{*}{ Week 14} & Apr 5-9 & 1 & & $3 \& 4$ & Present PowerPoint to staff on outcomes of the occupation-based program and the role of $0 T$ \\
\hline & & 1 & & & Attend Cor Rangers meeting \\
\hline & & 22 & & & Implement activites at Covenant House (e.g. table top games, movies, etc.) and continune engaging with youth \\
\hline & & 3 & & & Provide youth with volunteer opportunities at Covenant House for community sevice hours \\
\hline & & 4 & & & Attend dally staff meetings \\
\hline & & 1 & & & Meet with supervisor for weekly meeting \\
\hline & & & 2 & & Search journals and submit capstone paper for publication \\
\hline & & & 1 & & Submit capstone paper into SOAR \\
\hline & & & 1 & & Meet with project mentor for weekly meeting \\
\hline & & & 1 & & Attend free webinar recording \\
\hline & & & 1 & & Complete deliverable 14 \\
\hline & & & 1 & & Meet with doctoral coordinatiors and peers to discuss USA poster symposium \\
\hline & & & 3 & & Create and submit poster for USA poster symposium \\
\hline & TOTAL HOURS & 448 & & & \\
\hline
\end{tabular}

\section{Data Analysis}

When information from the GSES, social skills assessment, and survey questionnaires are collected, data will be analyzed to determine any significant outcomes and effectiveness of the program. The GSES will determine if self-perceived, self-efficacy of the other participants have 
increased or remained the same from the beginning to the end of the program. The social skills assessment will provide the participants with a perspective on their communication skills. The survey questionnaire will provide insight into the participants from each session. When the program measures have been collected and analyzed, the data will be presented in tables to provide an overall analysis of the program outcomes.

Tables for the GSES and social skills assessment will be provided in separate tables as pre-measures and post-measures. The item descriptions for both measures will be provided in their corresponding tables with the responses from the participants. A table for the survey questionnaires responses for every session will be provided under each session description. The tables will provide the item descriptions of the survey questionnaires from numbers 1-4 along with the responses from the participants from the sessions.

\section{Presentation of Findings}

When the program is completed and evaluations are analyzed, descriptions of the sessions and outcomes of the program will be presented to the staff at the Covenant House Florida. The presentation will also emphasize the role of occupational therapy and how OTs can assist the at-risk youth population at Covenant House, especially to improve their social participation and self-regulation skills. Additionally, the findings and outcomes of the program will be presented as a poster to current and future OTs at the University of St. Augustine for Health Sciences. The formal presentation will also include the population at Covenant House Florida and the current staff who work with the youth. When the capstone project is completed, it will be published in a journal to provide evidence and outcomes on the occupation-based program with at-risk youth.

\section{Conclusion}


The occupation-based program will be developed and implemented at Covenant House Florida to improve social participation and self-regulation skills in at-risk youth. The project itself will demonstrate awareness of OT's role in mental health and their ability to help the atrisk youth population, along with other disciplines, such as counselors, educators, and social workers. The development of the sessions within the program will be based on activities used in research, interests of at-risk youth at Covenant House, and suggestions provided by both the project mentor and site supervisor. The program will be guided by the theoretical frameworks, MOHO and SCT. Activities will correspond with at least one SEL competency to ensure necessary skills are being addressed including managing emotions, emphasizing with others, and maintaining positive relationships (Minney et al., 2019).

When the program is completed and data is analyzed, the staff at Covenant House will be provided a presentation to discuss the profession of occupational therapy and the outcomes of the program. If the program proves to have been effective, it is hoped that the staff at Covenant House will sustain the program to continue with the youth and for future purposes, consider the idea of having occupational therapy at Covenant House. The outcomes of the occupation-based program will additionally be presented to occupational therapy students and faculty and the University of St. Augustine for Health Sciences. The capstone project will provide evidence on OT's role working with at-risk youth and how OTs can help improve social participation and self-regulation skills with an occupation-based program. The author hopes current or future occupational therapy students who are interested in the population and would like to work with at-risk youth may utilize the occupation-based program created for this capstone project. These current or future occupational therapy students who use the program can make it more effective 
after looking at the outcomes and strengths and weaknesses from the program within this capstone project. 


\section{Chapter 4: Results and Analysis}

\section{Introduction}

The purpose of this chapter is to provide the details and outcomes of the occupationbased program to improve social participation and self-regulation skills in at-risk youth at Covenant House Florida. The problem is at-risk youth participate in youth violence due to poorly developed social participation and self-regulation skills (Cid, 2016; Forrest-Bank et al, 2016; Shea \& Jackson, 2014). The lack of these skills results in difficulty maintaining healthy relationships, managing their emotions in adverse situations, and making positive lifestyle choices within the context of their environment (Leigers et al., 2016; Mcdaniel et al., 2016). A secondary problem is that occupational therapy practitioners used to fit in the role as mental health professionals but now they do not (Baltag et al., 2015; Cahill \& Egan, 2017b). Underdeveloped social participation and self-regulation skills can lead to poor mental health, including risky behaviors and psychological problems (Baltag et al., 2015; Leigers et al., 2016). OTs have the knowledge and training to work with at-risk youth to target social participation and self-regulation skills and to help improve their mental health; however, OTs are underutilized to work with at-risk youth (Leigers et al., 2016; Parsons \& Safer, 2018).

The purpose of the project was to implement an occupation-based program to improve social participation and self-regulation skills in at-risk youth to prevent youth violence. A needs assessment was conducted at Covenant House to learn about the program and activities offered to the youth as well as additional activities that youth would be interested in that are currently not offered. The program was created and implemented for an 8-week duration, twice a week. When the program was completed and assessments were collected and analyzed, the staff at Covenant House were educated on the purpose and outcomes of the program and the role of 
occupational therapy working with the at-risk youth population. The results and analysis of the occupation-based program at Covenant House detail the data collection and key outcomes of the project.

\section{Outcomes Data Collection}

\section{Time Frame and Data Collection}

The period of the capstone experience provided enough time to run the occupation-based program within the 14 weeks. From the dates of January $4^{\text {th }}, 2021$, to April $8^{\text {th }}, 2021,448$ experiential hours were to be completed at Covenant House Florida. The program itself was for 8 weeks, twice a week for one-hour sessions. The dates of the program were from January $18^{\text {th }}$ to March $11^{\text {th }}, 2021$. For the first 4 weeks, sessions were held on Mondays and Wednesdays from 2 p.m. to 3 p.m. However, close to the second half of the program, sessions were held on Tuesdays and Thursdays from 7 p.m. - 8 p.m. to provide greater chances of increased participants.

Several forms of data collection techniques were provided to the participants throughout the program. In the first week of the program two pre-measures, the GSES and the social skills assessment were given at the beginning of each session. Providing the pre-measures during the second session was to potentially provide greater measure when determining the outcomes and effectiveness of the program due to the program being an open group versus a closed group. At the end of every session, each participant was given the survey questionnaire to anonymously complete. Participants would provide their insight on the session on a 4-point Likert scale as well as describe what they liked about the session and suggestions to improve the session. The survey questionnaires were the primary source of measure to determine the effectiveness of the sessions and the overall program.

\section{Participants and Recruitment}


Participants in the program were a mix of both boys and girls. Youth who participated in the program ranged from 15-21 years old. The youth were given the option to freely choose whether they wanted to attend the entire program because participation was voluntary. In Covenant House, some of the youth go to work and/or school, attend other programs required in Covenant House, choose to walk off-site during their break, and/or may become discharged, providing limited opportunities for some of the youth to attend the occupation-based program. To recruit participants, a weekly schedule of events was placed around the site, such as in the case manager's offices, prior to the beginning of each week for the youth to view. Some of the case managers inserted the program days on the youth's weekly action plans as an optional session to attend. On the day of the sessions, youth were also notified during lunch or dinner hours of the time, location, and activity for the session.

\section{Discrepancies Between Planned and Final Project}

When conducting the needs assessment during the two weeks prior to the start of the program, the staff at Covenant House would provide ideas and activities to potentially use within the program. Youth were casually asked about activities they are interested in or would like to see more of. However, minimal suggestions on activities were provided from the youth, secondary to the stage of adolescence that youth are in and preferring to do an activity outside the building with peers. The initial plan was to implement the program during the fourth week of experiential hours, but the program was implemented during the third week instead. Rapport with the youth was much greater than the first week, allowing comfortability to implement the program sooner. During the first four weeks of the experiential hours, several activities within the program were removed and/or altered. Although the program was to be finalized before implementation, adjusting the program during the first two weeks of the implementation phase 
occurred. It was realized that some of the activities within the sessions may not entirely engage the youth's attention as hoped, therefore, a few activities were changed for the sessions to be more diverting and to increase youth participation.

\section{Population Sample}

The individuals who participated in the program shared several similarities and differences within the at-risk youth population mentioned in the literature review. Several participants in the program shared characteristics such as poor mental health, lack of social participation, and/or self-regulation skills. The participants demonstrating poor mental health and lack of social and self-regulation skills, are either diagnosed with one or multiple mental health diagnoses, come from a low SES background, and/or have experienced traumatic events within their lives, such as disruptions within their families, substance abuse, and/or living in unstable environments. In contrast, several other of the participants demonstrated appropriate social participation and/or self-regulation skills, and prosocial behaviors. Participants that demonstrated appropriate skills and behaviors were more common to have had a better upbringing, healthier mindset, increased motivation to participate in activities, and/or the ability to cope with their mental health diagnosis more well than others.

\section{Organization or Personal Conditions}

The impact of Corona Virus Disease 2019 (COVID-19) required guidelines to be followed at Covenant House. Minor adaptations within the activities for the program had to be made to follow COVID restrictions such as no physical contact with participants and wearing face masks. For example, in the field day activity, a three-legged race was unable to occur due to physical contact with participants. Another restriction due to COVID-19 that may have influenced participation during the program was the curfew hours for the youth. Youth at 
Covenant House was given break times and allowed outside the facility in the mornings from 10 a.m. to 12 p.m. and afternoons from 2 p.m. to 5 p.m., which was concurrent with the time of the program. Previously before COVID-19, youth were given a longer period of break times.

However, due to current time restrictions, youth may have preferred to leave the site during the break times than to participate in the program.

\section{Project Objectives.}

\section{Learning Objectives.}

\begin{tabular}{|c|c|}
\hline Learning Objectives & Outcomes and Deliverables \\
\hline $\begin{array}{l}\text { - Compare and contrast problems and } \\
\text { issues at-risk youth experience that led } \\
\text { them to participate in youth violence } \\
\text { and/or experience maladaptive } \\
\text { behaviors at Covenant House as } \\
\text { compared to the literature. }\end{array}$ & $\begin{array}{l}\text { Objective met - discussed and listed with staff } \\
\text { members about the distinct reasons' youth at } \\
\text { Covenant House experience maladaptive } \\
\text { behaviors. The list was then compared to the } \\
\text { information that was read from the literature } \\
\text { and a 2-page summary paper was written } \\
\text { (Appendix E). }\end{array}$ \\
\hline $\begin{array}{l}\text { - Compare and contrast the problems } \\
\text { experienced by at-risk youth, who } \\
\text { participate in youth violence and/or } \\
\text { demonstrate maladaptive behaviors, } \\
\text { with poorly developed social } \\
\text { participation and self-regulation skills. }\end{array}$ & $\begin{array}{l}\text { Objective met-discussed and listed with staff } \\
\text { members about distinct reasons' youth at } \\
\text { Covenant House demonstrate maladaptive } \\
\text { behaviors with poor social participation and } \\
\text { self-regulation skills. The list was then } \\
\text { compared to the information that was read } \\
\text { from the literature and submitted as a 2-page } \\
\text { summary paper (Appendix F). }\end{array}$ \\
\hline $\begin{array}{l}\text { - Identify and describe professionals } \\
\text { who serve at-risk youth with poor } \\
\text { social participation and self-regulation } \\
\text { skills who participate in youth violence } \\
\text { and/or demonstrate maladaptive }\end{array}$ & $\begin{array}{l}\text { Objective met - professionals were asked their } \\
\text { roles within Covenant House and how they } \\
\text { assist at-risk youth. Staff at Covent House } \\
\text { consist of: Ombud persons, therapists, case } \\
\text { managers within different departments, nurses, }\end{array}$ \\
\hline
\end{tabular}




\begin{tabular}{|l|l|l|}
\hline $\begin{array}{l}\text { behaviors in the literature and at } \\
\text { Covenant House. }\end{array}$ & $\begin{array}{l}\text { and educators. A 2-page summary paper was } \\
\text { submitted as a deliverable discussing the staff } \\
\text { working at Covenant House (Appendix G). }\end{array}$ \\
\hline $\begin{array}{l}\text { Describe how OTs would fit within the } \\
\text { organization of Covenant House to } \\
\text { address at-risk youth with poorly } \\
\text { developed social participation and self- } \\
\text { objective met - staff at Covenant House were } \\
\text { briefly explained the role of occupational } \\
\text { therapy to address at-risk youth with poorly } \\
\text { reimbursement and job description. }\end{array}$ & $\begin{array}{l}\text { developed social participation and self- } \\
\text { regulation skills. However, role of } \\
\text { occupational therapy or how occupational } \\
\text { therapy would fit into Covenant House was } \\
\text { further explained in Project-based objective 4. } \\
\text { A 2-page summary paper was submitted as a } \\
\text { deliverable (Appendix H). }\end{array}$ \\
\hline
\end{tabular}

Project-based Objectives.

\begin{tabular}{|l|l|}
\hline \multicolumn{1}{|c|}{ Project-based Objectives } & \multicolumn{1}{|c|}{ Outcomes } \\
\hline $\begin{array}{l}\text { Conduct a needs assessment at } \\
\text { Covenant House Florida to learn the } \\
\text { types of services provided, social } \\
\text { participation skills currently taught, } \\
\text { and by which disciplines by 1 month } \\
\text { of my program development project. }\end{array}$ & $\begin{array}{l}\text { Objective met - Learned about and attended } \\
\text { several of the courses taught to the youth, } \\
\text { such as Independent Living courses. Spoke to } \\
\text { different staff at Covenant House and }\end{array}$ \\
$\begin{array}{l}\text { Develop an occupation-based } \\
\text { program to improve social } \\
\text { participation skills and self-regulation } \\
\text { skills for at-risk youth (Appendix C). }\end{array}$ & weeks, twice a week (Appendix C for \\
\hline $\begin{array}{l}\text { Implement an occupation-based } \\
\text { program to improve social } \\
\text { participation skills and self-regulation }\end{array}$ & Objective met - occupation-based program \\
\hline
\end{tabular}




\begin{tabular}{|l|l|}
\hline $\begin{array}{l}\text { skills for at-risk youth by } 2 \text { months of } \\
\text { my program development project. }\end{array}$ & $\begin{array}{l}\text { experiential hours from the dates of January } \\
18,2021, \text { to March 10, 2021 (Appendix C). }\end{array}$ \\
\hline $\begin{array}{l}\text { Develop and collect assessments of } \\
\text { the program at the end of the 8-week } \\
\text { program }\end{array}$ & $\begin{array}{l}\text { Objective met- GSES and social skills } \\
\text { assessments were collected at the start, } \\
\text { midway, and end of the program. }\end{array}$ \\
\hline $\begin{array}{l}\text { Train staff on an occupation-based } \\
\text { program to improve social } \\
\text { participation and self-regulation skills } \\
\text { for at-risk youth by } 4 \text { months of the } \\
\text { program. }\end{array}$ & $\begin{array}{l}\text { Objective met - Staff at Covenant House } \\
\text { plorida was provided with a PowerPoint } \\
\text { occupation-based program and the role of } \\
\text { occupational therapy in working with at-risk } \\
\text { youth. }\end{array}$ \\
\hline
\end{tabular}

\section{Project Outcomes}

The project outlined in chapter 1 has been carried out successfully with minimal limitations and challenges throughout the experiential hours at Covenant House. The program was developed with the suggestions and interests provided by the staff and youth as well as taking into consideration the activities that would engage and motivate youth to participate. Various youth would participate in the sessions because the program was an open group allowing anyone to join. After the end of every session, the youth would engage in an open conversation and answer questions to discuss and understand in-depth the purpose of the session provided.

When all questions were answered, the youth would anonymously fill out the survey questionnaire to provide their insight and opinions of the session. The program ran for 8 weeks, twice a week for a total of 16 sessions.

\section{Session 1}


Three participants joined the instructional painting activity that was provided for session 1 (Appendix $\mathrm{C}$ for the module). Prior to beginning the activity, the purpose of the program and the role of occupational therapy were explained to the participants. Participants were given two pre-measures, the GSES and the social skills survey, to fill out before starting the activity. Participants were additionally notified of the survey questionnaires that will be provided at the end of the session to receive their input on the session.

Before participants began painting, everyone engaged in an ice breaker to introduce and relax everyone in the group. After the icebreaker, a video on an instructional painting of a sunset and mountains was played. Participants followed the video during the activity. During the activity, participants would give words of encouragement and make positive comments on each other's paintings. Once the paintings were completed, participants answered the discussion questions.

A challenge faced during the discussion was encouraging the participants to answer the questions. Most of the time, some participants would not fully respond despite being directly asked their opinion. However, one participant would consistently engage in the discussion. When the discussion finished, participants completed the survey questionnaires. Responses from numbers 1 to 4 on the survey questionnaires are provided in Table 1. Participants provide positive feedback towards the session with no further suggestions. One of the participants stated she liked "the art and how calm it made me."

Table 1.

\begin{tabular}{|c|c|}
\hline 1. The session was engaging and meaningful. & $\begin{array}{l}\text { Strongly agree: } 1 \\
\text { Agree: } 2\end{array}$ \\
\hline $\begin{array}{l}\text { 2. What I learned in this session is/will be valuable for my } \\
\text { future. }\end{array}$ & Agree: 3 \\
\hline $\begin{array}{l}\text { 3. The session helped me further develop my social } \\
\text { interaction skills (ex: conversating appropriately, }\end{array}$ & $\begin{array}{l}\text { Strongly agree: } 2 \\
\text { Agree: } 1\end{array}$ \\
\hline
\end{tabular}




\begin{tabular}{|l|l|}
\hline $\begin{array}{l}\text { listening to others, being respectful when speaking to } \\
\text { others, etc.) }\end{array}$ & \\
\hline $\begin{array}{l}\text { 4. } \\
\text { The session helped me further develop my self- } \\
\text { regulation skills (ex: coping, regulating emotions, } \\
\text { managing behaviors, etc.). }\end{array}$ & $\begin{array}{l}\text { Strongly agree: } 2 \\
\text { Agree: } 1\end{array}$ \\
\hline
\end{tabular}

A delimitation is that participants will continue benefiting from improving their social participation and self-regulation skills with the painting activity. The activity allowed them to feel different emotions when following the instructions on the video, such as stress, calm, or relaxation. Participants were able to understand how painting or art can be a means of communication for others and how it can be an emotional release. An assumption made is that participants were truthful on the survey measures and survey questionnaires. A limitation faced was facilitating active engagement during the discussion. Participants could have been more timid than others to speak.

\section{Session 2}

Six participants attended the field day activity for session 2 (Appendix C for module). Participants explained the purpose of the program and the role of occupational therapy. Participants who did not attend session 1 were given the pre-measures to complete prior to starting the activity and were informed of the survey questionnaire that would be given at the end of the session. When the pre-measures were completed, participants were put into pairs of two.

Participants were given instructions of each task within the field day activity and notified of small prizes available at the end. Participants were encouraged to communicate with one another to work better and succeed in completing the tasks. When participants score points, the number of points would be written on a board. When all tasks were completed, scores for each pair were totaled. First place winners were able to choose their prizes first, then second place 
winners places, and lastly third place winners. After the activity, participants engaged in discussion questions.

A challenge faced during the discussion was encouraging several of the participants to provide their opinions or answers. Usually, the same participants would be the ones to actively engage in answering the questions. No other challenges were experienced during the activity itself. Responses from statements 1 to 4 on survey questionnaires are listed in Table 2. A participant wrote on the survey questionnaire that he liked the "emotional support" throughout the session. For a suggestion to improve the session, another participant wrote to provide "more age-appropriate activities".

Table 2.

\begin{tabular}{|c|c|}
\hline 1. The session was engaging and meaningful. & $\begin{array}{l}\text { Strongly agree: } 4 \\
\text { Agree: } 2\end{array}$ \\
\hline $\begin{array}{l}\text { 2. What I learned in this session is/will be valuable for my } \\
\text { future. }\end{array}$ & $\begin{array}{l}\text { Strongly agree } 5 \\
\text { Agree: } 1\end{array}$ \\
\hline $\begin{array}{l}\text { 3. The session helped me further develop my social } \\
\text { interaction skills (ex: conversating appropriately, } \\
\text { listening to others, being respectful when speaking to } \\
\text { others, etc.) }\end{array}$ & $\begin{array}{l}\text { Strongly agree: } 4 \\
\text { Disagree } 2\end{array}$ \\
\hline $\begin{array}{l}\text { 4. The session helped me further develop my self- } \\
\text { regulation skills (ex: coping, regulating emotions, } \\
\text { managing behaviors, etc.). }\end{array}$ & $\begin{array}{l}\text { Strongly agree: } 3 \\
\text { Agree: } 1 \\
\text { Disagree: } 2\end{array}$ \\
\hline
\end{tabular}

Several limitations occurred during the session: considering the safety of the participants and the environment, utilizing limited space for the field day activity, and following COVID precautions. Tasks provided on the field day were not extremely aggressive or competitive for safety precautions and to prevent any injuries. The space for the activity was completed indoors versus outdoors, to prevent bumping or hitting cars in the driveway or driving by. Participants 
were always required to maintain their masks during the activity and were unable to touch or hold one another during the tasks to follow COVID precautions.

An assumption made was that all participants were honest in their survey questionnaires when providing their opinions. Another assumption is that the participants would continue benefiting from further improving their social participation and self-regulation skills. A delimitation was that participants were able to understand the pros and cons of being competitive and how to communicate with one another when working in teams. In addition, the session allowed participants to understand how to calm their emotions when they are running high and how to apply the concepts grasped in the session for future situations.

\section{Pre-measures from Sessions 1 and 2}

Participants were given the GSES, and social skills assessments as premeasures during the first week of the program (Appendix D). A total of 7 participants completed these assessments from sessions 1 and 2. In the first session of the occupation-based program, 3 participants completed the measures since only 3 participants joined the session. In the second session, 6 participants joined, in which 2 of the 3 participants from the first session participated. However, because the 2 participants from the first session attended session 2 , the remaining 4 participants were given the pre-measures to complete. Responses from both the GSES and social skills assessments are provided in tables 3 and 4, respectively. Participants were told to only write their initials on the measures. The initials on the GSES and social skills assessment would allow the author to indicate if participants have increased their self-efficacy and improved their social participation and self-regulation skills because of the occupation-based program when given the measures again later in future sessions. 
Most of the participants responded with 3's and 4's on their GSES, indicating they perceived the item description to be moderately true or exactly true to them. In the social skills assessments, most of the participants agreed with the item descriptions. It is assumed participants were honest in their measures and perceived themselves as they believe. However, it is unsure if participants were responding truthfully or rushing through the assessments without carefully reading each of the items.

Table 3

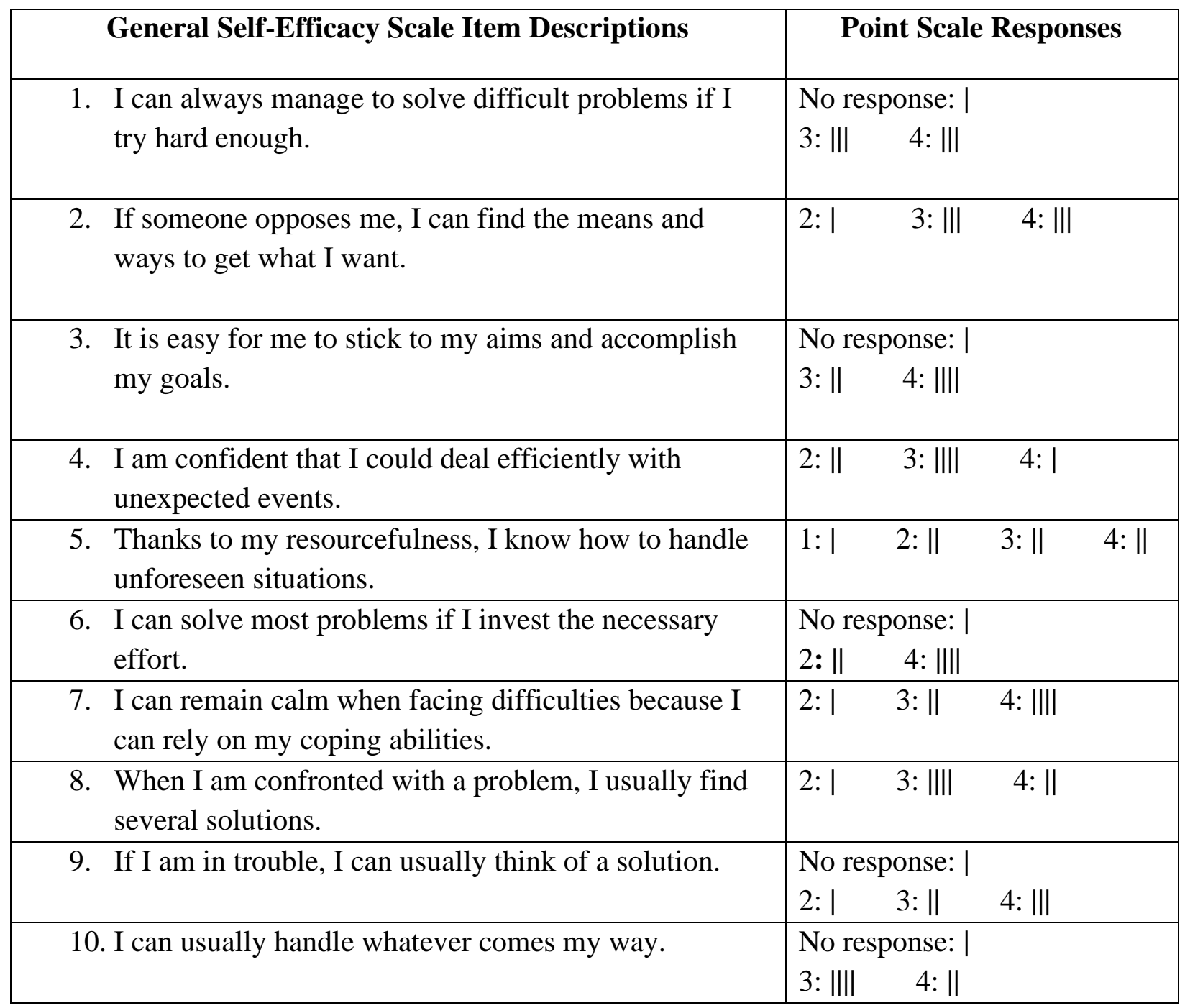

Table 4 


\begin{tabular}{|c|c|}
\hline Social Skills Assessment Items & Responses \\
\hline $\begin{array}{l}\text { 1. I maintain eye contact and pay } \\
\text { attention while engaged in } \\
\text { conversation with others. }\end{array}$ & $\begin{array}{l}\text { Strongly agree: } 2 \\
\text { Agree: } 4 \\
\text { Strongly disagree: } 1\end{array}$ \\
\hline $\begin{array}{l}\text { 2. I support and compliment others on } \\
\text { their accomplishments. }\end{array}$ & $\begin{array}{l}\text { Strongly agree: } 4 \\
\text { Agree: } 1 \\
\text { Disagree: } 1 \\
\text { Strongly disagree: } 1\end{array}$ \\
\hline $\begin{array}{l}\text { 3. I am able to clearly describe my } \\
\text { feelings. }\end{array}$ & $\begin{array}{l}\text { Strongly agree: } 1 \\
\text { Agree: } 5 \\
\text { Strongly disagree: } 1\end{array}$ \\
\hline $\begin{array}{l}\text { 4. I carefully listen to and acknowledge } \\
\text { other people's points of view. }\end{array}$ & $\begin{array}{l}\text { Strongly agree: } 1 \\
\text { Agree: } 5 \\
\text { Disagree: } 1\end{array}$ \\
\hline $\begin{array}{l}\text { 5. I share, taken turns, and/or } \\
\text { demonstrate fairness when it comes to } \\
\text { situations that require cooperation. }\end{array}$ & $\begin{array}{l}\text { Strongly agree: } 2 \\
\text { Agree: } 5\end{array}$ \\
\hline $\begin{array}{l}\text { 6. I maintain appropriate social } \\
\text { boundaries and respect the personal } \\
\text { space of others. }\end{array}$ & $\begin{array}{l}\text { Strongly agree: } 2 \\
\text { Agree: } 3 \\
\text { Disagree: } 1 \\
\text { Strongly disagree: } 1\end{array}$ \\
\hline
\end{tabular}

\section{Session 3}

The social bingo activity was utilized in session 3 (Appendix C). 4 participants attended the session. They were informed of the program and of the survey questionnaire that was to be filled out after the end of the session. Participants were explained the rules of the game, which included reading and answering aloud or performing an action if they obtained a marked space on the bingo board and requiring a straight or diagonal row to win the game. Participants were also notified of small prizes if someone had won the game.

Throughout the activity, participants were actively engaging with one another. The game was played three times because of the limited amount of bingo boards created. When the activity was over, participants shared the benefits of the activity, such as the positive interaction with 
others and finding common interests. Some participants further explained how they can use those interactions and interests found in others in future interactions. Participant responses from the survey questionnaires from numbers 1 through 4 are provided in table 5. One participant wrote on the questionnaire that they enjoyed the "social interaction." For future suggestions to improve the session one participant wrote "use an app on the phone, instead of thinking of the number to call". No further suggestions were provided.

A limitation from the activity was the minimal amount of bingo boards created, which caused some repetitiveness when starting the game over. An assumption made is that participants were honest in their survey questionnaires when providing their opinions on the session. A delimitation is that participants will continue benefiting from the occupation-based program to improve social participation and self-regulation skills.

Table 5.

\begin{tabular}{|l|l|}
\hline 1. The session was engaging and meaningful. & $\begin{array}{l}\text { Strongly agree: } 1 \\
\text { Agree: } 3\end{array}$ \\
\hline $\begin{array}{l}\text { 2. What I learned in this session is/will be valuable for my } \\
\text { future. }\end{array}$ & $\begin{array}{l}\text { Agree: } 2 \\
\text { Disagree: } 2\end{array}$ \\
\hline 3. The session helped me further develop my social \\
$\begin{array}{l}\text { interaction skills (ex: conversating appropriately, } \\
\text { listening to others, being respectful when speaking to } \\
\text { others, etc.) }\end{array}$ & Agree: 4 \\
\hline $\begin{array}{l}\text { 4he session helped me further develop my self- } \\
\text { regulation skills (ex: coping, regulating emotions, } \\
\text { managing behaviors, etc.). }\end{array}$ & $\begin{array}{l}\text { Agree: } 3 \\
\text { Disagree: } 1\end{array}$ \\
\hline
\end{tabular}

\section{Session 4}

Session 4 involved the vision board activity (Appendix C). 2 participants joined the session. Participants were informed of the activity which included placing their goals and values on their boards and being as creative as they wanted to while utilizing pictures and words from 
magazines, printouts, and scrapbook supplies. Participants were also informed of the survey questionnaire to be completed at the end of the session.

Participants were engaging with one another throughout the session while completing the activity. At times, participants would help one another find a certain picture or word that they were looking for to place on their boards. When participants completed their boards, they shared them with one another and discussed some of their goals as well as pictures and words they used and why. Participants continued to engage in the discussion and explained the benefits of setting goals for their future and how it felt learning about the goals of others. When the discussion was over, participants anonymously completed the survey questionnaire. Responses from numbers 1 through 4 are provided in Table 6 . Positive feedback was provided from the session and no further suggestions were made.

An assumption made was that participants were honest in their survey questionnaires. A limitation that occurred was the minimal number of participants that joined the session. A delimitation is that participants will continue benefiting from the occupation-based program to improve social participation and self-regulation skills.

Table 6.

\begin{tabular}{|c|c|}
\hline 1. The session was engaging and meaningful. & Agree: 2 \\
\hline $\begin{array}{l}\text { 2. What I learned in this session is/will be valuable for my } \\
\text { future. }\end{array}$ & Agree: 2 \\
\hline $\begin{array}{l}\text { 3. The session helped me further develop my social } \\
\text { interaction skills (ex: conversating appropriately, listening } \\
\text { to others, being respectful when speaking to others, etc.) }\end{array}$ & Agree: 2 \\
\hline $\begin{array}{l}\text { 4. The session helped me further develop my self-regulation } \\
\text { skills (ex: coping, regulating emotions, managing } \\
\text { behaviors, etc.). }\end{array}$ & Agree: 2 \\
\hline
\end{tabular}

\section{Session 5}


Session 5 was the movie synopsis of Disney's and Pixar's Soul (Appendix C). 4 participants participated in the session to watch the movie and engage in the open discussion when it was done. Participants provided their reactions and their interpretations of the movie and the meaning of life. Participants discussed the emotions of the characters and how they caused conflict or agreements within the movie. After the discussion, participants completed the survey questionnaires. Responses from participants on numbers 1 through 4 of the surveys are provided in Table 7. Positive responses from the session were provided from the participants such as the movie providing a new outlook on life. One participant stated, "it helped me think about a greater purpose in life". Another participant stated, "it provided perspective of the human psychology and soul." No further suggestions were made for the session.

An assumption made during the session was the participants were truthful in the survey questionnaires. A delimitation is that participants will continue benefiting from the occupationbased program to improve social participation and self-regulation skills. No limitations occurred during the session.

Table 7

\begin{tabular}{|l|l|}
\hline 1. The session was engaging and meaningful. & $\begin{array}{l}\text { Strongly agree: } 3 \\
\text { Agree: } 1\end{array}$ \\
\hline $\begin{array}{l}\text { 2. } \\
\text { What I learned in this session is/will be valuable for my } \\
\text { future. }\end{array}$ & $\begin{array}{l}\text { Strongly agree: } 3 \\
\text { Agree: } 1\end{array}$ \\
\hline $\begin{array}{l}\text { 3. } \\
\text { The session helped me further develop my social } \\
\text { interaction skills (ex: conversating appropriately, } \\
\text { listening to others, being respectful when speaking to } \\
\text { others, etc.) }\end{array}$ & $\begin{array}{l}\text { Strongly agree: } 2 \\
\text { Agree: } 1 \\
\text { Disagree: } 1\end{array}$ \\
\hline $\begin{array}{l}\text { The session helped me further develop my self- } \\
\text { regulation skills (ex: coping, regulating emotions, } \\
\text { managing behaviors, etc.). }\end{array}$ & $\begin{array}{l}\text { Strongly agree: } 2 \\
\text { Agree: } 1 \\
\text { Disagree: } 1\end{array}$ \\
\hline
\end{tabular}

\section{Session 6}


Session 6 involved the survival simulation game (Appendix C). 2 participants joined in for the session. Participants were explained the activity and informed of the survey questionnaires at the end of the session. When the activity was over, participants engaged in the open discussion of thinking rationally in situations and collaborating and listening to others. Responses from the survey questionnaires from numbers 1 to 5 are provided in Table 8 . Positive comments were provided about the session and not further suggestions were made.

An assumption made is that participants were honest in their survey questionnaires. A limitation was the minimal number of participants that joined the session. A delimitation is that the participants would continue benefiting from the occupation-based program to improve social participation and self-regulation skills.

Table 8

\begin{tabular}{|l|l|}
\hline 1. The session was engaging and meaningful. & $\begin{array}{l}\text { Strongly agree: } 1 \\
\text { Agree: } 1\end{array}$ \\
\hline $\begin{array}{l}\text { 2. } \\
\text { What I learned in this session is/will be valuable for my } \\
\text { future. }\end{array}$ & $\begin{array}{l}\text { Strongly agree: } 1 \\
\text { Agree: } 1\end{array}$ \\
\hline 3. $\begin{array}{l}\text { The session helped me further develop my social } \\
\text { interaction skills (ex: conversating appropriately, } \\
\text { listening to others, being respectful when speaking to } \\
\text { others, etc.) }\end{array}$ & $\begin{array}{l}\text { Strongly agree: } 1 \\
\text { Agree: } 1\end{array}$ \\
\hline $\begin{array}{l}\text { The session helped me further develop my self- } \\
\text { regulation skills (ex: coping, regulating emotions, } \\
\text { managing behaviors, etc.). }\end{array}$ & $\begin{array}{l}\text { Strongly agree: } 1 \\
\text { Disagree: } 1\end{array}$ \\
\hline
\end{tabular}

\section{Session 7}

Charades were utilized for session 7 (Appendix $\mathrm{C}$ for module). 5 participants joined the session. Participants were informed of the occupation-based program, the role of occupational therapy, and the GSES, social skills assessments, and the survey questionnaire. Session 7 marked the halfway point of the occupation-based program, therefore, the GSES and social skills 
assessment was provided to the participants. When the activity was over, participants engaged in the open discussion.

Participants discussed how charades can assist with improving communication, such as reading body language and paying attention to others. Participants also provided their input on how they manage their emotions when they are feeling excited or impatient in certain situations. After the discussion, participants filled out the GSES, social skills assessment, and the survey questionnaire. Responses from the survey questionnaires from numbers 1 to 4 are provided in Table 9. Participants provided positive feedback from the session, primarily stating the session was "fun". For further suggestions, one participant stated "level up" such as in providing more challenging actions or roles for the activity.

An assumption made during the session was that all participants were honest in their assessments and survey questionaries. No limitations were made for the session. A delimitation is that participants would continue benefiting from the occupation-based program to improve social participation and self-regulation skills.

Table 9.

\begin{tabular}{|l|l|}
\hline 1. The session was engaging and meaningful. & $\begin{array}{l}\text { Strongly agree: } 2 \\
\text { Agree: } 3\end{array}$ \\
\hline $\begin{array}{l}\text { 2. } \\
\text { What I learned in this session is/will be valuable for my } \\
\text { future. }\end{array}$ & $\begin{array}{l}\text { Strongly agree: } 1 \\
\text { Agree: } 4\end{array}$ \\
\hline $\begin{array}{l}\text { 3. } \\
\text { The session helped me further develop my social } \\
\text { interaction skills (ex: conversating appropriately, } \\
\text { listening to others, being respectful when speaking to } \\
\text { others, etc.) }\end{array}$ & $\begin{array}{l}\text { Strongly agree: } 2 \\
\text { Agree: } 3\end{array}$ \\
\hline $\begin{array}{l}\text { The session helped me further develop my self- } \\
\text { regulation skills (ex: coping, regulating emotions, } \\
\text { managing behaviors, etc.). }\end{array}$ & $\begin{array}{l}\text { Strongly agree: } 1 \\
\text { Agree: } 4\end{array}$ \\
\hline
\end{tabular}

\section{Session 8}


Session 8 involved the obstacle course activity (Appendix $C$ for module). 5 participants joined the session. Participants were informed of the occupation-based program, the rules of the activity, and the GSES, social skills assessment, and survey questionnaire. Session 8 occurred during the same week of session 7 marking the halfway point of the program, therefore the GSES and social skills assessment were to be provided to the participants.

During the activity, participants were placed into two groups. Groups were informed to choose one team member to walk across the obstacle course blindfolded while the other team members were to guide their blindfolded teammate using only verbal communication. Each team member was to take turns being blindfolded to feel the unique perspective of listening to others versus appropriately communicating. When the activity was over, participants engaged in the open discussion. Participants discussed how they realized they had to provide clearer instructions for their teammates walking through the obstacle course. Participants explained their reactions when crossing the obstacle course versus leading their teammates through the obstacle course. After the discussion, participants completed the assessments and survey questionnaires.

Responses from numbers 1 to 4 on the survey questionnaires are provided in Table 10. Positive comments were made towards the session. One participant stated the session "allowed me to recognize I like to be in control of my surroundings." Another participant stated he/she liked "the meaning behind it [the session]." No further suggestions were made for the session. Table 10.

\begin{tabular}{|c|c|}
\hline 1. The session was engaging and meaningful. & $\begin{array}{l}\text { Strongly agree: } 1 \\
\text { Agree: } 4\end{array}$ \\
\hline $\begin{array}{l}\text { 2. What I learned in this session is/will be valuable for my } \\
\text { future. }\end{array}$ & $\begin{array}{l}\text { Strongly agree: } 1 \\
\text { Agree: } 3 \\
\text { Disagree: } 1\end{array}$ \\
\hline $\begin{array}{l}\text { 3. The session helped me further develop my social } \\
\text { interaction skills (ex: conversating appropriately, }\end{array}$ & $\begin{array}{l}\text { Strongly agree: } 2 \\
\text { Agree: } 1\end{array}$ \\
\hline
\end{tabular}




\begin{tabular}{|l|l|}
\hline $\begin{array}{l}\text { listening to others, being respectful when speaking to } \\
\text { others, etc.) }\end{array}$ & $\begin{array}{l}\text { Disagree: } 1 \\
\text { Strongly Disagree: } 1\end{array}$ \\
\hline $\begin{array}{l}\text { 4. } \begin{array}{l}\text { The session helped me further develop my self- } \\
\text { regulation skills (ex: coping, regulating emotions, } \\
\text { managing behaviors, etc.). }\end{array} \\
\text { Agree: } 2 \\
\text { Disagree: } 2 \\
\text { Strongly disagree: } 1\end{array}$ \\
\hline
\end{tabular}

\section{Mid-measures from Sessions 7 and 8}

Participants from sessions 7 and 8 were provided with the GSES and social skills assessment to complete as mid-measures because these sessions marked the halfway point of the occupation-based program. No participants from the first week of the program participated in session 7 and 8 . Therefore, responses from new participants were recorded. A total of 9 participants completed the mid-measures. In session 7, 5 participants joined the session and completed the GSES and social skill assessment. In session 8, 5 participants joined the session, however, only of the 1 the participants had previously attended session 7 . Therefore, the remaining 4 of the participants were provided with the GSES and social skill assessment to complete. Participants were told to only place their initials on the assessments. The initials would help the author indicate if participants have increased their self-efficacy and improved their social participation and self-regulation skills because of the occupation-based program when given the measures again at the end of the program.

Tables 11 and 12 display the responses from the 9 participants on their GSES and social skills assessment, respectively (Appendix D). Most of the participants responded with 3's and 4's on their GSES, indicating they perceived the item description to be moderately true or exactly true to them. In the social skills assessments, most of the participants agreed with the item descriptions. It is assumed participants were honest in their measures and perceived themselves as they believe. However, it is unsure if participants were responding truthfully or rushing through the assessments without carefully reading each of the items. 
Table 11

\begin{tabular}{|c|c|c|c|}
\hline General Self-Efficacy Scale Item Descriptions & \multicolumn{3}{|c|}{ Point Scale Responses } \\
\hline $\begin{array}{l}\text { 1. I can always manage to solve difficult problems if I } \\
\text { try hard enough. }\end{array}$ & 3: 田|l| & 4: ||| & \\
\hline $\begin{array}{l}\text { 2. If someone opposes me, I can find the means and } \\
\text { ways to get what I want. }\end{array}$ & $1: \mid$ & $2: \|$ & 3: |WW| \\
\hline $\begin{array}{l}\text { 3. It is easy for me to stick to my aims and accomplish } \\
\text { my goals. }\end{array}$ & 3: \#卅 & 4: $\|$ & \\
\hline $\begin{array}{l}\text { 4. I am confident that I could deal efficiently with } \\
\text { unexpected events. }\end{array}$ & 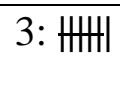 & 4: ||| & \\
\hline $\begin{array}{l}\text { 5. Thanks to my resourcefulness, I know how to handle } \\
\text { unforeseen situations. }\end{array}$ & $1: \mid$ & 3: Wll & 4: $\| \mid$ \\
\hline $\begin{array}{l}\text { 6. I can solve most problems if I invest the necessary } \\
\text { effort. }\end{array}$ & 3: \||| & 4: 冊 & \\
\hline $\begin{array}{l}\text { 7. I can remain calm when facing difficulties because I } \\
\text { can rely on my coping abilities. }\end{array}$ & $2: 1$ & 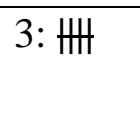 & 4: ||| \\
\hline $\begin{array}{l}\text { 8. When I am confronted with a problem, I usually find } \\
\text { several solutions. }\end{array}$ & 3: $\mid$ WIII & 4: & \\
\hline 9. If I am in trouble, I can usually think of a solution. & $2: \mid$ & 3: \|\| $\mid$ & 4: \|\| $\mid$ \\
\hline 10. I can usually handle whatever comes my way. & 3: 冊|| & 4: \| & \\
\hline
\end{tabular}

Table 12

\begin{tabular}{|c|c|}
\hline Social Skills Assessment Items & Responses \\
\hline $\begin{array}{l}\text { 1. I maintain eye contact and pay } \\
\text { attention while engaged in } \\
\text { conversation with others. }\end{array}$ & $\begin{array}{l}\text { Strongly agree: } 1 \\
\text { Agree: } 6 \\
\text { Disagree: } 1 \\
\text { Strongly disagree: } 1\end{array}$ \\
\hline $\begin{array}{l}\text { 2. I support and compliment others on } \\
\text { their accomplishments. }\end{array}$ & $\begin{array}{l}\text { Strongly agree: } 2 \\
\text { Agree: } 7\end{array}$ \\
\hline 3. I can clearly describe my feelings. & $\begin{array}{l}\text { Strongly agree: } 2 \\
\text { Agree: } 6 \\
\text { Strongly disagree: } 1\end{array}$ \\
\hline $\begin{array}{l}\text { 4. I carefully listen to and acknowledge } \\
\text { other people's points of view. }\end{array}$ & $\begin{array}{l}\text { Strongly agree: } 2 \\
\text { Agree: } 6 \\
\text { Disagree: } 1\end{array}$ \\
\hline
\end{tabular}




\begin{tabular}{|l|l|}
\hline $\begin{array}{l}\text { 5. I share, taken turns, and/or } \\
\text { demonstrate fairness when it comes to } \\
\text { situations that require cooperation. }\end{array}$ & $\begin{array}{l}\text { Strongly agree: } 2 \\
\text { Agree: } 6 \\
\text { Disagree: } 1\end{array}$ \\
\hline 6. I maintain appropriate social & Strongly agree: 1 \\
boundaries and respect the personal & Agree: 7 \\
space of others. & Strongly disagree: 1 \\
\hline
\end{tabular}

\section{Session 9}

Session 9 involved the gardening activity (Appendix $\mathrm{C}$ for module). 7 participants joined the session. Participants were informed of the activity and the survey questionnaires to be completed at the end of the session. Each participant was given a medium-sized flowerpot to paint on. During the activity, participants would provide positive comments about each other's pots or suggest ideas to paint on the pots. When they were finished and the pot was dried, each participant planted flowers into the pot, watered the flowers, and placed them around in the courtyard.

When the activity was completed, participants engaged in the open discussion. Participants discussed the benefits of gardening how gardening can teach someone how to take care of themselves. Additionally, participants discussed how an environment can influence someone's mood or way of thinking. After the discussion, participants completed the survey questionnaires. Responses from the participants from numbers 1 to 4 are provided in Table 13 . Positive comments were provided from the session. One participant stated he/she liked "the selfresponsibility" of the session. No further suggestions were made for the session.

A limitation during the session was encouraging some of the participants to actively engage in the open discussion. Examples would be provided during the open discussion to encourage some of the participants to speak, however, they would remain quiet. An assumption made is that all participants were honest in their survey questionnaires. A delimitation is that 
participants will continue benefiting from the occupation-based program to improve social participation and self-regulation skills.

Table 13.

\begin{tabular}{|l|l|}
\hline $\begin{array}{l}\text { 1. The session was engaging and meaningful. } \\
\text { That I learned in this session is/will be valuable for my } \\
\text { future. }\end{array}$ & $\begin{array}{l}\text { Strongly agree: } 2 \\
\text { Agree: } 4 \\
\text { Disagree: } 1\end{array}$ \\
\hline $\begin{array}{l}\text { Strongly agree: } 2 \\
\text { Agree: } 4 \\
\text { Disagree } 1\end{array}$ \\
\hline $\begin{array}{l}\text { The session helped me further develop my social } \\
\text { interaction skills (ex: conversating appropriately, } \\
\text { listening to others, being respectful when speaking to } \\
\text { others, etc.) }\end{array}$ & $\begin{array}{l}\text { Strongly agree: } 3 \\
\text { Agree: } 1\end{array}$ \\
\hline $\begin{array}{l}\text { Disagree: } 2 \\
\text { The session helped me further develop my self- } \\
\text { regulation skills (ex: coping, regulating emotions, } \\
\text { managing behaviors, etc.). }\end{array}$ & $\begin{array}{l}\text { Strongly agree: } 3 \\
\text { Agree: } 3\end{array}$ \\
\hline
\end{tabular}

\section{Session 10}

Session 10 involved playing the game Monopoly (Appendix C for module). 5 participants joined the session. Participants were informed of the objective and rules of the game as well as the survey questionnaires to be completed at the end of the session. During the session, participants were playing appropriately and negotiating with one another to obtain properties. A projected winner was determined and given a small prize due to the game consuming two hours and the limited period.

When the game was over, participants engaged in the open discussion. Participants discussed how Monopoly targets communication skills, such as expressing their needs or wants, building the confidence to speak, and negotiating with others. Participants also explained appropriate ways to react and handle their emotions when they seem that life isn't fair. After the discussion, participants were given the survey questionnaires to complete. Table 14 provides 
responses from the participants from numbers 1 to 4 from the survey questionnaires. Positive comments were made from the session. No further suggestions for the session were made.

An assumption made was that all participants were honest in their survey questionnaires. No limitations were made during the session. A delimitation is that participants will continue benefiting from the occupation-based program.

Table 14.

\begin{tabular}{|c|c|}
\hline 1. The session was engaging and meaningful. & $\begin{array}{l}\text { Strongly agree: } 4 \\
\text { Strongly disagree: } 1\end{array}$ \\
\hline $\begin{array}{l}\text { 2. What I learned in this session is/will be valuable for my } \\
\text { future. }\end{array}$ & Strongly agree: 5 \\
\hline $\begin{array}{l}\text { 3. The session helped me further develop my social } \\
\text { interaction skills (ex: conversating appropriately, } \\
\text { listening to others, being respectful when speaking to } \\
\text { others, etc.) }\end{array}$ & Strongly agree: 5 \\
\hline $\begin{array}{l}\text { 4. The session helped me further develop my self- } \\
\text { regulation skills (ex: coping, regulating emotions, } \\
\text { managing behaviors, etc.). }\end{array}$ & Strongly agree: 5 \\
\hline
\end{tabular}

\section{Session 11}

Session 11 included the debate activity (Appendix $\mathrm{C}$ for module). 6 participants joined the session. Participants were informed of the activity and of the survey questionnaires to be completed at the end of the session. Participants were divided into two groups. Both groups were notified of the different topics that will be debated throughout the activity. The topics included: summer vs winter, tacos vs pizza, and positive effects of social media versus negative effects of social media. Groups were encouraged to communicate with one another and use their phones to find information to help make their topics stronger. When groups were done discussing their topics with one another, team leaders were chosen from each group to defend their assigned topics. 
After the activity, participants engaged in the open discussion. Participants discussed how the activity targeted social skills, such as in communicating with one another and listening to different perspectives of others. They described their reactions during the activity, such as feeling excitement or impatient. Participants discussed appropriate ways to handle their emotions if experiencing a situation where someone is in a disagreement with him/her. After the discussion, participants were given the survey questionnaires to complete. Responses from the participants from numbers 1 to 4 on the survey questionnaires are provided in Table 15. Positive comments were made about the activity. One participant stated he/she liked "how everybody got everything out". Another participant stated he/she liked "the way it improves social skills." For suggestions, a participant stated to provide "better vs. [versus] to debate that will help with life." Two other participants similarly stated to provide better topics.

A limitation faced during the session was managing the youth to debate appropriately and civilized. Despite being told to regulate themselves, many of the youth would become disruptive or loud when debating. An assumption made during the session is that all participants were honest in their survey questionnaires. A delimitation is that participants will continue to benefit from the occupation-based program.

Table 15.

\begin{tabular}{|c|c|}
\hline 1. The session was engaging and meaningful. & $\begin{array}{l}\text { Strongly agree: } 4 \\
\text { Agree: } 1 \\
\text { Strongly disagree: } 1\end{array}$ \\
\hline $\begin{array}{l}\text { 2. What I learned in this session is/will be valuable for my } \\
\text { future. }\end{array}$ & $\begin{array}{l}\text { Strongly agree: } 3 \\
\text { Agree: } 1 \\
\text { Disagree: } 1 \\
\text { Strongly disagree: } 1\end{array}$ \\
\hline $\begin{array}{l}\text { 3. The session helped me further develop my social } \\
\text { interaction skills (ex: conversating appropriately, }\end{array}$ & $\begin{array}{l}\text { Strongly agree: } 2 \\
\text { Agree: } 4\end{array}$ \\
\hline
\end{tabular}




\begin{tabular}{|l|l|}
\hline $\begin{array}{l}\text { listening to others, being respectful when speaking to } \\
\text { others, etc.) }\end{array}$ & \\
\hline $\begin{array}{l}\text { 4. } \\
\text { The session helped me further develop my self- } \\
\text { regulation skills (ex: coping, regulating emotions, } \\
\text { managing behaviors, etc.). }\end{array}$ & $\begin{array}{l}\text { Strongly agree: } 2 \\
\text { Agree: } 4\end{array}$ \\
\hline
\end{tabular}

\section{Session 12}

Session 12 included the cooking lab activity. 9 participants joined the session.

Participants were informed to split into two groups depending on who wanted chicken tacos and who wanted beef tacos. Both groups were also given chocolate chip cookies to bake as desert. Participants were informed of the activity and the survey questionnaire to be completed at the end of the session. Participants were given various tasks, such as dicing tomatoes, stirring the meat, washing dishes, etc., to assign one another. When participants assigned their tasks to one another, they were called to the kitchen to begin the prepping and cooking process. When the activity finished, participants engaged in the open discussion.

Participants discussed how the activity targeted social skills, such as cooperating with one another, sharing, and working as a team. Participants explained how cooking can teach responsibility, including setting goals for oneself, managing emotions, and learning to plan of time. In addition, participants discussed how cooking can teach about patience and benefit of challenging work and perseverance. After the discussion, participants completed the survey questionnaires for the session. Responses from numbers 1 to 4 of the survey questionnaires from the participants are provided in Table 16. Positive comments were provided from the session. A participant stated he/she "liked cooking with others". Another participant stated he/she liked how “everybody cooperated and had fun." For further suggestions, one participant mentioned providing more challenging foods to cook. No additional suggestions were made. 
No limitations occurred during the session. An assumption made was that all participants were honest in their survey questionnaires. A delimitation is that all participants will continue to benefit from the occupation-based program to improve their social participation and selfregulation skills.

Table 16.

\begin{tabular}{|l|l|}
\hline 1. The session was engaging and meaningful. & $\begin{array}{l}\text { Strongly agree: } 7 \\
\text { Agree: } 1 \\
\text { Disagree: } 1\end{array}$ \\
\hline $\begin{array}{l}\text { 2. } \begin{array}{l}\text { What I learned in this session is/will be valuable for my } \\
\text { future. }\end{array} \\
\begin{array}{l}\text { Strongly agree: } 6 \\
\text { Agree: } 2\end{array} \\
\text { Disagree: } 1\end{array}$ \\
$\begin{array}{l}\text { The session helped me further develop my social } \\
\text { listening to others, being respectful when speaking to } \\
\text { others, etc.) }\end{array}$ & $\begin{array}{l}\text { Strongly agree: } 5 \\
\text { Agree: } 3\end{array}$ \\
Strongly disagree: 1 \\
\hline $\begin{array}{l}\text { The session helped me further develop my self- } \\
\text { regulation skills (ex: coping, regulating emotions, } \\
\text { managing behaviors, etc.). }\end{array}$ & $\begin{array}{l}\text { Strongly agree: } 5 \\
\text { Agree: } 3 \\
\text { Strongly disagree: } 1\end{array}$ \\
\hline
\end{tabular}

\section{Session 13}

Session 13 included the tie-dyed shirt activity. 12 participants joined the session. Participants were informed of the activity, including how to tie the shirts and add the color dye to them. Each participant was given a white shirt of their corresponding size. Participants were to put into pairs of twos to help one another make the shirts. Each pair was given 3 assorted color dye bottles to share. When everyone was finished making their shirts, each participant had to wrap their shirt in plastic wrap to leave outside for 24 hours before washing. When the activity was completed, participants engaged in the open discussion.

Participants discussed how each tie-dye shirt is unique and isn't meant to be perfect. Participants explained how striving for perfectionism can affect someone mentally. Moreover, 
they discussed how tie-dying can teach them about letting go of self-judgment and judging others. Participants described their plan prior to starting the activity, how it changed during the activity, and how to handle situations appropriately when a plan does not turn out as expected. Furthermore, participants discussed how being in pairs promoted engagement and assistance with one another. After the discussion, participants completed their survey questionnaires.

Responses from numbers 1 through 4 on the survey questionnaires are provided in table 17. Positive comments were provided from the participants. One participant stated he/she liked "interacting with everyone". Another participant stated he/she liked how the "session provided a way to express myself". Similar comments were made from the participants on how they enjoyed talking to others and were able to make a tie-dyed shirt. For further suggestions on the session, 2 participants stated to provide more options for colors. One participant stated, "to have less people" and another participant stated, "more authorities."

A limitation faced during the session was the limited amount of space utilized during the activity. The activity was completed in the courtyard at Covenant house. However, due to the evening time, the walking pathway was the only area with adequate lighting to make the tie-dye shirts. Some participants remained within the pathway and some participants completed their shirts in a different area near the pathway. An assumption made during the session was that all participants were made honest on their survey questionnaires. A delimitation is that all participants will continue to benefit from the occupation-based program to improve their social participation and self-regulation skills.

Table 17.

\begin{tabular}{|l|l|}
\hline 1. The session was engaging and meaningful. & Strongly agree: 7 \\
& Agree: 4 \\
& Disagree: 1 \\
\hline
\end{tabular}




\begin{tabular}{|l|l|}
\hline \begin{tabular}{l} 
2. $\begin{array}{l}\text { What I learned in this session is/will be valuable for my } \\
\text { future. }\end{array}$ \\
\hline $\begin{array}{l}\text { The session helped me further develop my social } \\
\text { interaction skills (ex: conversating appropriately, } \\
\text { listening to others, being respectful when speaking to } \\
\text { others, etc.) }\end{array}$
\end{tabular} & $\begin{array}{l}\text { Strongly agree: } 4 \\
\text { Agree: } 6 \\
\text { Disagree: } 2\end{array}$ \\
\hline $\begin{array}{l}\text { Agree: } 7 \\
\text { The session helped me further develop my self- } \\
\text { regulation skills (ex: coping, regulating emotions, } \\
\text { managing behaviors, etc.). }\end{array}$ & $\begin{array}{l}\text { Strongly agree: } 3 \\
\text { Agree: } 4 \\
\text { Disagree: } 5\end{array}$ \\
\hline
\end{tabular}

\section{Session 14}

Session 14 included playing the game "Hedbanz". 3 participants joined the session. Participants were informed of the session and the survey questionnaire to be completed at the end. Each participant was given a card and without looking at the picture of their card, participants placed their card onto the headband so other participants could view their card. Participants took turns asking questions to find out the picture on their cards. When the activity finished, participants engaged in the open discussion.

Participants discussed how the activity targeted communication skills, such as listening to others, working on description skills, and problem-solving. Participants explained how the game allowed them to work on perspective taking and the value of considering different perspectives, including how it teaches others to self-control their thoughts and emotions. They then applied the concepts discussed for future purposes. After the discussion, participants completed the survey questionnaires. Responses from numbers 1 to 4 on the survey questionnaires are provided in table 18. Positive comments were made from the participants. A participant stated he/she "got to laugh". Another participant stated he/she liked "the bonding”. For further suggestions, 2 participants both stated "more people" to improve the session. 
A limitation that occurred during the session was the limited number of participants. An assumption made is that all the participants were honest in their survey questionnaires. A delimitation is that all participants will continue to benefit from the occupation-based program to improve social participation and self-regulation skills.

Table 18

\begin{tabular}{|c|c|}
\hline 1. The session was engaging and meaningful. & $\begin{array}{l}\text { Strongly agree: } 1 \\
\text { Agree: } 2\end{array}$ \\
\hline $\begin{array}{l}\text { 2. What I learned in this session is/will be valuable for my } \\
\text { future. }\end{array}$ & $\begin{array}{l}\text { Agree: } 2 \\
\text { Disagree: } 1\end{array}$ \\
\hline $\begin{array}{l}\text { 3. The session helped me further develop my social } \\
\text { interaction skills (ex: conversating appropriately, } \\
\text { listening to others, being respectful when speaking to } \\
\text { others, etc.) }\end{array}$ & $\begin{array}{l}\text { Strongly agree: } 1 \\
\text { Agree: } 1 \\
\text { Disagree: } 1\end{array}$ \\
\hline $\begin{array}{l}\text { 4. The session helped me further develop my self- } \\
\text { regulation skills (ex: coping, regulating emotions, } \\
\text { managing behaviors, etc.). }\end{array}$ & $\begin{array}{l}\text { Agree: } 2 \\
\text { Disagree: } 1\end{array}$ \\
\hline
\end{tabular}

\section{Session 15}

Session 15 included a team-building exercise called "egg drop" (Appendix C). 5 participants joined the activity. Participants were split into 2 teams and provided the materials needed for the activity. Teams were informed of the activity and encouraged to communicate and cooperate with their team members when constructing the structure for their egg. Participants were informed of the survey questionnaire to be completed at the end of the session as well as the GSES and social skills assessment. Session 15 marked the last week of the program, therefore, to receive additional responses on the post-measure's participants were provided the assessments.

Teams were checked on throughout the activity to make sure team members were working well with one another and if they needed additional materials to complete their 
structures. When both teams completed their structures for their eggs, one team member from each group dropped their egg from a certain height. The team members had to disassemble their egg structure to determine if their egg cracked. Both teams' eggs had cracked, however, participants were given small prizes for their efforts.

When the activity was finished participants engaged in the open discussion. Participants discussed their reactions during the activity, such as being stressed. They explained how to manage themselves during stressful situations in which a few of them stated to breathe or to not overthink and avoid the situation. Participants described positive aspects of working with their team members. Participants further discussed the benefits of setting goals and analyzing or thinking responsibly in situations. After the discussion, participants completed the assessments and survey questionnaires. Responses from numbers 1 through 4 from the survey questionnaires are provided in table 19. Positive comments were made from the participants. One participant stated he/she liked "the idea of inventing to protect something". Another participant stated he/she liked the "teamwork". For further suggestions to improve the session, one participant stated, "better work materials" and another participant stated, "better partners".

A limitation faced during the activity was encouraging a participant to cooperate and communicate effectively with his teammates as this activity was a teambuilding exercise. The participant did allow his teammates to create the structure for their egg afterward but would not continue to interact inappropriately. An assumption made is that all participants were honest in their survey questionnaires and assessments provided. A delimitation is that participants would continue to benefit from the occupation-based program.

Table 19

1. The session was engaging and meaningful.
Strongly agree: 2

Agree: 3 


\begin{tabular}{|l|l|}
\hline $\begin{array}{l}\text { 2. What I learned in this session is/will be valuable for my } \\
\text { future. }\end{array}$ & $\begin{array}{l}\text { Strongly agree: } 2 \\
\text { Agree: } 2 \\
\text { Disagree: } 1\end{array}$ \\
\hline $\begin{array}{l}\text { The session helped me further develop my social } \\
\text { interaction skills (ex: conversating appropriately, } \\
\text { listening to others, being respectful when speaking to } \\
\text { others, etc.) }\end{array}$ & $\begin{array}{l}\text { Strongly agree: } 1 \\
\text { Agree: } 3 \\
\text { Strongly disagree: } 1\end{array}$ \\
\hline $\begin{array}{l}\text { The session helped me further develop my self- } \\
\text { regulation skills (ex: coping, regulating emotions, } \\
\text { managing behaviors, etc.). }\end{array}$ & $\begin{array}{l}\text { Strongly agree: } 2 \\
\text { Agree: } 2 \\
\text { Disagree: } 1\end{array}$ \\
\hline
\end{tabular}

\section{Session 16}

Session 16 included playing the game "Clue". 1 participant joined the session. The participant was informed of how to play the game and of the survey questionnaire to be provided at the end of the session. This participant had joined session 15, therefore, he was not given the post-measures to complete again. After playing the game for two rounds, the participant engaged in the open discussion.

During the discussion, the participant described how critical thinking and deductive reasoning are helpful throughout life situations. He discussed how emotions can influence a person's way of thinking and how both emotions and critical thinking can influence communication styles. When the discussion was over, the participant completed the survey questionnaire. Responses from numbers 1 through 4 on the survey questionnaire are provided in Table 20. He stated that he liked "everything" about the session and provided no further suggestions to improve the session.

A limitation that occurred was the number of participants that joined the session. Having only one participant provided no opportunities to engage with other peers. An assumption made was that the participant was honest in the survey questionnaire.

Table 20. 


\begin{tabular}{|l|l|}
\hline 1. The session was engaging and meaningful. & Strongly agree: 1 \\
\hline $\begin{array}{l}\text { 2. } \\
\text { What I learned in this session is/will be valuable for my } \\
\text { future. }\end{array}$ & Strongly agree: 1 \\
\hline $\begin{array}{l}\text { 3. } \\
\text { The session helped me further develop my social } \\
\text { interaction skills (ex: conversating appropriately, } \\
\text { listening to others, being respectful when speaking to } \\
\text { others, etc.) }\end{array}$ & Strongly agree: 1 \\
\hline $\begin{array}{l}\text { 4. } \\
\text { The session helped me further develop my self- } \\
\text { regulation skills (ex: coping, regulating emotions, } \\
\text { managing behaviors, etc.). }\end{array}$ & Strongly agree: 1 \\
\hline
\end{tabular}

\section{Post-measures from Sessions 15 and 16}

Post-measures were provided to the participants in sessions 15 and 16 because these were the last two sessions of the occupation-based program. A total of 5 participants completed the GSES and social skill assessment (Appendix D). In session 15, 5 participants joined the session and were given the measures to complete. From this session, 2 of the participants had previously completed the mid-measures, however, they have been inconsistent when attending the program since then. In session 16, 1 participant joined the session but had previously attended session 15 , therefore was not given the post-measure to complete again.

Tables 21 and 22 display the responses from the participants on their GSES and social skills assessments, respectively. Most of the participants responded with 3's and 4's on the GSES, indicating their perceived item description to be moderately true or exactly true to them. On the social skills assessment, participants primarily agreed with the item descriptions. It is assumed participants were honest in their measures and perceived themselves as they believe. However, it is unsure if participants were responding truthfully or rushing through the assessments without carefully reading each of the items.

Table 21 


\begin{tabular}{|c|c|}
\hline General Self-Efficacy Scale Item Descriptions & Point Scale Responses \\
\hline $\begin{array}{l}\text { 1. I can always manage to solve difficult problems if I } \\
\text { try hard enough. }\end{array}$ & 4: |||| \\
\hline $\begin{array}{l}\text { 2. If someone opposes me, I can find the means and } \\
\text { ways to get what I want. }\end{array}$ & 3: || \\
\hline $\begin{array}{l}\text { 3. It is easy for me to stick to my aims and accomplish } \\
\text { my goals. }\end{array}$ & 4: ||| \\
\hline $\begin{array}{l}\text { 4. I am confident that I could deal efficiently with } \\
\text { unexpected events. }\end{array}$ & $2:|\quad 3:|$ \\
\hline $\begin{array}{l}\text { 5. Thanks to my resourcefulness, I know how to handle } \\
\text { unforeseen situations. }\end{array}$ & 4: ||| \\
\hline $\begin{array}{l}\text { 6. I can solve most problems if I invest the necessary } \\
\text { effort. }\end{array}$ & 4: |||| \\
\hline $\begin{array}{l}\text { 7. I can remain calm when facing difficulties because I } \\
\text { can rely on my coping abilities. }\end{array}$ & $1: \mid \quad 3: \|$ \\
\hline $\begin{array}{l}\text { 8. When I am confronted with a problem, I usually find } \\
\text { several solutions. }\end{array}$ & 4: ||| \\
\hline 9. If I am in trouble, I can usually think of a solution. & 3: || \\
\hline 10. I can usually handle whatever comes my way. & 4: \|\| $\mid$ \\
\hline
\end{tabular}

Table 22

\begin{tabular}{|c|c|}
\hline Social Skills Assessment Items & Responses \\
\hline $\begin{array}{l}\text { 1. I maintain eye contact and pay } \\
\text { attention while engaged in } \\
\text { conversation with others. }\end{array}$ & $\begin{array}{l}\text { Strongly agree: } 2 \\
\text { Agree: } 2 \\
\text { Disagree: } 1\end{array}$ \\
\hline $\begin{array}{l}\text { 2. I support and compliment others on } \\
\text { their accomplishments. }\end{array}$ & $\begin{array}{l}\text { Strongly agree: } 1 \\
\text { Agree: } 4\end{array}$ \\
\hline $\begin{array}{l}\text { 3. I am able to clearly describe my } \\
\text { feelings. }\end{array}$ & $\begin{array}{l}\text { Strongly agree: } 2 \\
\text { Agree: } 3\end{array}$ \\
\hline $\begin{array}{l}\text { 4. I carefully listen to and acknowledge } \\
\text { other people's points of views. }\end{array}$ & $\begin{array}{l}\text { Strongly agree: } 1 \\
\text { Agree: } 2 \\
\text { Disagree: } 2\end{array}$ \\
\hline $\begin{array}{l}\text { 5. I share, taken turns, and/or } \\
\text { demonstrate fairness when it comes to } \\
\text { situations that require cooperation. }\end{array}$ & $\begin{array}{l}\text { Strongly agree: } 2 \\
\text { Agree: } 2 \\
\text { Disagree: } 1\end{array}$ \\
\hline
\end{tabular}



6. I maintain appropriate social boundaries and respect the personal
Strongly agree: 1 space of others.
Agree: 4

\section{Data Analysis and Findings}

A total of 37 participants joined the occupation-based program, with some of them participating in more than one session. From the 16 sessions held throughout the program, a sum of 79 survey questionnaires was collected from the participants providing 79 responses for each item on the survey questionnaires. Table 23 lists the number of total responses from the participants on their survey questionnaires from all the sessions. Data shows for item 1 that $93 \%$ of the participants agreed or strongly agreed that the sessions were engaging and meaningful, with $6 \%$ disagreeing or strongly disagreeing. For item $2,86 \%$ agreed or strongly agreed that the sessions were valuable for their future with 14\% disagreeing or strongly disagreeing. For item 3 , $86 \%$ of participants agreed or strongly agreed that the sessions helped them further develop their social interaction skills with $14 \%$ disagreeing or strongly disagreeing. For item $4,78 \%$ agreed or strongly agreed that the sessions helped further develop their self-regulation skills with $22 \%$ disagreeing or strongly disagreeing.

Table 23

\begin{tabular}{|c|c|c|c|c|}
\hline $\begin{array}{c}\text { Items 1-4 on } \\
\text { Survey } \\
\text { Questionnaires }\end{array}$ & \multicolumn{4}{|c|}{ Total Participant Responses from Sessions 1-16 } \\
\hline & $\begin{array}{c}\text { Strongly } \\
\text { Disagree }\end{array}$ & Disagree & Agree & Strongly Agree \\
\hline $\mathbf{1}$ & 2 & 3 & 33 & 41 \\
\hline $\mathbf{2}$ & 1 & 10 & 34 & 34 \\
\hline $\mathbf{3}$ & 4 & 7 & 32 & 36 \\
\hline $\mathbf{4}$ & 2 & 15 & 32 & 30 \\
\hline
\end{tabular}




\section{Conclusion}

In conclusion, the findings indicate that participants agreed the sessions were engaging and meaningful, learned concepts that were valuable in the future, and further developed their social participation and self-regulation skills. The results and data collected from the project described the participants within the program, discrepancies that occurred, organizational conditions that influenced the study, and descriptions of the sessions within the program. The occupation-based program was held for the planned duration of 8 weeks twice a week for a total of 16 sessions. Participants within the program signified the similarities between the population researched from the literature review (chapter 2), such as having poor mental health, demonstrating maladaptive behaviors, or coming from a low SES background. Sessions for the program were open groups to allow any youth to join for the session. However, results to determine if the occupation-based program is primarily effective are insignificant due to the inconsistent or various participations joining the sessions.

Most of the participants within the program provided positive feedback towards the sessions but very few suggestions were given. Assumptions made throughout each session are that participants were being honest in their survey questionnaires provided. Several limitations occurred throughout the program due to several factors, such as the number of participants in some of the sessions, following COVID-19 restrictions, and encouraging youth to actively participate in the open discussions or follow the structure of the session properly. Description and outcomes of the occupation-based program were presented to the staff at Covenant House Florida to demonstrate the role of occupational therapy in addressing at-risk youth and how the program may be beneficial to be sustained at the site. 


\section{Chapter 5: Summary, Discussion, and Conclusion}

\section{Introduction}

The purpose of this chapter is to communicate the findings of the capstone project of the occupation-based program for at-risk youth who participate in youth violence and demonstrate maladaptive behaviors to develop social participation and self-regulation skills. The problem is children and adolescents who participate in youth violence do so because of poorly developed social participation and self-regulation skills (Cid, 2016; Forrest-Bank, et al., 2016; Shea \& Jackson, 2014). A secondary problem is that OTs used to fill in the role of mental health professionals but now they do not (Baltag et al., 2015; Cahill \& Egan, 2017b). OTs can further develop social participation and self-regulation skills; however, they are underutilized on intervention teams for the at-risk youth population (Leigers et al., 2016; Parsons \& Saffer, 2018). Deficits in social participation and self-regulation skills impair initiating and maintaining positive relationships and the ability to cope and adapt to the social environment (Leigers et al., 2016; Mcdaniel et al., 2016). The inability to sustain positive relationships and to cope appropriately during life challenges will gradually worsen the mental health and self-efficacy of at-risk youth (Leigers et al., 2016; Mcdaniel et al., 2016). At-risk youth are specifically disadvantaged due to risk factors that prevent success, such as having a lack of social support from family or peers or limited resources within the environment. OT's ability to facilitate a supportive environment and participation in valuable occupations can help improve daily roles, behaviors, and patterns to be successful as at-risk youth continue to grow (Moses \& Villodas, 2017).

The increased concern for youth violence has called for efforts in safety and promoting positive mental health (Modzeleski, 2018; Jonson, 2017). Currently, there are minimal effective 
intervention-based programs that are supportive of refining children's and adolescent's social participation and self-regulation to eliminate at-risk behaviors (Bonell et al., 2016; Farajzadegan et al., 2018; Whitten et al., 2017). Therefore, the purpose of the project was to implement an occupation-based program to improve social participation and self-regulation skills in at-risk youth to prevent youth violence and decrease maladaptive behaviors. The program was implemented at Covenant House Florida for 8 weeks, twice a week for a total of 16 sessions. The author believes that the program was successful in engaging youth to participate in various activities provided. Several challenges and limitations occurred throughout the program that was and was not foreseen, influencing the outcomes of the project. However, the program did support OTs' role in addressing social participation and self-regulation skills in at-risk youth.

\section{Interpretations of Findings}

The findings confirm that occupation-based groups can be engaging and meaningful, teach skills that are meaningful for the future, and help improve social participation skills and self-regulation skills. As described in the literature, OTs promote engagement in age-appropriate, meaningful, and purposeful activities and occupations for at-risk youth. The benefit of providing such activities is the ability to further develop necessary skills, such as social participation and self-regulation skills while allowing at-risk youth to engage in activities of interest. Applying occupation-based interventions focused on play, leisure, and social participation is supportive to develop prosocial behaviors and interests, opportunities to use time productively, and promote positive mental health. Utilizing age-appropriate and meaningful activities throughout the occupation-based program for the capstone project allowed the author to realize the importance of providing activities or interventions that at-risk youth will seem more responsive to and willing to participate in. This holds especially true when some of the youth at Covenant House 
would identify an activity in the program that they enjoy or in contrast, have no experience with the activity and wanted to try it out.

Providing group sessions for the occupation-based program provided opportunities for the at-risk youth that were confirmed in the literature and supported the profession of OT. The group sessions provided plenty of opportunities to problem-solve and make decisions with their peers, such as during the team-building exercises, cooking lab, and debate activity. Engaging the youth in the open discussions after the activities as a group influenced and provided some of the youth confidence to speak and to provide their insight after hearing others voice their thoughts and opinions. Moreover, group sessions allowed the participants to demonstrate positive interactions, social connections and identified similar interests with one another while participating in the activities provided.

\section{Findings with the Literature}

Similarities between the findings of the project outcomes and the literature in chapter 2 were appreciated. The literature explains how at-risk youth experience issues or factors that lead them to experience maladaptive behaviors which include but are not limited to lack of social support from family and peers, low-SES, poor mental health, exposure to community violence, disruptions within families, substance abuse, and/or not seeking the services needed. In Covenant House, many of the youth have experienced the issues or factors identified within the literature and more. Some of the youths have undergone domestic violence or abusive relationships, aged out of foster care, family members with mental health issues, and/or exposure to substance abuse from family. At-risk youth consistently experiencing stressors and trauma, such as the ones listed, leads to a decrease in coping abilities and psychological issues, which can hinder their social participation and self-regulation skills. 
Social participation and self-regulation skills are necessary skills that assist in achieving desired goals, higher levels of self-efficacy, and help in developing and maintaining positive relationships. Problems experienced by at-risk youth who demonstrate maladaptive behaviors with poorly developed social participation and self-regulation skills, as described in the literature, are mental health issues, trauma, disadvantaged environment, consistent stressors, lack of social support, and minimal to no attendance to therapy sessions. The staff at Covenant House mentioned similar findings to the literature with additional problems experienced by the youth. Additional problems include trauma anniversaries, poor attention capacity or cognitive rigidity, numb or unable to tap into reinforcers, and major surgery within the first 3 years of life.

The author believes the findings from the literature and Covenant House Florida corresponded to the youth seen during the experiential hours. Many of the youth who demonstrate maladaptive behaviors and have poor social participation and self-regulation skills are diagnosed with mental health issues, such as anxiety, depression, and/or bipolar disorder. Although many of the youth may have experienced different challenges within their lives, they have experienced traumatic events and stressors, and demonstrate behaviors, such as insecurity, hopelessness, low impulse control, and fluctuating moods. Some of the youth would require redirection to communicate appropriately with others if they sounded disrespectful, passiveaggressive, or demanding. Fortunately, youth at Covenant House are provided with therapists for no cost, therefore, can schedule and attend therapy sessions. However, it was seen that some youth would express disinterest in attending therapy sessions, secondary to not wanting to express their feelings or talk to an adult. The author believes that occupational therapy can provide a distinct perspective on how to use occupations and purposeful activities to improve social participation and self-regulation skills with youth demonstrating maladaptive behaviors 
during treatment sessions. Occupational therapy may help the youth realize their strengths and interests and identify the personal factors affecting them. With that information, OTs can assist the youth in replacing negative habits and behaviors with more positive ones while incorporating meaningful activities and occupations of the youth as interventions. The incorporations of activities during treatment sessions also provide a means for the youth to be distracted in the activity provided as well as the occupational therapist and the youth to be comfortable with one another and bond since they can both engage in the activity together.

The professional backgrounds that the staff at Covenant House Florida are trained and educated to work in are primarily social work, psychology, criminal justice, education, nursing, and business administration. With these professional backgrounds, the staff is divided and given the roles as therapists, case managers, Ombud's person, educator, and nurse. The therapists at CHF are each assigned to a specific gender and age group. For example, one therapist will see females below the ages of 18 , and another therapist will see females from the age of 18 years and older. The therapists provide the youth with individual and group therapy, family therapy, and behavioral health therapy, such as CBT and trauma, and solution-focused treatments.

Case managers are assigned within different departments at CHF. One case manager is placed for the female floor and the other for the male floor. The main responsibilities of the case managers on the floor are to create the action plan for the youth and assure that they are following their action plan throughout the week as well as handle dilemmas with their assigned residents. The life skills case manager oversees activities within the life skills or recreational area as well as coordinates with the independent living coordinator to provide basic life skills courses, such as first aid, budgeting, and resume building. When entering CHF, there is an intake case manager and Ombud's person. The intake case manager will complete the initial intake forms for 
newly admitted youth, answer phone calls from the crisis hotline for youth, and assist with discharges and referrals to the community. The Ombud's person hears and appeals grievances from the youth. This person will review the facts related to an outcome and will assist with determining if that outcome should be charged. In addition, the Ombud's person helps youth find interim and outside services during their time away from $\mathrm{CHF}$, such as when youth are being discharged.

An educator is located on-site to provide educational services and the necessary skills to prepare the youth who wish to obtain their general education development (GED). Youth are offered tutoring, mentoring, and access to laptops and computers. Youth are also given the option of whether they prefer to attend public school. The nurses at CHF provide medical health care to the youth. Within the first 3 days of intake, newly admitted youth is to receive a physical exam and health assessment. Youth are also provided services such as laboratory tests, pre-and post-natal care, HIV/STD counseling, and health, substance abuse assessments, and referrals to other health care providers.

The author believes the information provided in the literature is primarily valid on the disciplines or professionals that often help at-risk youth. Professionals that obtain backgrounds in social work, psychology, and education are available at Covenant House Florida to assist the youth. The role of occupational therapy had to be provided to some of the staff upon starting experiential hours because some were not aware of OT's role and how occupational therapy can help this population. When the occupation-based program was completed, a PowerPoint presentation was provided to the staff to reemphasize the role of occupational therapy, a brief history of the profession, the services included in occupational therapy, outcomes, and limitations of the program, and suggestions to implement with the youth at Covenant House 
Florida. During the presentation, some of the staff were taking down notes and asking questions about the elements that made the program effective. When the presentation was over, the staff expressed their appreciation for the presentation, how much they have learned about the profession as well as their understanding of how the program relates to occupational therapy. The staff mentioned hoping to sustain the program as it does provide the youth with the opportunity to be productive during their time at Covenant House Florida and hope to be able to hire an occupational therapist in the future.

After researching online, the author found an occupational therapist working at the Covenant House Toronto in Canada. The author was able to speak over the phone with the occupational therapist to understand her role in Covenant House Toronto and how she helps the at-risk youth. The occupational therapist mentioned how she focuses on mental health and helps the youth manage their anxiety, depression, ADHD (attention deficit hyperactivity disorder), and/or other emotions or behaviors disorders they experience. The occupational therapist focuses on poor hygiene as that may accompany poor mental health as well as mindfulness techniques and independent living skills. The occupational therapist also focuses on sleep hygiene and insomnia to identify barriers that are lacking proper sleep for the youth and to develop healthy sleep habits. She looks at the youth contexts and will provide environmental assessments in the youth's room if needed. When youth with autism spectrum disorder (ASD) come to Covenant House Toronto, the occupational therapist incorporates sensory processing techniques depending on the needs of the youth. The occupational therapist at Covenant House Toronto truly emphasized how she advocates for the needs of the youth as many youths are receptive to different feedback, have different interests and learning styles as well as may require different accommodations. Speaking to the occupational therapist at Covenant House Toronto allowed the 
author to appreciate the profession of occupational therapist more, validate the role of the profession in mental health and how it can help the at-risk youth population.

\section{Outcomes and Theoretical Models}

The theoretical models and frameworks used to guide the occupation-based program were MOHO, SCT, and the SEL process. MOHO focuses on promoting engagement in meaningful activities and appropriate behaviors that organize healthy lifestyles and motives (Bowyer et al., 2019; Graham et al., 2016). Many of the youth at Covenant House Florida experience disruption in their occupational performance due to trouble in their volition, habituation, performance capacity, and environmental contexts. The findings of this study align with the assumptions postulated by MOHO since $93 \%$ of the participants or 74 out of the 79 participant responses agreed or strongly agreed that the sessions were engaging and meaningful. The engagement and meaning were created by incorporating group sessions to allow participants to interact with one another and participate in healthy and safe activities together within their environment. Utilizing MOHO throughout the program allowed the author to focus on motivating and encouraging healthy habits and routines in the youth to decrease maladaptive behaviors. Activities provided in the program were incorporated to focus primarily on social participation and self-regulation skills, which were the skills identified to be underdeveloped in at-risk youth.

The SCT focuses on the triadic interaction between an individual's environment, personal factors, and behavior, also known as reciprocal determinism, which influences and determines human behavior (Knol et al., 2016). The outcomes of the study aligned with the theory because $86 \%$ of participants agreed or strongly agreed that the sessions helped them further develop their social interaction skills and $78 \%$ agreed or strongly agreed that the sessions helped further 
develop their self-regulation skills. The participants demonstrated positive interactions and were able to rationalize their behaviors and emotions during activities and open discussions. During discussions especially, participants were able to discuss in depth the reactions felt during the activities and how to manage emotions or reactions when heightened in various situations. SCT guided the program to allow the youth to observe the actions and behaviors of peers during the sessions to help influence and learn from one another.

The SEL process provides individuals with the acquired skills, behaviors, and attitudes to develop prosocial behaviors, achieve positive goals, and reduce mental health risks (Dowling et al., 2019; Whatman et al., 2019). The SEL process follows 5 competencies: social awareness, self-management, self-awareness, responsible decision making, and relationship skills. These 5 competencies provide a foundation for healthy development and promote positive social and emotional development. Each activity provided in the sessions corresponded to at least one SEL competency to help develop certain skills in the youth. Some of the questions that were asked to the youth during the open discussion were based on the SEL competencies to assure youth were critically thinking of the skills and concepts grasped from the activities. The outcomes of the program aligned with the SEL process because the youth were given engaging and purposeful activities to learn from such as managing their emotions, problem-solving, understanding the perspectives of others, and working with one another.

\section{Consistencies and Inconsistencies}

Few consistencies and inconsistencies occurred throughout the program. Inconsistencies mainly occurred during the first 3 weeks of the program when it would run from 2 p.m. to 3 p.m. on Mondays and Wednesdays. Of the 6 sessions that occurred those 3 weeks, sessions would range from 1 to 6 participants, in which 3 of those sessions consisted of only 2 participants. 
Many of the youth were allowed outside of Covenant House Florida during the time the program was held, therefore great inconsistency with participants would occur. When the program times changed to the evenings from 7 p.m. to 8 p.m. significant consistency in participants was noted. The remaining 10 sessions would range from 1 to 12 participants, with most of the sessions having a minimum of 5 participants. Attendance also became consistent with some of the participants who attended 3 to 4 consistent sessions, however, many left the facility or had work duties being unable to attend or complete the program.

\section{Strengths and Limitations}

The occupation-based program was developed and implemented to provide at-risk youth opportunities to engage in purposeful and meaningful activities while developing the necessary skills of social participation and self-regulation, to decrease maladaptive behaviors and prevent youth violence. The program would additionally increase safe and positive lifestyle choices for the future of the at-risk youth. Further developing social participation and self-regulation skills will enable at-risk youth to develop and maintain positive relationships, increase self-esteem, and build the self-efficacy to respond effectively in diverse situations (Bonell et al., 2018).

\section{Strengths}

The implementation of the program provided several strengths for the project. Providing group activities allowed for increased engagement and interaction with participants to primarily target social participation and self-regulation skills. All activities within the program were enjoyed by if not all, most of the participants evidenced by positive verbal comments during the activities or written comments on the survey questionnaires made throughout the sessions. Before the program, minimal activities were provided at Covenant House, particularly due to COVID-19 and a decrease in staff. Therefore, with the implementation of the program additional 
activities were provided, allowing the youth to have more options to participate in other activities not often seen.

The program, being a length of 8 weeks, was a strength. The change of times or days for the program was possible to see if more participants would join. If the program was a shorter duration, it may have been too late or unforeseen to consider changing the times. Initially, the program was held during early afternoons from 2 p.m. to 3 p.m., however, only a few participants would show. After 3 weeks, it was decided to change the program to evening times from 7 p.m. to 8 p.m., in which more participants would come for the program. The increase in participants during the evening times may have been due to youth being unable to leave Covenant House after 5 p.m. unless they attend work. Additional strengths of the program included the ample amount of space to provide the activities, gifts, or prizes that Covenant House provided to utilize in some of the activities for the youth to be more engaged, and materials provided by Covenant House to facilitate the sessions.

\section{Delimitations}

Delimitations made before beginning the project experiential hours were consistent throughout the entire duration of the project. The project took place in Fort Lauderdale, Florida with at-risk youth living at Covenant House. Occupation-based interventions were used throughout the program to support participant's engagement in occupations such as social participation, leisure, play, and education. A variety of activities were included such as gardening, painting, and team-building exercises.

\section{Assumptions}

Few assumptions made prior to the experiential hours were consistent and changed throughout the program. It was assumed that youth were honest in their survey questionnaires 
and pre-and post- measures provided for the program. However, it became evident that some of the youth were not being fully honest on the survey questionnaires, causing a limitation to occur. It was assumed that participants would fully participate throughout the program, which they did. Lastly, it was an assumption that some of the participants required interventions to improve or increase their social participation and self-regulation skills. When facilitating the program, several participants mentioned wanting to improve their social engagement skills. Other participants within the program did not mention wanting to improve any skills, however, displayed negative behaviors, such as low impulse control or defiance. The demonstration of these negative behavior's aids in the assumption that participants would benefit from interventions and the occupation-based program to improve social participation and selfregulation skills.

\section{Limitations}

Several limitations occurred throughout the capstone experience that was expected as well as unforeseen. Limitations made prior to starting the experiential hours were the sample size of participants, the cost of materials and activities that needed to be considered, and not following-up with staff at Covenant House to determine if social participation and self-regulation skills have maintained or declined since the program. Another limitation is the length of time to conduct the study because the experiential hours were for a duration of 14 weeks.

The sample size of the participants was less than hoped for due to youth attending school, work, or a program required at Covenant House. In addition, some youth would prefer to partake in another activity other than the program, such as leaving the site, spending time with friends, or being on an electronic device. In some cases, throughout the program, the cost or availability of materials was considered, which was a limitation to have a session a certain way or as hoped. For 
example, during the gardening session, it would have been greater if a garden bed were provided or cost-effective to allow youth to engage with one another more in building a garden than to garden plants individually. Although experiential hours for the project were 14 weeks, the program itself was for 8 weeks, twice a week. The short duration of the program was a limitation to see significant changes in the pre-and post-measures provided by the youth to help determine the effectiveness of the program. The length of the sessions itself may also be a limitation because it could have been longer to further build the skills with the participants. No follow-up has been made with Covenant House to determine if the youth who have participated in the program have maintained or declined in social participation and self-regulation skills since the end of the program.

Through the ongoing course of the project, additional limitations were identified. Having an open group versus a closed group of participants made it difficult to properly measure the effectiveness of the program with the pre-and post-measures of the participants because of the constant change of participants joining the sessions. Following COVID-19 guidelines, such as wearing masks and no physical contact with others, required activities in the program to be adjusted or removed, such as in the field day activity. Throughout the experiential hours at Covenant House, many of the youth did not provide ideas or suggestions for activities to be implemented into the program creating a challenge to consider and incorporate more meaningful activities of interest. In some sessions, some of the youth would not actively engage in open discussions at the end of the activity, limiting the ability to determine if the youth are learning from the program or understanding the main concept of the activity provided. Moreover, it was noted that some youth would go straight through the survey questionnaires and circle an answer than take the time to read the statements or questions provided. As a result, some of the answers 
provided from the survey questionnaires about the sessions may not be considered accurate or reliable information to determine the effectiveness of the program. Youth providing unthoughtful answers to the questionnaires could potentially be because some of the youths are not interested in performing a task they don't want to do, such as taking the time to read something they are uninterested in. Despite being unable to prevent the limitations from occurring, the limitations have impacted the outcomes of the project.

\section{Future Recommendations}

Based on the outcomes of this capstone experience project, the occupation-based program can become a useful tool for OTs working with at-risk youth and for Covenant House Florida to sustain with the youth. Youth participating in the program primarily demonstrated positive behaviors and interactions with others and agreed that the sessions provided were meaningful, engaging, and further developed social participation and self-regulation skills. For future projects, it is recommended to utilize other activities that may be purposeful and interesting to the youth, especially activities that may require more cost if they fit the financial budget. Another recommendation for future projects is to have a closed group of participants instead of an open group for consistency of the participants. If future projects are held for a much longer duration than 14-weeks and with consistent participants, then an Institutional Review Boards (IRB) approval would be recommended to determine if the participants within the occupationbased program are truly improving their social participation and self-regulation skills.

At-risk youth will benefit from the occupation-based program because it offers leisure activities that provide opportunities to develop social interaction skills, manage emotions, think responsibly, and problem-solve. Whether at Covenant House or other locations with at-risk

youth, this population can learn to decrease their maladaptive behaviors or prevent themselves 
from participating in youth violence with the program. The occupation-based program aims to improve social participation and self-regulation skills by providing purposeful, healthy, and ageappropriate activities that can help at-risk youth change their negative habits and behaviors to more positive habits and behaviors. At-risk youth will be able to carry on their newly developed behaviors and attitudes with them within their environment and help create a positive atmosphere. Moreover, further developing their social participation and self-regulation skills will enable them to be successful as they transition into adulthood and handle normal life stressors appropriately, such as employment, finances, parenting, and secondary or postsecondary education.

The capstone experience project highlights how occupational therapy could help the atrisk youth population. OTs understanding the benefits of providing activities and occupations during their interventions and treatment plans. Providing activities and occupations based on the client's interests provides a means to motivate and engage individuals to participate which also helps to improve their mental health and self-awareness. OTs can work alongside other mental health professionals, such as psychologists and social workers, to help at-risk youth and to help improve their social participation and self-regulation skills with various activities. Professionals and staff at Covenant House Florida will be more aware of OT's role and implement strategies provided to them based on the program and evidence provided by the author. Moreover, because they recently learned by the author that an occupational therapist currently works at Covenant House Toronto, the staff may potentially hire an occupational therapist in the future for Covenant House Florida. The author believes many mental health professionals consider OTs to be helpful in the physical health aspect when that is not the only case. More advocacy on the profession of 
occupational therapy needs to be made aware of and how mental health is a component for occupational therapy interventions, especially when helping at-risk youth.

\section{Conclusion}

The purpose of the capstone project was to develop and implement an occupation-based program for at-risk youth to improve their social participation and self-regulation skills to prevent maladaptive behavior and youth violence. At-risk youth face constant stressors or trauma that impact their abilities to manage their emotions, interact appropriately, develop healthy relationships, and make responsible decisions within their environment. These poor abilities not only impact social participation and self-regulation skills but can influence a youth's self-esteem and lower their self-efficacy due to the dissatisfaction they may feel within themselves. Both social participation and self-regulation skills may be influenced by surrounding factors such as their environment, family, peers, and resources (Gestsdottir et al., 2014). If one of these factors is lacking or negatively influencing a youth, this may cause poor personality and intellectual development. Limitations in social-emotional development can affect youth to become independent and active individuals in their communities (Gestsdottir et al., 2014).

Mental health professionals, such as social workers, psychologists, and psychiatrists, and other professionals, including school counselors and teachers, are primarily mentioned within the literature to help at-risk youth. However, despite occupational therapy being well-grounded in the metal health field, OTs are not often considered as mental health professionals or seen to work with at-risk youth. Completing the experiential hours at Covenant House Florida allowed the author to see firsthand the behaviors demonstrated by the youth. Despite not knowing indepth the past histories of the youth, poor social participation and self-regulation skills were noted or mentioned by some of the youth. 
The occupation-based program provided activities that were engaging and pleasurable for the youth, thus providing a means to participate in leisure, social participation, and play occupations. The use of activities and group sessions demonstrated healthy and positive behaviors and social engagement in the participants which can improve social participation, selfregulation skills, and mental health in youth. Additionally, the program provides the opportunity to further discuss activities held and how concepts learned or grasped from the activity can be applied in present or future situations and challenges. The author believes the occupation-based program would be effective if sustained at Covenant House Florida. Youth will have the opportunities to interact with others, share similar interests, learn to listen, and manage emotions appropriately, and learn from different perspectives of a person. The results and outcomes of this capstone project provided the evidence demonstrating the role of occupational therapy and how an occupation-based program can improve social participation and self-regulation skills in at-risk youth. 


\section{References}

Abaoğlu H., Buket Cesim, O., Kars, S. \& Çelik, Z. (2017). Life skills in occupational therapy. In M. Huri (Ed.) Occupational therapy - occupation focused holistic practice in rehabilitation (pp. 49-65) IntechOpen. http://doi:10.5772/intechopen.68462.

Al-Mehsin, S. A. (2017). Self-efficacy and its relationship with social skills and the quality of decision-making among the students of Prince Sattam Bin Abdul-Aziz University. International Education Studies, 10(7), 108-117. http://doi:10.5539/ies.v10n7p108

American Occupational Therapy Association. (2008). AOTAs societal statement on youth violence. American Journal of Occupational Therapy, 62(6), 709-710. http://doi: 10.5014/ajot.62.6.709

American Occupational Therapy Association. (2017). Mental health promotion, prevention, and intervention in occupational therapy practice. American Journal of Occupational Therapy, 71(2), 7112410035. https://doi.Org/10.5014/ajot.2017.716S03

American Occupational Therapy Association. (2020) Occupational therapy practice framework: domain \& process ( $4^{\text {th }}$ ed.). The American Journal of Occupational Therapy, 74(2), S1-S87. https://doi.org/10.5014/ajot.2020.74S2001

American Occupational Therapy Association. 2015. Occupational therapy code of ethics. The American Journal of Occupational Therapy. 69(3). 1-8. https://doi.org/10.5014/ajot.2015.696S03

American Psychological Association. (2017, July). Education and socioeconomic status. https://www.apa.org/pi/ses/resources/publications/education

American Psychological Association. (n.d.). Socioeconomic status. https://www.apa.org/topics/socioeconomic-status/ 
Anderson, M. \& Grinder, S. (2017). Occupational therapy’s role in social-emotional development throughout childhood. OT Practice, 22(7), CE1-CE8. https://search.proquest.com/docview/1892742510?accountid=158603

Annesi James, J., Walsh, S. M., \& Greenwood, B. L. (2016). Increasing children's voluntary physical activity outside of school hours through targeting social cognitive theory variables. Journal of Primary Care \& Community Health, 7(4), 234-241. http://dx.doi.org/10.1177/2150131916656177

Arbesman, M., Bazyk, S., \& Nochajski, S. M. (2013). Systematic review of occupational therapy and mental health promotion, prevention, and intervention for children and youth. American Journal of Occupational Therapy, 67(6), 120-130. http://doi.org/10.5014/ajot.2013.008359

Artuch-Garde, R., González-Torres, M. D. C., Fuente, J. D. L., Vera, M. M., FernándezCabezas, M., \& López-García, M. (2017). Relationship between resilience and selfregulation: A study of Spanish youth at risk of social exclusion. Frontiers in Psychology, 8. http://doi.org./10.3389/fpsyg.2017.00612

Atienzo, E. E., Baxter, S. K., \& Kaltenthaler, E. (2016). Interventions to prevent youth violence in Latin America: A systematic review. International Journal of Public Health, 62(1), 15-29. http://doi.org/10.1007/s00038-016-0909-6

At-Risk Youth Programs Editorial Team. (2021, February 22). At risk youth statistics 2020: Have they changed for better or worse over the past decade? Retrieved from, https://atriskyouthprograms.com/information-on-at-risk-youth-statistics/

Balli, D. (2016). Role and challenges of school social workers in facilitating and supporting the 
inclusiveness of children with special needs in regular schools. Academicus, (14), 148157. http://dx.doi.org/10.7336/academicus.2016.14.10

Baltag, V., Pachyna, A., \& Hall, J. (2015). Global overview of school health services: Data from 102 countries. Health Behavior and Policy Review, 2(4), 268-283. http://doi.org/10.14485/hbpr.2.4.4

Barnes, A., Lafavor, T., Cutuli, J., Zhang, L., Oberg, C., \& Masten, A. (2017). Health and selfregulation among school-age children experiencing family homelessness. Children, 4(8), 1-11. http://doi.org/10.3390/children4080070

Bazyk, S., Demirjian, L., LaGuardia, T., Thompson-Repas, K., Conway, C., \& Michaud, P. (2015). Building capacity of occupational therapy practitioners to address the mental health needs of children and youth: A mixed-methods study of knowledge translation. American Journal of Occupational Therapy, 69(6), 1-10. http://dx.doi.org/10.5014/ajot.2015.019182

Benson, J. D., Szucs, K. A., \& Mejasic, J. J. (2016). Teachers' perceptions of the role of occupational therapist in schools. Journal of Occupational Therapy, Schools, \& Early Intervention, 9(3), 290-301. http://doi.org/10.1080/19411243.2016.1183158

Bonell, C., Allen, E., Warren, E., Mcgowan, J., Bevilacqua, L., Jamal, F., ... Viner, R. M. (2018). Effects of the learning together intervention on bullying and aggression in English secondary schools (inclusive): A cluster randomized controlled trial. The Lancet, 392(10163), 2452-2464. http://doi.org/10.1016/s0140-6736(18)31782-3

Bonell, C., Hinds, K., Dickson, K., Thomas, J., Fletcher, A., Murphy, S., ... Campbell, R. (2016). What is positive youth development and how might it reduce substance use and 
violence? A systematic review and synthesis of theoretical literature. BMC Public Health, 16(136), 1-13. http://doi.org/10.1186/s12889-016-28173

Bowyer, P., Munoz, L., Tkach, M. M., Moore, C. C., \& Tiongco, C. G. (2019). Long-term impact of model of human occupation training on therapeutic reasoning. Journal of Allied Health, 48(3), 188-193. Retrieved from https://search.proquest.com/docview/2292895777?accountid=158603

Burger, K., \& Samuel, R. (2017). The role of perceived stress and self-efficacy in young people's life satisfaction: A longitudinal study. Journal of Youth and Adolescence, 46(1), 78-90. http://dx.doi.org/10.1007/s10964-016-0608-x

Buzgar, R., \& Giurgiuman, T. (2019). Teaching social and emotional competencies: A pilot survey on social and emotional learning programs implemented in Romania. Journal of Educational Sciences and Psychology, 9(71) 10-16. Retrieved from https://search.proquest.com/docview/2302389428?accountid=158603

Cadima, J., Verschueren, K., Leal, T., \& Guedes, C. (2016). Classroom interactions, dyadic teacher-child relationships, and self-regulation in socially disadvantaged young children. Journal of Abnormal Child Psychology, 44(1), 7-17. http://dx.doi.org/10.1007/s10802-015-0060-5

Cahill, S. M., Egan, B. E., \& Seber, J. (2020a). Activity- and occupation-based interventions to support mental health, positive behavior, and social participation for children and youth: A systematic review. American Journal of Occupational Therapy, 74(2), 1-28. http://doi.org/10.5014/ajot.2020.038687

Cahill, S. M., \& Egan, B. E. (2017b). Perceptions of occupational therapy involvement in school mental health: A pilot study. The Open Journal of Occupational Therapy, 5(1), 1-10. 
http://dx.doi.org/10.15453/2168-6408.1281

Capuzzi, D., \& Gross, D. R. (Eds.). (2019). Youth at risk: A prevention resource for counselors, teachers, and parents. ProQuest eBook Central. https://ebookcentral.proquest.com

Centers for Disease Control and Prevention. (2020, August 20). CDC releases 2019 youth risk behavior survey results. Retrieved from https://www.cdc.gov/healthyyouth/data/yrbs/feature/index.htm

Centers for Disease Control and Prevention. (2020, March 30). Data and statistics on children's mental health. Retrieved from https://www.cdc.gov/childrensmentalhealth/data.html\#ref

Center for Disease Control and Prevention. (2019, February 27). Prevention strategies. Retrieved from https://www.cdc.gov/violenceprevention/youthviolence/prevention.html

Children's Defense Fund. (2019, October 10). New census data reveals continued child poverty crisis in America. Retrieved from https://www.childrensdefense.org/2019/newcensus-data-reveals-continued-child-poverty-crisis-in-america/

Children's Social Work Matters. (n.d.) Roles and Career Progression. https://www.childrenssocialworkmatters.org/csw-roles/

Chong, A. M., Lee, P. G., \& Baba, M. (2015). Emotional intelligence and at-risk students. SAGE Open, 1-8. http://doi.org/10.1177/2158244014564768

Chung, S., \& McBride, A. M. (2015). Social and emotional learning in middle school curricula: A service-learning model based on positive youth development. Children and Youth Services Review, 53, 192-200. http://doi.org/10.1016/j.childyouth.2015.04.008

Cid, A. (2016). Interventions using regular activities to engage high-risk school-age youth: A review of after-school programs in Latin America and the Caribbean. Prevention Science, 18(7), 879-886. http://doi.org/10.1007/s11121-016-0708-6 
Covenant House Florida (n.d.). Frequently Asked Questions. https://www.covenanthousefl.org/

Crawford, C., \& Burns, R. (2016). Reducing school violence. Policing: An International Journal of Police Strategies \& Management, 39(3), 455-477. http://doi.org/10.1108/pijpsm-052016-0061

de Matos, M. G., \& Simões, C. (2016). From positive youth development to youth's engagement: The dream teens. International Journal of Emotional Education, 8(1), 4-17. Retrieved from https://search.proquest.com/docview/1788745408?accountid=158603

De Wet, N., Somefun, O., \& Rambau, N. (2018). Perceptions of community safety and social activity participation among youth in South Africa. PLoS One, 13(5) http://dx.doi.org/10.1371/journal.pone.0197549

Demarco, J., Llan-Clarke, Y., Bunn, A., Isaac, T., Criddle, J., Holdsworth, G., \& Bifulco, A. (2016). Improving mental health and lifestyle outcomes in a hospital emergency department based youth violence intervention. Journal of Public Mental Health, 15(3), 119-133. http://doi.org/10.1108/jpmh-07-2015-0031

Devenish, B., Hooley, M., \& Mellor, D. (2017). The pathways between socioeconomic status and adolescent outcomes: A systematic review. American Journal of Community Psychology, 59(1), 219-221,223-224,230-238. http://dx.doi.org/10.1002/ajcp.12115

Dowling, K., Simpkin, A. J., \& Barry, M. M. (2019). A cluster randomized-controlled trial of the MindOut social and emotional learning program for disadvantaged post-primary school students. Journal of Youth and Adolescence, 48(7), 1245-1263. http://dx.doi.org/10.1007/s10964-019-00987-3 
Esen-Aygun, H., \& Sahin-Taskin, C. (2017). Teachers' views of social-emotional skills and their perspectives on social-emotional learning programs. Journal of Education and Practice, 8(7), 205-215. https://files.eric.ed.gov/fulltext/EJ1137527.pdf

Espelage, D. L., Merrin, G. J., Hong, J. S., \& Resko, S. M. (2018). Applying social cognitive theory to explore relational aggression across early adolescence: A within- and between-person analysis. Journal of Youth and Adolescence, 47(11), 2401-2413. http://doi.org/10.1007/s10964-018-0910-x

Farajzadegan, Z., Golshiri, P., Tavakoli, A., \& Heidari, K. (2018). Youth violence and related risk factors: A cross-sectional study in 2800 adolescents. Advanced Biomedical Research, 7(1), 1-8. http://doi.org/10.4103/abr.abr_137_18

Forrest-Bank, S. S., Nicotera, N., Bassett, D. M., \& Ferrarone, P. (2016). Effects of an expressive art intervention with urban youth in low-income neighborhoods. Child and Adolescent Social Work Journal, 33(5), 429-441. http://doi.org/10.1007/s10560-0160439-3

Frost, N. (2017). From "silo" to "network" profession - a multi-professional future for social work. Journal of Children's Services, 12(2-3), 174-183. http://dx.doi.org/10.1108/JCS05-2017-0019

Gallagher, M., Muldoon, O. T., \& Pettigrew, J. (2015a). An integrative review of social and occupational factors influencing health and wellbeing. Frontiers in Psychology, 6. http://doi.org/10.3389/fpsyg.2015.01281

Gallagher, M., Muldoon, O., Pettigrew, J., (2015b). Occupational choice of youth in a disadvantaged community. British Journal of Occupational Therapy, 78(10), 622-629. http://doi.org10.1177/0308022615583065 
Gestsdottir, S., Geldhof, G. J., Paus, T., Freund, A. M., Adalbjarnardottir, S., Lerner, J. V., \& Lerner, R. M. (2014). Self-regulation among youth in four Western cultures. International Journal of Behavioral Development, 39(4), 346-358. http:doi.org/10.1177/0165025414542712

Graham, A., Harbottle, C., \& King, D. (2016). Resolve: A community-based forensic learning disability service specialising in supporting male sex offenders - our model, approach and evidence base for effective intervention. Journal of Intellectual Disabilities and Offending Behaviour, 7(4), 186-194. http://dx.doi.org/10.1108/JIDOB-10-2014-0014

Griswold, L. A. (2016). Promoting a student's social interaction skills to enhance participation with peers. SIS Quarterly Practice Connections. 1(3), 4-6.

Haggis, D. (2017). Influencing positive outcomes for troubled youth. Contemporary Issues in Education Research (CIER), 10(3), 179-184. http://doi.org/10.19030/cier.v10i3.9978

Hardaway, C. R., Sterrett-Hong, E., Larkby, C. A., \& Cornelius, M. D. (2016). Family resources as protective factors for low-income youth exposed to community violence. Journal of Youth and Adolescence, 45(7), 1309-1322. http://doi.org/10.1007/s 10964-015-0410-1

Hines, E. M., Moore, J. L., Mayes, R. D., Harris, P. C., Vega, D., Robinson, D. V., ... Jackson, C. E. (2017). Making student achievement a priority: The role of school counselors in turnaround schools. Urban Education, 55(2), 216-237. http://doi.org/10.1177/0042085916685761

Holland, K. M., Vivolo-Kantor, A., Logan, J. E., \& Leemis, R. W. (2017). Antecedents of suicide among youth aged 11-15: A multistate mixed methods analysis. Journal of Youth and Adolescence, 46(7), 1598-1610. http://dx.doi.org/10.1007/s10964-016-0610-3

Hopper, T. D., \& Iwasaki, Y. (2017). Engagement of 'at-risk' youth through meaningful 
leisure. Journal of Park and Recreation Administration, 35(1). Retrieved from https://search.proquest.com/docview/2006816320?accountid=158603

Hosokawa, R., \& Katsura, T. (2018). Socioeconomic status, emotional/behavioral difficulties, and social competence among preschool children in Japan. Journal of Child and Family Studies, 27(12), 4001-4014. http://dx.doi.org/10.1007/s10826-018-1231-0

Ioannou, M., Hammond, L., \& Simpson, O. (2015). A model for differentiating school shooters characteristics. Journal of Criminal Psychology, 5(3), 188-200. http://dx.doi.org/10.1108/JCP-06-2015-0018

Ivzori, Y., Sachs, D., Reiter, S., \& Schreuer, N. (2020). Transition to employment program (SUPER) for youth at risk: A conceptual and practical model. International Journal of Environmental Research and Public Health, 17(11), 3904. http://dx.doi.org/10.3390/ijerph17113904

Jaegers, L. A., Skinner, E., Conners, B., Hayes, C., West-Bruce, S., Vaughn, M. G., . . . Barney, K. F. (2020). Evaluation of the jail-based occupational therapy transition and integration services program for community reentry. American Journal of Occupational Therapy, 74(3), 7403205030. https://doi.org/10.5014/ajot.2020.035287

January, S. A., Duppong Hurley, K., Stevens, A. L., Kutash, K., Duchnowski, A. J., \& Pereda, N. (2016). Evaluation of a community-based peer-to-peer support program for parents of atrisk youth with emotional and behavioral difficulties. Journal of Child and Family Studies, 25(3), 836-844. http://dx.doi.org/10.1007/s10826-015-0271-y

Jones, D. E., Greenberg, M., \& Crowley, M. (2015). Early social-emotional functioning and public health: The relationship between kindergarten social competence and future wellness. American Journal of Public Health, 105(11), 2283-2290. 
http:/doi.org/10.2105/ajph.2015.302630

Jonson, C. L. (2017) Preventing school shootings: The effectiveness of safety measures, victims \& offenders. An International Journal of Evidence-based Research, Policy, and Practice 12(6), 956-973. http://doi.org/10.1080/15564886.2017.1307293

Juan, S.-C., \& Hemenway, D. (2017). From depression to youth school gun carrying in America: Social connectedness may help break the link. Cogent Social Sciences, 3(1), 1-5. http://doi.org/10.1080/23311886.2017.1314877

Knol, L. L., Myers, H. H., Black, S., Robinson, D., Awololo, Y., Clark, D., . . . Higginbotham, J. C. (2016). Development and feasibility of a childhood obesity prevention program for rural families: Application of the social cognitive theory. American Journal of Health Education, 47(4), 204-214. Retrieved from https://search.proquest.com/docview/1807691945?accountid=158603

Koc, N., \& Celik, B. (2015). The impact of number of students per teacher on student achievement. Procedia - Social and Behavioral Sciences, 177, 65-70. https://doi.org/10.1016/j.sbspro.2015.02.335

Kos, D., Duportail, M., Meirte, J., Meeus, M., D’hooghe, M. B., Nagels, G., . . Nijs, J. (2016). The effectiveness of a self-management occupational therapy intervention on activity performance in individuals with multiple sclerosis-related fatigue: A randomizedcontrolled trial. International Journal of Rehabilitation Research, 39(3), 255-262. http://doi.org/10.1097/mrr.0000000000000178

Kundu, A., \& Debdulal, D. R. (2016). Innovative work behaviour of schoolteachers: Role of belief for innovation and personality patterns. Journal of Organization and Human Behaviour, 5(1) Retrieved from 
https://search.proquest.com/docview/1774430912?accountid=158603

Lee, Y. S., \& Jonson-Reid, M. (2015). The role of self-efficacy in reading achievement of young children in urban Schools. Child and Adolescent Social Work Journal, 33(1), 7989. http://doi.org/10.1007/s10560-015-0404-6

Leigers, K., Myers, C., \& Schneck, C. (2016). Social participation in schools: A survey of occupational therapy practitioners. American Journal of Occupational Therapy, 70, 7005280010. http://dx.doi.org/10.5014/ajot.2016.020768

Lodder, G. M., A., Goossens, L., Scholte, R. H., J., Engels, R. C., . . Verhagen, M. (2016). Adolescent loneliness and social skills: Agreement and discrepancies between self-, meta-, and peer-evaluations. Journal of Youth and Adolescence, 45(12), 2406-2416. http://dx.doi.org/10.1007/s10964-016-0461-y

Lohhndorf, R. T., Vermeer, H. J., Carcamo, R., A., \& Mesman, J. (2018). Preschoolers' vocabulary acquisition in Chile: The roles of socioeconomic status and quality of home environment. Journal of Child Language, 45(3), 559-580. http://dx.doi.org/10.1017/S0305000917000332

Mahaffey, L. M. (2016). Mental health in children and youth: The benefit and role of occupational therapy. American Occupational Therapy Association. https://www.aota.org/About-Occupational-Therapy/Professionals/MH/children-youthmental-health.aspx

Malla, A., Iyer, S., Mcgorry, P., Cannon, M., Coughlan, H., Singh, S., . . Joober, R. (2016). From early intervention in psychosis to youth mental health reform: A review of the evolution and transformation of mental health services for young people. Social Psychiatry and Psychiatric Epidemiology, 51(3), 319-326. 
http://dx.doi.org/10.1007/s00127-015-1165-4

Martinez, G. F., \& Deil-Amen, R. (2015). College for all Latinos? The role of high school messages in facing college challenges. Teachers College Record, 117(3), 1-50. Retrieved from https://search.proquest.com/docview/1697504116?accountid=158603

Mcdaniel, S. C., Bruhn, A. L., \& Troughton, L. (2016). A brief social skills intervention to reduce challenging classroom behavior. Journal of Behavioral Education, 26(1), 5374. http://doi.org/10.1007/s10864-016-9259-y

American Occupational Therapy Association. (2017). Mental health promotion, prevention, and intervention in occupational therapy practice. The American Journal of Occupational Therapy, 71, 1-19. Retrieved from https://search.proquest.com/docview/1985875517?accountid=158603

Merali, N. (2017). The role of school counsellors in the national aboriginal youth suicide prevention strategy: An illustration. Canadian Journal of Counselling and Psychotherapy (Online), 51(3), 246-265. Retrieved from https://search.proquest.com/docview/2078624726?accountid=158603

Minney, D., Garcia, J., Altobelli, J., Perez-Brena, N., \& Blunk, E. (2019). Social-emotional learning and evaluation in after-school care: A working model. Journal of Youth Development, 14(3), 130-145. http://dx.doi.org/10.5195/jyd.2019.660

Modzeleski, W. (2018). School threat assessment in the USA: Lessons learned from 15 years of teaching and using the federal model to prevent school shootings. Contemporary School Psychology, 22(2), 109-115. http://doi.org/10.1007/s40688-018-0188-8

Murdoch, K. C., \& Larsen, D. (2018). Experiences of hope for youth workers engaging at-risk 
and street-involved young people: Applications to the field of counselling and psychotherapy. Canadian Journal of Counselling and Psychotherapy (Online), 52(4), 319-338. Retrieved from https://search.proquest.com/docview/2137435395?accountid=158603

Nabors, L., Poteet, A., Clare, Z. B., \& Kamphaus, A. (2019). Adolescents as coaches during service-learning: Teaching children social and emotional skills. Child \& Youth Care Forum, 48(5), 719-736. http://dx.doi.org/10.1007/s10566-019-09503-x

Nols, Z., Haudenhuyse, R., \& Theeboom, M. (2017). Urban sport-for-development initiatives and young people in socially vulnerable situations: Investigating the 'deficit model'. Social Inclusion, 5(2), 210-222. http://dx.doi.org/10.17645/si.v5i2.881

O’Conner, R., De Feyter, J., Carr, A., Luo, J. L., \& Romm, H. (2017). A review of the literature on social and emotional learning for students ages 3-8: Characteristics of effective social and emotional learning programs (part 1 of 4). Regional Educational Laboratory MidAtlantic, 1-31. Retrieved from https://search.proquest.com/docview/1895979762?accountid=158603

Oscós-Sánchez, M. Á. (2017). Youth violence and mental health: Repeating exposures. International Journal of Human Rights in Healthcare, 10(3), 174-186. http://dx.doi.org/10.1108/IJHRH-02-2017-0007

Park, J., Gross, D. P., Rayani, F., Norris, C. M., Roberts, M. R., James, C., ... Esmail, S. (2019). Model of human occupation as a framework for implementation of motivational Interviewing in occupational rehabilitation. Work, 62(4), 629-641. http://doi.org10.3233/wor-192895

Parsons, H., \& Saffer, A. (2018, June 4). Fighting for adequate federal, state, and local 
education funding. Retrieved from https://www.aota.org/PublicationsNews/otp/Archive/2018/Fighting-for-Adequate-Federal-State-Local-EducationFunding.aspx

Patel, M. M., Liddell, J. L., \& Ferreira, R. J. (2018). An evaluation of the positive action program for youth violence prevention: From schools to summer camps. Child and Adolescent Social Work Journal, 35(5), 519-530. http://doi.org/10.1007/s10560-0180536-6

Pears, K. C., Kim, H. K., Healey, C. V., Yoerger, K., \& Fisher, P. A. (2015). Improving child self-regulation and parenting in families of pre-kindergarten children with developmental disabilities and behavioral difficulties. Prevention Science, 16(2), 222-232. http://dx.doi.org/10.1007/s11121-014-0482-2

Pfeiffer, B., Clark, G. F., \& Arbesman, M. (2017). Effectiveness of cognitive and occupation-based interventions for children with challenges in sensory processing and integration: A systematic review. American Journal of Occupational Therapy, 72(1). http://doi.org/10.5014/ajot.2018.028233

Pincham, H. L., Bryce, D., Fonagy, P., \& Fearon, R. M. P. (2018). Psychosocial intervention in at-risk adolescents: using event-related potentials to assess changes in decision making and feedback processing. European Child \& Adolescent Psychiatry, 28(2), 223-236. http://doi.org/10.1007/s00787-018-1167-3

Piškur, B., Daniëls, R., Jongmans, M. J., Ketelaar, M., Smeets, R. J., Norton, M., \& Beurskens, J. (2014). Participation and social participation: Are they distinct concepts? Clinical Rehabilitation, 28(3), 211-220. https://doi.org/10.1177/0269215513499029

Popova, E. S., \& Wescott, J. J. (2019). Art as occupation: Promoting the occupational therapy 
role in evaluating community-based programs. SIS Quarterly Practice Connections, 4(1), $5-7$.

Preyde, M., Parekh, S., Warne, A., \& Heintzman, J. (2017). School reintegration and perceived needs: The perspectives of child and adolescent patients during psychiatric hospitalization: C \& A. Child \& Adolescent Social Work Journal, 34(6), 517-526. http://dx.doi.org/10.1007/s10560-017-0490-8

Ridings, L. E., Beasley, L. O., \& Silovsky, J. F. (2017). Consideration of risk and protective factors for families at risk for child maltreatment: An intervention approach. Journal of Family Violence, 32(2), 179-188. http://dx.doi.org/10.1007/s10896-016-9826-y

Youth.Gov. (n.d.) Risk and Protective Factors.

https://youth.gov/youth-topics/youth-mental-health/risk-and-protective-factors-youth

Robertson, D. L., Lloyd-Hazlett, J., Zambrano, E., \& McClendon, L. (2016). Program directors’ perceptions of school counselor roles. Journal of Professional Counseling, Practice, Theory, \& Research, 43(2), 1-13. Retrieved from https://search.proquest.com/docview/1906364743? accountid=158603

Salimi, N., Karimi-Shahanjarini, A., Rezapur-Shahkolai, F., Hamzeh, B., Roshanaei, G., \& Babamiri, M. (2019). Aggression and its predictors among elementary students. Journal of Injury and Violence Research, 11(2), 159-170. http://dx.doi.org/10.5249/jivr.v11i2.1102

Samson, D. O., \& Sankar, U, G. (2018). A study to assess levels of aggressive and violent behavior in high school adolescents and potential roles of occupational therapy. Biosciences Biotechnology Research Asia, 15(4), 1001-1006. http://dx.doi.org/10.13005/bbra/2713 Santamaría-García H., Baez, S., Gómez, C., Rodríguez-Villagra O., Huepe, D., Portela, M., .. . 
Agustin, I. (2020). The role of social cognition skills and social determinants of health in predicting symptoms of mental illness. Translational Psychiatry, 10(1) http://dx.doi.org/10.1038/s41398-020-0852-4

Schonert-Reichl, K. A. (2017). Social and emotional learning and teachers. The Future of Children, 27(1), 137-155. https://files.eric.ed.gov/fulltext/EJ1145076.pdf

Schwartz, D., Kelly, B. M., Mali, L. V., \& Duong, M. T. (2016). Exposure to violence in the community predicts friendships with academically disengaged peers during middle adolescence. Journal of Youth and Adolescence, 45(9), 1786-1799. http://doi.org/10.1007/s10964-016-0485-3

Scott, P. J., Cacich, D., Fulk, M., Michel, K., \& Whiffen, K. (2017). Establishing concurrent validity of the role checklist version 2 with the OCAIRS in measurement of participation: A pilot study. Occupational Therapy International, 2017 http://dx.doi.org/10.1155/2017/6493472

Serrano-villar, M., Huang, K., \& Calzada, E. J. (2017). Social support, parenting, and social emotional development in young Mexican and Dominican American children. Child Psychiatry and Human Development, 48(4), 597-609. http://dx.doi.org/10.1007/s10578016-0685-9

Shahraki-Sanavi, F., Ansari-Moghaddam, A., Mohammadi, M., Nour-Mohammad Bakhshani, \& Salehiniya, H. (2020). Effectiveness of school-based mental health programs on mental health among adolescents. Journal of Education and Health Promotion, 9(1), 142. http://dx.doi.org/10.4103/jehp.jehp_421_19

Shankar, S., Hubley, A. M. \& Zumbo, B. D. (2017). General, health-specific, and housing- 
specific self-efficacy scales: Preliminary reliability and validity evidence with homeless or vulnerably housed adults. Journal of Well-Being Assessment 1, 57-75. https://doi.org/10.1007/s41543-018-0005-1

Shea, C.-K., \& Jackson, N. (2014). Client perception of a client-centered and occupation-based intervention for at-risk youth. Scandinavian Journal of Occupational Therapy, 22(3), 173-180. http://doi.org/10.3109/11038128.2014.958873

Shewark, E. A., Zinsser, K. M., \& Denham, S. A. (2018). Teachers' perspectives on the consequences of managing classroom climate. Child \& Youth Care Forum, 47(6), 787 802. http://dx.doi.org/10.1007/s10566-018-9461-2

Sibinga, E., Copeland-Linder, N., Webb, L., Shields, A., \& Perry-Parrish, C. (2016). Improving self-regulation in adolescents: current evidence for the role of mindfulness-based cognitive therapy. Adolescent Health, Medicine and Therapeutics, Volume 7, 101-108. http://doi.org/10.2147/ahmt.s65820

Simpson, E. K., Lukas, A., Jones, S., \& James. M. M. (2018). Leisure-based group intervention for at-risk, urban dwelling children. SIS Quarterly Practice Connections, 3(3), 16-18.

Slaten, C. D., Elison, Z. M., Hughes, H., Yough, M. \& Shemwell, D. (2015). Hearing the voices of youth at risk for academic failure: What professional school counselors need to know. The Journal of Humanistic Counseling, 54(3), 203-220. https://doi.org/10.1002/johc.12012

Slesnick, N., Zhang, J., \& Brakenhoff, B. (2017). Personal control and service connection as paths to improved mental health and exiting homelessness among severely marginalized homeless youth. Children and youth services review, 73, 121-127. https://doi.org/10.1016/j.childyouth.2016.11.033 
Tanner, K., Hand, B. N., O’Toole, G., \& Lane, A. E. (2015). Effectiveness of interventions to improve social participation, play, leisure, and restricted and repetitive behaviors in people with autism spectrum disorder: A systematic review. American Journal of Occupational Therapy, 69(5), 1-12. http://dx.doi.org/10.5014/ajot.2015.017806

Torchalla, I., Killoran, J., Fisher, D., \& Bahen, M. (2019). Trauma-focused treatment for individuals with posttraumatic stress disorder: The role of occupational therapy. Occupational Therapy in Mental Health, 35(4), 386-406. http://dx.doi.org/10.1080/0164212X.2018.1510800

Trancă, L. M. (2020). The role of social workers and current difficulties faced by social workers in the prevention of school dropout in western Romania. Revista De Asistenta Sociala, (1), 157-167. Retrieved from https://search.proquest.com/docview/2441573711 accountid=158603

Ungar, M., \& Ikeda, J. (2017). Rules or no rules? Three strategies for engagement with young people in mandated services: C \& A. Child \& Adolescent Social Work Journal, 34(3), 259-267. http://dx.doi.org/10.1007/s10560-016-0456-2

van der Stouwe, T., Asscher, J. J., Hoeve, M., van der Laan, P. H., \& Stams, G. J. M. (2016). Social skills training for juvenile delinquents: post-treatment changes. Journal of Experimental Criminology, 12(4), 515-536. http://doi.org/10.1007/s11292-016-9262-2

Viau, A., Denault, A., \& Poulin, F. (2015). Organized activities during high school and adjustment one year post high school: Identifying social mediators. Journal of Youth and Adolescence, 44(8), 1638-1651. http://dx.doi.org/10.1007/s10964-014-0225-5

Wesely, J. K., Dzoba, N. P., Miller, H. V., \& Rasche, C. E. (2017). Mentoring at-risk youth: An 
examination of strain and mentor response strategies. American Journal of Criminal Justice: AJCJ, 42(1), 198-217. http://dx.doi.org/10.1007/s12103-016-9353-7

Whatman, S., Thompson, R., \& Main, K. (2019). The recontextualization of youth wellbeing in Australian schools. Health Education, 119(5), 321-340. http://dx.doi.org/10.1108/HE-01-2019-0003

Whitten, T., Vecchio, N., Radford, K., \& Fitzgerald, J. A. (2017). Intergenerational care as a viable intervention strategy for children at risk of delinquency. Australian Journal of Social Issues, 52(1), 48-62. http://dx.doi.org/10.1002/ajs4.6

Yasuhiro, K., Su-Hie, T., \& Neary, S. (2021). Mental health of Malaysian university students: U.K comparison, and relationship between negative mental health attitudes, selfcompassion, and resilience. Higher Education, 81(2), 403-419. http://dx.doi.org/10.1007/s10734-020-00547-w

Yung, A. R. (2016). Youth services: The need to integrate mental health, physical health and social care: Commentary on malla et al.: From early intervention in psychosis to youth mental health reform: A review of the evolution and transformation of mental health services for young people. Social Psychiatry and Psychiatric Epidemiology, 51(3), 327329. http://dx.doi.org/10.1007/s00127-016-1195-6

Zhou, M. (2016). A revisit of general self-efficacy scale: Uni- or multi-dimensional? Research and reviews. Current Psychology, 35(3), 427-436. http://dx.doi.org/10.1007/s12144-0159311-4 


\title{
Appendix A
}

\author{
Memorandum of Understanding (MOU)
}

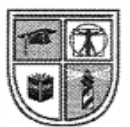

\section{University of St. Augustine \\ FOR H E A L T H S C I E N C E S}

Capstone Manual Appendix D

Memorandum of Understanding

Capstone Experience Course Numbers: OCT 6731 \& OCT 6832

\begin{abstract}
Purpose: The purpose of this memorandum is to establish, and confirm, an understanding between the doctoral candidate (student) and their supervisor at the mentored practice setting of their capstone experiential component. This understanding relates to the learning and outcome objectives to be addressed at the mentored practice setting (experiential site) by the doctoral candidate.
\end{abstract}

Mentored Practice Setting Name: Covenant House Florida

Address:

733 Breakers Ave \#4100, Fort Lauderdale, FL 33304

Mentored Practice Setting Supervisor:

Email address:

Work Phone:

Student Name: Jasmine Shahin

Dates of experience requested: 01/04/2021 - 04/09/2021

Email address: j.shahin@usa.edu

Work Phone: 786-380-3274

Home Phone:

Mentor: Dr. Marcia Hamilton

Doctoral Coordinator: Dr. Pamela Kasyan-Howe \& Dr. Kristen Domville

Responsibilities

Responsibilities of Student:

- Student will participate in at least 548 hours within the mentored practice setting

- Student initiate and track progress towards identified objectives and submit weekly timesheets (time logs)

- Student will regularly communicate progress to all involved parties

- Student will seek regular feedback on performance

\section{Responsibilities of Site Supervisor:}

- Advise and assist regarding orientation, scheduling, resources, and requirements of site

- Provide feedback on student performance as needed, including a midterm and final evaluation

- Confirm student hours of participation 
Capstone Topic: Improving social participation and self-regulation skills in at-risk youth with an occupation-based program

\begin{tabular}{|l|l|}
\multicolumn{1}{|c|}{\begin{tabular}{c}
\multicolumn{1}{|c|}{ Objectives for the Mentored Practice Setting } \\
(What the student will accomplish from this experience.
\end{tabular}} & $\begin{array}{c}\text { Progress/Expected } \\
\text { Completion Dates }\end{array}$ \\
\hline $\begin{array}{l}\text { Compare and contrast problems and issues at-risk youth experience that lead them to experience } \\
\text { maladaptive behaviors at Covenant House as compared to the literature. }\end{array}$ & Week 1 \\
\hline $\begin{array}{l}\text { Compare and contrast the problems experienced by at-risk youth, who experience/demonstrate } \\
\text { maladaptive behaviors, with poorly developed social participation and self-regulation skills. }\end{array}$ & Week 2 \\
\hline $\begin{array}{l}\text { Identify and describe professionals who serve at-risk youth with poor social participation and self- } \\
\text { regulation skills who experience maladaptive behaviors in the literature and at Covenant House }\end{array}$ & Week 3 \\
\hline $\begin{array}{l}\text { Conduct a needs assessment at a community center to learn the types of services provided, social } \\
\text { participation skills currently taught, and by which disciplines by 1 month of my program development } \\
\text { project. }\end{array}$ & Weeks 1-3 \\
\hline $\begin{array}{l}\text { Develop an occupation-based program to improve social participation skills and self-regulation skills } \\
\text { for at-risk youth - Develop and review with mentor and site mentor week 1 and 2 program. }\end{array}$ & Weeks 1-3 \\
\hline $\begin{array}{l}\text { Implement an occupation-based program to improve social participation skills and self-regulation skills } \\
\text { for at-risk youth by 2 months of my program development project. }\end{array}$ & Weeks 3/4 \\
\hline $\begin{array}{l}\text { Describe how OTs would fit within the organization of Covenant House to.address at-risk youth with } \\
\text { poorly developed social participation and self-regulation skills, including reimbursement and job } \\
\text { description. }\end{array}$ & Week 8-10 \\
\hline $\begin{array}{l}\text { Train staff on an occupation-based program to improve social participation skills and self-regulation } \\
\text { skills for at-risk youth }\end{array}$ & Complete by week 14 \\
\hline
\end{tabular}

\section{Plans for Supervision:}

Supervision and mentoring will be provided on an individualized basis and dependent on the needs of the student and demands of capstone. The supervisory relationship will demonstrate a mutual understanding of expectations through continuous monitoring of set objectives.

Site Supervisor Signature:

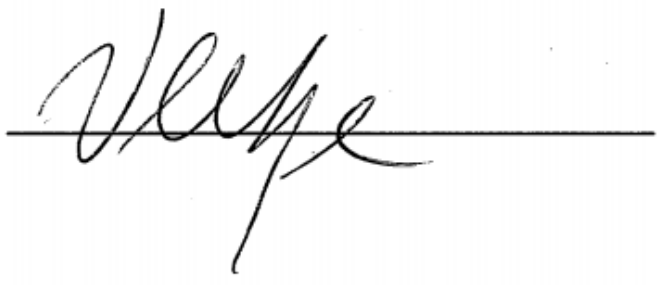

Date:

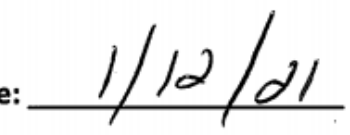




\section{Appendix B}

Doctoral Candidate: Jasmine Shahin

Date: $07 / 06 / 2020$

General Overview of Capstone Project:

The purpose of my program development type project is to create and implement an occupation-based program at Covenant House Florida to improve social participation skills and self-regulation skills for at-risk youth participating in youth violence and demonstrating maladaptive behaviors. The occupation-based program will consist of activities such as arts and crafts, sports, team-building exercises, etc. This capstone project will enable at-risk youth to engage in a program to develop positive social relationships and self-regulation skills to increase safe and healthy lifestyle choices in the future. Along with the development of social participation and self-regulation skills, this program will also build the support of OTs and create an optimal environment for the community.

\section{AGREEMENT}

I, Dr. Marcia A Hamilton, (Mentor) agree to the following:

1. I will serve as Capstone Mentor for this student throughout their OTD program beginning in the student's $5^{\text {th }}$ term (January 2020) and working with them through their final project in their $8^{\text {th }}$ term (April 2021).

2. I will provide advice and resources to the student as needed regarding identified area of expertise.

3. I have reviewed the "Mentor Checklist" ( $2^{\text {nd }}$ page of this document) and agree to the time expectations of this role.

4. I will participate in a mentoring meeting with my mentee at least once a month from start of $7^{\text {th }}$ term (November 2020) to end of $8^{\text {th }}$ term (April 2021) either virtually, by phone, or other negotiated form of contact.

5. I will communicate with the Doctoral Coordinator regarding any concerns or needs during the experience.

6. I will provide evidence of my expertise in the identified area.

OTD Student Signature

Jasmine Shahin Jasmine Shahin

Capstone Mentor Signature
Date

$\underline{07 / 06 / 2020}$

Date

Marcia Hamilton

$07 / 12 / 2020$ 


\section{Appendix C}

\section{Activity Modules}

\section{Activity: Painting}

SEL competency: self-awareness

Description: Participants will follow an instructional video to imitate painting. Participants may adapt their painting to their liking. When completed, participants will demonstrate their painting to the group. Participants will share positive feedback and comments on the paintings of others. Materials: canvases, acrylic paint, paintbrushes, newspapers, cup, water, paper towels Questions discussed:

1. What were your reactions during the activity?

2. How did you feel about the feedback provided by the group?

3. How does painting or art in general allow you and others to better communicate?

4. How or why can painting be an emotional release for you and others?

5. What additional activities do you engage in to self-regulate or self-calm? 


\section{Activity: Field day}

SEL competency: relationship skills, self-management

Description: Participants will compete in various activities individually, in pairs, or groups.

(Balance egg on a spoon to finish line, hula-hoop for time, corn-hole for points, carry a beach ball in pairs using only their backs, transfer ball between their legs to finish line, toss bean bag for length, toss hula hoops over small baskets/cones).

Materials: hula-hoops, beach balls, eggs, spoons, corn-hole, beans bags, tennis ball, basket/cones Questions discussed:

1. What were your reactions during the activity?

2. What were the challenges of this activity?

3. What are the pros and cons of being competitive?

4. How do you bring yourself back to a calmer state when your emotions are running high, such as when competing?

5. How did you keep yourself motivated throughout the activity?

6. Why should teammates encourage and support one another?

7. What is the mindset you should have if you ever lose?

8. How can you apply the concepts discussed or learned and apply those to your future? 


\section{Activity: Social Bingo}

SEL competency: self-awareness, social awareness

Description: Participants will engage in playing bingo and answering questions and statements based on the letter and number called.

Materials: bingo cards, chips/tokens

Questions discussed:

1. What are the benefits of this activity?

2. What did you learn from this activity?

3. What were your reactions when interacting with everyone?

4. Describe an example of a positive interaction you had during the activity.

5. From what you learned, how can you use that in future interactions with everyone in the group or with others?

\begin{tabular}{|c|c|c|c|c|}
\hline $\begin{array}{c}\text { B } \\
(1-10)\end{array}$ & $\begin{array}{c}I \\
(11-20)\end{array}$ & $\begin{array}{c}\mathrm{N} \\
(21-30)\end{array}$ & $\underset{(31-40)}{G}$ & $\begin{array}{c}O \\
(41-50)\end{array}$ \\
\hline $\begin{array}{c}\text { Give a } \\
\text { compliment to } \\
\text { the person on } \\
\text { your left }\end{array}$ & $\begin{array}{c}\text { Play rock, } \\
\text { paper scissors } \\
\text { with someone. }\end{array}$ & $\begin{array}{l}\text { Are you a morning } \\
\text { person or night } \\
\text { person? }\end{array}$ & $\begin{array}{c}\text { What trait do you } \\
\text { love about } \\
\text { yourself? }\end{array}$ & $\begin{array}{l}\text { Describe a time } \\
\text { you helped } \\
\text { someone. }\end{array}$ \\
\hline $\begin{array}{c}\text { What is } \\
\text { something you } \\
\text { would like to get } \\
\text { better at? }\end{array}$ & $\begin{array}{l}\text { Give someone } \\
\text { a high-five. }\end{array}$ & $\begin{array}{l}\text { Ask someone what } \\
\text { he/she is grateful } \\
\text { for. }\end{array}$ & Favorite animal & $\begin{array}{c}\text { What emotion do } \\
\text { you feel right } \\
\text { now? }\end{array}$ \\
\hline $\begin{array}{c}\text { Describe a } \\
\text { personal } \\
\text { achievement }\end{array}$ & $\begin{array}{c}\text { Describe a time } \\
\text { someone } \\
\text { helped you. }\end{array}$ & FREE & $\begin{array}{l}\text { Tag someone to do } \\
5 \text { push-ups with }\end{array}$ & $\begin{array}{c}\text { What is your } \\
\text { dream career/job? }\end{array}$ \\
\hline $\begin{array}{l}\text { Name one thing } \\
\text { you're grateful } \\
\text { for. }\end{array}$ & $\begin{array}{l}\text { Do you like } \\
\text { cold or hot } \\
\text { weather? }\end{array}$ & $\begin{array}{l}\text { Name one thing } \\
\text { that makes you } \\
\text { happy. }\end{array}$ & $\begin{array}{c}\text { What do you do } \\
\text { when you feel } \\
\text { stressed/overwhelm } \\
\text { ed? }\end{array}$ & Pet-peeve \\
\hline $\begin{array}{l}\text { Tag someone to } \\
\text { do } 5 \text { jump squats } \\
\text { with }\end{array}$ & Favorite food & $\begin{array}{c}\text { Find someone with } \\
\text { the same birthday } \\
\text { month as you. }\end{array}$ & $\begin{array}{l}\text { Ask the person to } \\
\text { your right how their } \\
\text { day went }\end{array}$ & $\begin{array}{l}\text { Rainy days or } \\
\text { sunny days? }\end{array}$ \\
\hline
\end{tabular}

\begin{tabular}{|c|c|c|c|c|}
\hline $\begin{array}{c}\text { B } \\
(1-10)\end{array}$ & $\underset{(11-20)}{I}$ & $\underset{(21-30)}{N}$ & $\underset{(31-40)}{\mathbf{G}}$ & $\underset{(41-50)}{O}$ \\
\hline $\begin{array}{l}\text { Describe a time you } \\
\text { helped someone. }\end{array}$ & $\begin{array}{c}\text { Name one thing } \\
\text { that makes you } \\
\text { happy. }\end{array}$ & $\begin{array}{c}\text { Tag someone } \\
\text { to do a 5-sec. } \\
\text { squat hold } \\
\text { with. }\end{array}$ & $\begin{array}{l}\text { Learn something } \\
\text { about another } \\
\text { culture/background }\end{array}$ & $\begin{array}{c}\text { Give a } \\
\text { compliment to } \\
\text { the person on } \\
\text { your right }\end{array}$ \\
\hline
\end{tabular}




\begin{tabular}{|c|c|c|c|c|}
\hline $\begin{array}{c}\text { Ask the person to your } \\
\text { left how their day went }\end{array}$ & $\begin{array}{c}\text { Are you an } \\
\text { introvert or } \\
\text { extrovert? }\end{array}$ & $\begin{array}{c}\text { Ask someone } \\
\text { what he/she is } \\
\text { grateful for. }\end{array}$ & $\begin{array}{c}\text { Describe a time } \\
\text { someone helped } \\
\text { you. }\end{array}$ & Pet-peeve \\
\hline $\begin{array}{c}\text { What do you do when } \\
\text { you feel } \\
\text { stressed/overwhelmed? }\end{array}$ & Favorite animal & FREE & $\begin{array}{c}\text { Are you morning } \\
\text { person or night } \\
\text { person? }\end{array}$ & Favorite food \\
\hline $\begin{array}{c}\text { What is something } \\
\text { you'd like to get better } \\
\text { at? }\end{array}$ & $\begin{array}{c}\text { What emotion } \\
\text { do you feel right } \\
\text { now? }\end{array}$ & $\begin{array}{c}\text { Play rock, } \\
\text { paper scissors } \\
\text { with someone. }\end{array}$ & $\begin{array}{c}\text { Describe a } \\
\text { personal } \\
\text { achievement }\end{array}$ & $\begin{array}{c}\text { Would you } \\
\text { rather read a } \\
\text { book or watch a } \\
\text { movie? }\end{array}$ \\
\hline $\begin{array}{c}\text { Exchange between you } \\
\text { and the person to your } \\
\text { right your dream job }\end{array}$ & $\begin{array}{c}\text { Describe } \\
\text { yourself in } 3 \\
\text { words. }\end{array}$ & $\begin{array}{c}\text { Find a } \\
\text { person(s) with } \\
\text { the same } \\
\text { birthday } \\
\text { month as you. }\end{array}$ & $\begin{array}{c}\text { Name one thing } \\
\text { you're grateful for. }\end{array}$ & $\begin{array}{c}\text { Give someone a } \\
\text { high-five. }\end{array}$ \\
\hline
\end{tabular}

\begin{tabular}{|c|c|c|c|c|}
\hline $\begin{array}{c}\text { B } \\
(1-10)\end{array}$ & $\begin{array}{c}I \\
(11-20)\end{array}$ & $\begin{array}{c}\mathrm{N} \\
(21-30)\end{array}$ & $\begin{array}{c}G \\
(31-40) \\
\end{array}$ & $\begin{array}{c}\mathrm{O} \\
(41-50) \\
\end{array}$ \\
\hline $\begin{array}{l}\text { Ask someone what } \\
\text { he/she is grateful } \\
\text { for. }\end{array}$ & $\begin{array}{l}\text { If you could } \\
\text { have any } \\
\text { superpower, } \\
\text { what would it } \\
\text { be? }\end{array}$ & $\begin{array}{c}\text { Find someone with the } \\
\text { same zodiac sign as } \\
\text { you. }\end{array}$ & $\begin{array}{l}\text { What is your } \\
\text { favorite genre } \\
\text { of music? }\end{array}$ & $\begin{array}{c}\text { What is your } \\
\text { favorite movie? }\end{array}$ \\
\hline $\begin{array}{l}\text { Ask the person to } \\
\text { your left how their } \\
\text { day went }\end{array}$ & $\begin{array}{c}\text { Give a } \\
\text { compliment to } \\
\text { the person on } \\
\text { your right }\end{array}$ & $\begin{array}{l}\text { Play rock, paper, } \\
\text { scissors with someone. }\end{array}$ & $\begin{array}{l}\text { Are you an } \\
\text { introvert or } \\
\text { extrovert? }\end{array}$ & $\begin{array}{l}\text { Tag someone to } \\
\text { do } 5 \text { squats } \\
\text { with }\end{array}$ \\
\hline $\begin{array}{l}\text { Name one thing } \\
\text { you're grateful for. }\end{array}$ & $\begin{array}{l}\text { What emotion } \\
\text { do you feel } \\
\text { right now? }\end{array}$ & FREE & $\begin{array}{l}\text { What is/was } \\
\text { your favorite } \\
\text { subject in } \\
\text { school? }\end{array}$ & $\begin{array}{c}\text { Find a } \\
\text { person(s) with } \\
\text { the same } \\
\text { birthday month } \\
\text { as you. }\end{array}$ \\
\hline $\begin{array}{l}\text { What is something } \\
\text { you'd like to get } \\
\text { better at? }\end{array}$ & $\begin{array}{c}\text { Describe a } \\
\text { personal } \\
\text { achievement }\end{array}$ & $\begin{array}{l}\text { What do you do when } \\
\text { you feel } \\
\text { stressed/overwhelmed? }\end{array}$ & $\begin{array}{c}\text { Exchange } \\
\text { between you } \\
\text { and the person } \\
\text { to your left } \\
\text { your dream job }\end{array}$ & $\begin{array}{c}\text { Describe a time } \\
\text { someone helped } \\
\text { you. }\end{array}$ \\
\hline $\begin{array}{l}\text { How do you comfort } \\
\text { a friend when he/she } \\
\text { is feeling down or } \\
\text { upset? }\end{array}$ & $\begin{array}{l}\text { Give the } \\
\text { person to your } \\
\text { left and right a } \\
\text { high-five. }\end{array}$ & $\begin{array}{c}\text { Describe yourself in } 3 \\
\text { words. }\end{array}$ & $\begin{array}{l}\text { Describe a time } \\
\text { you helped } \\
\text { someone. }\end{array}$ & $\begin{array}{l}\text { What is a future } \\
\text { goal you have? }\end{array}$ \\
\hline
\end{tabular}




\section{Activity: Vision Board}

SEL competency: self-awareness

Description: Participants will be provided with pictures, magazines, and newspapers to cut out images and letters/words to paste onto their board. The images and words will represent the values of the participants and goals they want to achieve in the future. When activity is completed, each participant will share their board with the group and identify and describe goals they envision to achieve in their future.

Materials: poster boards, print outs of images, magazines, newspapers, scissors, glue, markers Questions discussed:

1. Why is it beneficial to set goals for our future?

2. Were there similarities/interests in goals seen across the group? What were these?

3. How does it feel to learn about the values/goals of others?

4. How do you plan to achieve some of these goals?

5. In life we are sometimes faced with obstacles. How do we manage ourselves if an obstacle comes our way?

6. What other ways can we organize our goals?

\section{Activity: Movie Synopsis}

SEL competency: social awareness, self-awareness

Description: Participants will watch an educational movie (Disney and Pixar's: "Soul”). When the film is done participants will provide a synopsis of the movie.

Materials: TV, DVD player (if necessary)

Questions discussed:

1. What was the main idea of the movie?

2. What emotions or reactions did you experience during the movie? Why?

3. What emotions were expressed by the characters in the movie?

4. What is a concept you grasped from the movie that can influence your future decisions or situations you face? 


\section{Activity: Survival Simulation Game}

SEL competency: responsible decision-making, relationship skills

Description: Participants will be given a short story in which they landed on the moon but required to take only necessary items with them to continue their space mission. Participants will be given a list of items that they will individually rank to be necessary. Participants will then come together as a group to rank the items with one another. Correct answers will be based on the number of points that participants used as their rankings compared to rankings used from NASA scientists and engineers.

Materials: pen/pencils

Questions discussed:

1. Why is it important to think appropriately when we're feeling scared or upset, such as in a situation like the activity?

2. How did the challenge of choosing individually to change when choosing as a group?

3. How did everyone come to their decisions when collaborating?

4. How did the activity allow you to listen and understand another person's point of view or perspective?

5. How can you apply what you grasped or did during this activity (e.g., collaborating, listening to others) in real life situations, such as in school, work, or relationships?

Taken by: Insight by Grahame Knox is licensed under a Creative Commons AttributionNoncommercial-No Derivative Works 3.0 Unported License. Attribution-NoncommercialNoDerivs 3.0 Unported (CC BY-NC-ND 3.0) 


\section{Activity: Charades}

SEL competency: Social awareness, relationship skills, self-management

Description: Depending on the number of participants, participants will be placed in one or two groups. One person will choose an action to silently perform while other participants guess the action of the participant.

Materials: none

Questions discussed:

1. How do you think charades can assist with improving communication with others?

2. Why is it important to understand non-verbal communication?

3. How do charades help improve bonding opportunities?

4. What emotions occurred when your competitiveness increased during the game?

5. What are ways to calm down when we feel those emotions whether because of charades or in real life situations?

\section{Activity: Leading a Teammate through the Obstacle Course}

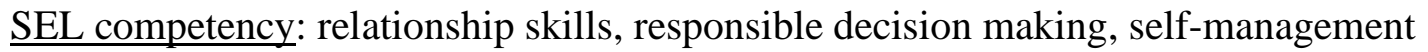
Description: Participants will be split into 2 groups. Groups will pick one person to begin the obstacle course. Participants picked to complete the obstacle course will be blindfolded, in which the rest of the group members will guide their blindfolded teammate across the course.

Materials: plastic cups, scarf

Questions discussed:

1. What did the groups have to do to be successful to complete the activity?

2. What changes would you have made in communication?

3. What reactions were felt when leading your teammate to cross the obstacle course?

4. What reactions were felt for those crossing the obstacle course?

5. How do we regulate or calm those reactions in real-life situations?

6. What was something positive that happened during the activity?

7. How can you apply what you learned in the future? 


\section{Activity: Gardening}

SEL competency: Self-management, self-awareness

Description: Participants will each be given a pot to paint and decorate themselves. Participants will scoop the amount of soil they need to place in their pots and plant the flowers provided. Participants will then water the plants and place them outside around the site.

Materials: soil, pots, shovels/plastic cups, gloves, flowers/plants, paint, paintbrushes, water Questions discussed:

1. What are the benefits of gardening?

2. What reactions did you have during the activity?

3. Why do you believe gardening is useful to relieve stress?

4. How do you think an environment can affect someone's mood or way of thinking?

5. How can gardening teach us how or why to take care of ourselves?

\section{Activity: Monopoly}

SEL competencies: Self-management, responsible decision-making

Description: Participants will engage in the game of Monopoly.

Materials: Monopoly Board game

Questions discussed:

1. How does Monopoly target communication or conversation skills?

2. In terms of negotiating with players, what does this game teach someone or can help them learn for future purposes like in school or work?

3. If someone is not agreeing with you the way you want them to be, how should you react?

4. In situations where you find yourself thinking or feeling life is not fair, how should you manage your emotions and overcome that? 


\section{Activity: Debate}

SEL competency: self-management, relationship skills

Description: Participants will be split into 2 groups. Groups will be given opposing topics and 5 minutes to think of why their topic is better than the other group. Groups will pick a leader to argue over their topic. Leaders will have 5-10 minutes to debate.

Materials: paper, pencils

Questions discussed:

1. How did this activity target social skills?

2. What were your reactions during this activity?

3. How should you react or manage your emotions when someone may disagree with you?

4. Do you feel you all communicated well as a team? What could have been done better?

5. How can you apply what you have learned or grasped from the activity in the future?

\begin{tabular}{|c|}
\hline Topics \\
\hline Summer vs Winter \\
\hline Tacos vs Pizza \\
\hline Positive effects of social media vs Negative effects of social media \\
\hline
\end{tabular}




\section{Activity: Cooking Lab}

$\underline{\text { SEL competencies: }}$ relationship skills, self-management, responsible decision making Description: Participants will work together as a group to cook a meal and desert, tacos and cookies. Participants will be given the recipe for tacos and cookies. Participants will decide with one another their assigned tasks and roles to make the food items (e.g., cut vegetables, stir the meat, mix the cookie dough, wash dishes, etc.). Once both food items are prepared, participants can enjoy the food.

Materials: meat, taco seasoning, cooking oil, tomatoes, lettuce, cheese, tortillas, sour cream, cookie dough mix, egg, butter, milk

Questions discussed:

1. How does cooking in a group target social skills?

2. How did you come to an agreement with one another to assign tasks and pick toles?

3. How can cooking teach responsibility not only for cooking, but for future purposes as well?

4. What does cooking teach us about patience and challenging work? 


\section{Activity: Tie-dye Shirts}

SEL competencies: relationship skills, social awareness

Description: Participants will be placed in pairs and help one another to create their own tie-dyed shirts. Participants will then wrap their shirts in plastic wrap to leave it alone for 24 hours before they wash and use their shirts.

Materials: Plain white T-shirts, tie-dye kits, newspaper, gloves, rubber bands, plastic wrap Questions discussed:

1. Tie-dying is not meant to be perfect. What can be a result of trying to achieve perfectionism?

2. How can tie-dying teach us about self-judgement and judging others?

3. Did you have a plan in your head for how to complete this activity? Did it change during the activity?

4. How should we handle a situation that did not turn out as expected?

5. Why do you think tie-dying was chosen as an activity that may help target social skills?

6. Why should we ask for help when needed?

\section{Activity: Hedbanz}

SEL competency: Responsible decision-making, social awareness

Description: Each participant will be given a card with an item on it. Participants are to place the card on their forehead without viewing what is on their card. In a group, participants will take turns asking questions to identify the picture on their card.

Materials: Hedbanz game

Questions discussed:

1. How does the game target communication skills?

2. How does the game work on perspective taking?

3. What is the value of perspective taking?

4. How can perspective-taking teach us to self-regulate or self-control our thoughts and emotions in the social world?

5. How can the skills discussed be used in future situations? 


\section{Activity: Egg Drop}

SEL competencies: relationship skills, responsible decision-making, self-management

Description: Participants will be placed into teams and will be given various materials to create a structure around an uncooked egg. The goal of the structure is to protect the egg from a high fall onto the ground.

Materials: eggs, straws, paper, tape, cardboard tubes, rubber bands, cotton balls, popsicle sticks Questions discussed:

1. What were your reactions during the activity?

2. What were some of the challenges faced when creating the structure for the egg?

3. How should we manage stressful situations?

4. A few goals were required for the activity (i.e., working as a team effectively, building a structure for the egg, keep the egg safe). What characteristics can set goals teach us?

5. This activity involved critical thinking and considering different ideas from others. Why is it helpful to analyze problems and think responsibly in any given situation?

6. What were the positive aspects of working in teams?

7. How can team-building exercises improve or build relationship skills or good leadership for others? 


\section{Activity: Clue}

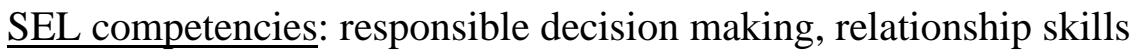

Description: Participants will engage in the game Clue which entails solving a murder.

Participants will solve problems throughout the game to figure out the murderer, weapon, and location to solve the game.

Materials: Clue game

Questions discussed:

1. How can the skills used in this game be applied to daily life tasks or challenges some of the challenges we may face?

2. How does critical thinking or deductive reasoning help you justify yourself in various situations?

3. How can self-regulation skills build critical thinking skills?

4. How do our emotions and critical thinking skills influence our way of communicating with others? What are some examples? 


\section{Appendix D Program Measures}

\section{Social Skills Assessment:}

1. I maintain eye contact and pay attention while engaged in conversation with others. Strongly Disagree, Disagree, Agree, Strongly Agree

2. I support and compliment others on their accomplishments. Strongly Disagree, Disagree, Agree, Strongly Agree

3. I can clearly describe my feelings.

Strongly Disagree, Disagree, Agree, Strongly Agree

4. I carefully listen to and acknowledge other people's points of view. Strongly Disagree, Disagree, Agree, Strongly Agree

5. I share, take turns, and/or demonstrate fairness when it comes to situations that require cooperation.

Strongly Disagree, Disagree, Agree, Strongly Agree

6. I maintain appropriate social boundaries and respect the personal space of others (e.g., asking personal questions or discussing topics that make others uncomfortable). Strongly Disagree, Disagree, Agree, Strongly Agree

\section{General Self-Efficacy Scale (GSES):}

$1=$ not at all true, $2=$ hardly true, $3=$ moderately true, $4=$ exactly true

\begin{tabular}{|c|c|}
\hline Item Description & $\begin{array}{l}\text { Point } \\
\text { Scale }\end{array}$ \\
\hline 1. I can always manage to solve difficult problems if I try hard enough. & \\
\hline $\begin{array}{l}\text { 2. If someone opposes me, I can find the means and ways to get what I } \\
\text { want. }\end{array}$ & \\
\hline 3. It is easy for me to stick to my aims and accomplish my goals. & \\
\hline 4. I am confident that I could deal efficiently with unexpected events. & \\
\hline $\begin{array}{l}\text { 5. Thanks to my resourcefulness, I know how to handle unforeseen } \\
\text { situations. }\end{array}$ & \\
\hline 6. I can solve most problems if I invest the necessary first. & \\
\hline $\begin{array}{l}\text { 7. I can remain calm when facing difficulties because I can rely on my } \\
\text { coping abilities. }\end{array}$ & \\
\hline
\end{tabular}


8. When I am confronted with a problem, I can usually find several solutions.

9. If I am in trouble, I can usually think of a solution.

10. I can usually handle whatever comes my way.

\section{Survey Questionnaire:}

1. The session was engaging and meaningful.

Strongly Disagree, Disagree, Agree, Strongly Agree

2. What I have learned in this session is/will be valuable for my future.

Strongly Disagree, Disagree, Agree, Strongly Agree

3. The session helped me further develop my social interaction skills (ex: conversating appropriately, listening to others, being respectful when speaking to others, etc.)

Strongly Disagree, Disagree, Agree, Strongly Agree

4. The session helped me further develop my self-regulation skills (ex: coping, regulating emotions, managing behaviors, etc.).

Strongly Disagree, Disagree, Agree, Strongly Agree

5. What did you like about the session provided?

6. What suggestions do you have for improving the session? 


\section{Appendix E}

Learning Objective and Deliverable 1: Compare and contrast problems and issues at-risk youth experience that led them to demonstrate maladaptive behaviors at Covenant House compared to the literature.

\begin{tabular}{|c|c|}
\hline Literature & Covenant House Florida (CHF) \\
\hline $\begin{array}{l}\text { Problems and factors that lead at-risk youth to } \\
\text { experience maladaptive behaviors read and } \\
\text { written from the literature: } \\
\text { - Lack of social support from family } \\
\text { and peers } \\
\text { - Low-socioeconomic status } \\
\text { - Poor mental health } \\
\text { - Exposure to community violence } \\
\text { - Broken families } \\
\text { - Substance abuse } \\
\text { - Associating with the "wrong" crowd, } \\
\text { - such as gangs } \\
\text { Not having/seeking the appropriate } \\
\text { help (e.g. therapy). }\end{array}$ & $\begin{array}{l}\text { Professionals/staff at CHF often see youth } \\
\text { who have experienced or are experiencing the } \\
\text { following problems: } \\
\text { - Mental health issues (e.g., anxiety, } \\
\text { ADHD, depression, sexual behaviors) } \\
\text { - Family members with mental health } \\
\text { problems } \\
\text { - Low-socioeconomic status } \\
\text { - Substance abuse or exposure to } \\
\text { - } \text { substance abuse from family } \\
\text { - } \text { Pomestic violence and abusive } \\
\text { - Parental divorce } \\
\text { - Ageath of loved one(s) }\end{array}$ \\
\hline
\end{tabular}

Several issues and factors seen from the youth at Covenant House Florida (CHF)

correspond to the issues and factors provided from the literature. As seen in the chart above, both the literature and CHF note that poor mental health, low-socioeconomic status, broken families, such as the loss of a loved one and parental divorce, exposure to violence, and substance abuse are commonly seen in at-risk youth, leading them to experience or demonstrate maladaptive behaviors. In some cases, the parents do not know how to handle the behaviors of the child or are always in disagreement with one another, which will lead youth to come to CHF.

Additional factors experienced by the youth were mentioned by the professionals and staff of CHF which were not mentioned in the literature. Exposure to family members with mental health issues and/or who have substance abuse problems negatively impacts the youth by 
leading them to the same issues or complications with family. In addition, youth who have aged out of foster care with little to no support have a higher risk of experiencing homelessness, lack of employment, and problems with physical and mental health. At-risk youth experiencing any of the factors mentioned within the chart have a higher likelihood of poor mental health and to experience negative outcomes, such as maladaptive behaviors, as they continue to get older. If not provided the appropriate help, such as therapy or support programs, the at-risk youth's mental health will continue to hinder. As a result of poor mental health and experiencing negative outcomes, at-risk youth will face challenges in their social participation and selfregulation skills. 


\section{Appendix F}

Learning Objective and Deliverable 2: Compare and contrast the problems experienced by atrisk youth, who demonstrate or experience maladaptive behaviors, with poorly developed social participation and self-regulation skills.

\begin{tabular}{|c|c|}
\hline $\begin{array}{l}\text { Problems experienced by at-risk youth, who } \\
\text { demonstrate maladaptive behaviors, with } \\
\text { poorly developed social participation and self- } \\
\text { regulation skills as mentioned in the literature: }\end{array}$ & $\begin{array}{l}\text { Problems experienced by at-risk youth, } \\
\text { who demonstrate maladaptive behaviors, } \\
\text { with poorly developed social participation } \\
\text { and self-regulation skills as mentioned in } \\
\text { Covenant House: }\end{array}$ \\
\hline $\begin{array}{l}\text { - Mental health issues (e.g., depression, low } \\
\text { impulse control, anxiety, aggression, etc.) } \\
\text { - Trauma } \\
\text { - Disadvantaged environment with minimal } \\
\text { resources provided } \\
\text { - Consistent stressors which lead to depleted } \\
\text { coping mechanisms } \\
\text { - Lack of social support leading to social } \\
\text { isolation } \\
\text { - Will attend minimal to no therapy sessions }\end{array}$ & $\begin{array}{l}\text { - Mental health issues } \\
\text { - Trauma (bullying, neglect, domestic } \\
\text { violence, separation from a parent, } \\
\text { physical/emotion/ sexual abuse) } \\
\text { - Trauma anniversaries } \\
\text { - Unsafe/unstable environment } \\
\text { - Major surgery within the first } 3 \text { years } \\
\text { - of life } \\
\text { - Cognitive rigidity/poor attention } \\
\text { - Social isolation } \\
\text { - Not all youth seek necessary help } \\
\text { - } \text { therapy) }\end{array}$ \\
\hline
\end{tabular}

Social participation and self-regulation skills are necessary skills that assist in achieving desirable outcomes, self-efficacy, and help in developing and maintaining positive relationships. Poorly developed social participation and self-regulation skills in at-risk youth will hinder the ability to make responsible decisions, communicate appropriately, form relationships, and much more. The factors mentioned within the literature were all covered from Covenant House Florida $(\mathrm{CHF})$. At-risk youth consistently experiencing stressors and trauma in their life leads to a decrease in coping abilities which affects temper and psychological issues. The lack of social support from family and/or peers may think an at-risk youth has no one to turn to and feel isolated. Living in a 
disadvantaged environment with limited resources may place an at-risk youth in a position of engaging in minimal activities and/or unsafe and unhealthy activities negatively affecting their social participation and self-regulation skills. Mental health issues are a primary concern in at-risk youth as they are more prone to experiencing negative behaviors, such as depression, poor conduct, low self-esteem, etc. If mental health issues are prolonged, at-risk youth face may experience homelessness, unemployment, and social deprivation. Not all at-risk youth experiencing mental health issues will seek the necessary services to assist them, especially due to the fear of being judged or not having funds.

Additional problems at-risk youth experience with poorly developed social participation and self-regulation skills were mentioned from CHF. Along with dealing with trauma, at-risk youth can remember traumatic anniversaries which may be a trigger for them, such as causing numbness. At-risk youth who have had a major or complicated surgery within their first 3 years may also feel negatively impacted. For example, a youth may feel traumatized from that event or insecure about the area of the body where the surgery occurred. Along with not seeking therapy services, at-risk youth may have difficulty in connecting with need services, such as a refugee without the appropriate documents. The limited resources and choices within the environment, lack of social support, mental health issues, trauma, and other factors listed above are significant reasons and problems to consider as to why at-risk youth demonstrating maladaptive behaviors have poorly developed social participation and self-regulation skills. 


\section{Appendix G}

Learning Objective and Deliverable 3: Identify and describe professionals who serve at-risk youth with poor social participation and self-regulation skills and engage in maladaptive behaviors in the literature and at Covenant House

\begin{tabular}{|r|}
\hline $\begin{array}{c}\text { Professional Backgrounds Primarily Graduated with from } \\
\text { the Staff at Covenant House }\end{array}$ \\
\hline 1. Social Work \\
2. Psychology \\
\hline 3. Criminal Justice/Criminology \\
4. Education \\
\hline 5. Nursing (family nurse practitioner and RN (Registered \\
Nurse)) \\
\hline 6. Business Administration \\
\hline
\end{tabular}

Listed above are the professional backgrounds that staff/faculty are trained and educated in to work and help the at-risk youth at Covenant House Florida (CHF). With these professional backgrounds, the staff is divided and given the roles as therapists, case managers, Ombud's person, educator, and nurse. The therapists at $\mathrm{CHF}$ are each assigned to a specific gender and age group. For example, one therapist would see females below the ages of 18, and another therapist will see females from the age of 18 years and older. The therapists will provide the youth with individual, group therapy and family therapy, behavioral health therapy, such as CBT and trauma, and solution-focused treatments.

Case managers are assigned within different departments at CHF. A case manager is placed for the female floor and another one for the male floor. The main responsibilities of the case managers on the floor are to create the action plan for the youth and assure that they are following their action plan throughout the week as well as handle dilemmas with their assigned residents. The life skills case manager oversees activities within the life skills (recreational) area as well as coordinating with the life skills/independent living coordinator to provide basic life 
skills courses, such as first aid, budgeting, and resume building. When entering CHF, there is an intake case manager and Ombud's person. The intake case manager will complete the initial intake forms for newly admitted youth, answer phone calls from the crisis hotline for youth, and assist with discharges and referrals to the community. The Ombud's person hears and appeals grievances from the youth. This person will review the facts related to an outcome and assist with determining if that outcome should be charged. In addition, the Ombud's person helps youth find interim and outside services during their time away from $\mathrm{CHF}$, such as when youth are being discharged.

An educator is located on-site to provide educational services and the necessary skills to prepare the youth who wish to obtain their general education development (GED). Youth are offered tutoring, mentoring, and access to laptops and computers. Youth are also given the option of whether they prefer to attend public school. The nurses at CHF provide medical health care to the youth. Within the first 3 days of intake, newly admitted youth is to receive a physical exam and health assessment. Youth are also provided services such as laboratory tests, pre-and post-natal care, HIV/STD counseling, and health, substance abuse assessments, and referrals to other health care providers. 


\section{Appendix H}

Learning Objective and Deliverable 4: Describe how OTs would fit within the organization of Covenant House to address at-risk youth with poorly developed social participation and selfregulation skills.

The role of occupational therapy and how occupational therapy can help at-risk youth was casually discussed to staff at Covenant House Florida (CHF). When the program is complete and all outcomes are collected, a power point will be made to provide to the staff as well as to reemphasize OT's role. The following was mentioned to staff at CHF: The role of occupational therapy is to help individuals of all ages become as independent and functional as possible in their daily and meaningful activities of life, despite any limitation they are facing whether it is physical or mental. The importance of encouraging and engaging individuals to continue participating in their daily and/or meaningful tasks and activities promotes positive mental health and less assurance to rely or depend on someone to help them, if necessary.

With at-youth especially, OTs provide them with purposeful and engaging activities to improve necessary life skills, such as health and social participation and self-regulation skills, to continue to make healthy lifestyle choices as they grow into adult hood. OTs can provide assessments to youth to determine strengths and weaknesses, and to determine the focus of interventions during treatment sessions. Within interventions, OTs promote participation in activities such as tabletop games, art, listening to music, exercise, cooking, cleaning, and much more. Within these activities and examples mentioned, it was discussed how youth can develop coping mechanisms and strategies when feeling uneasy. To further develop social participation and self-regulation skills, OTs provide and promote the ability to build social connections, improve positive interactions, and to make responsible decisions. Along with some of the staff at 
CHF, OT's can also help develop the life skills program and lead groups that involve money management, job readiness, health and wellness, and life skills. 